\title{
CHARACTERISATION OF THE MITOCHONDRIAL GENOME AND THE PHYLOGEOGRAPHIC STRUCTURE OF BLUE COD (PARAPERCIS COLIAS)
}

\author{
BY \\ HAYDEN MURRAY SMITH
}

A thesis submitted to the Victoria University of Wellington in fulfilment of the requirements for the degree of Masters of Science

Victoria University of Wellington

2012 


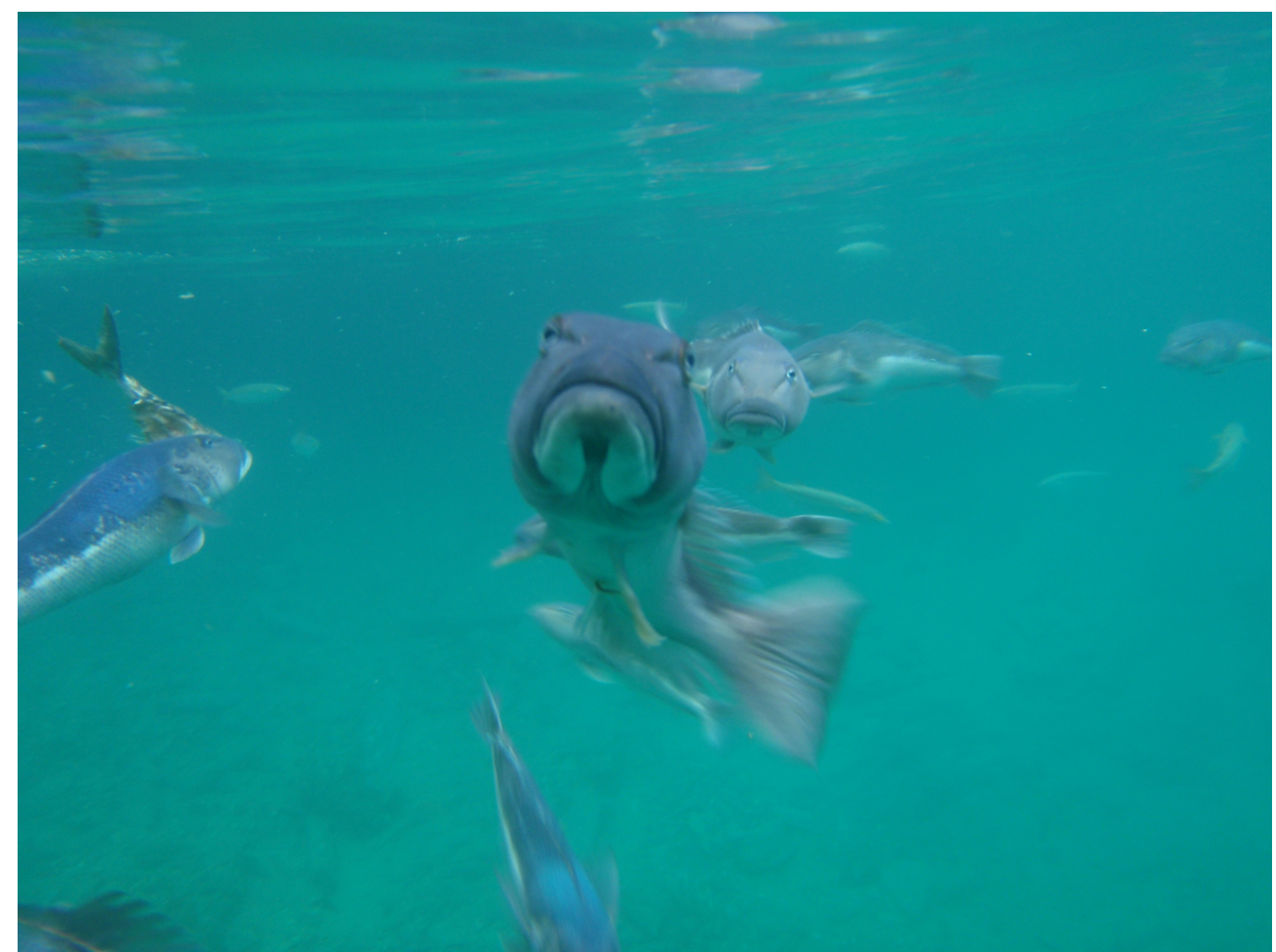

Blue cod patrol near the surface within a marine protected area in Queen Charlotte Sound; September 2011. Photo by Hayden Smith

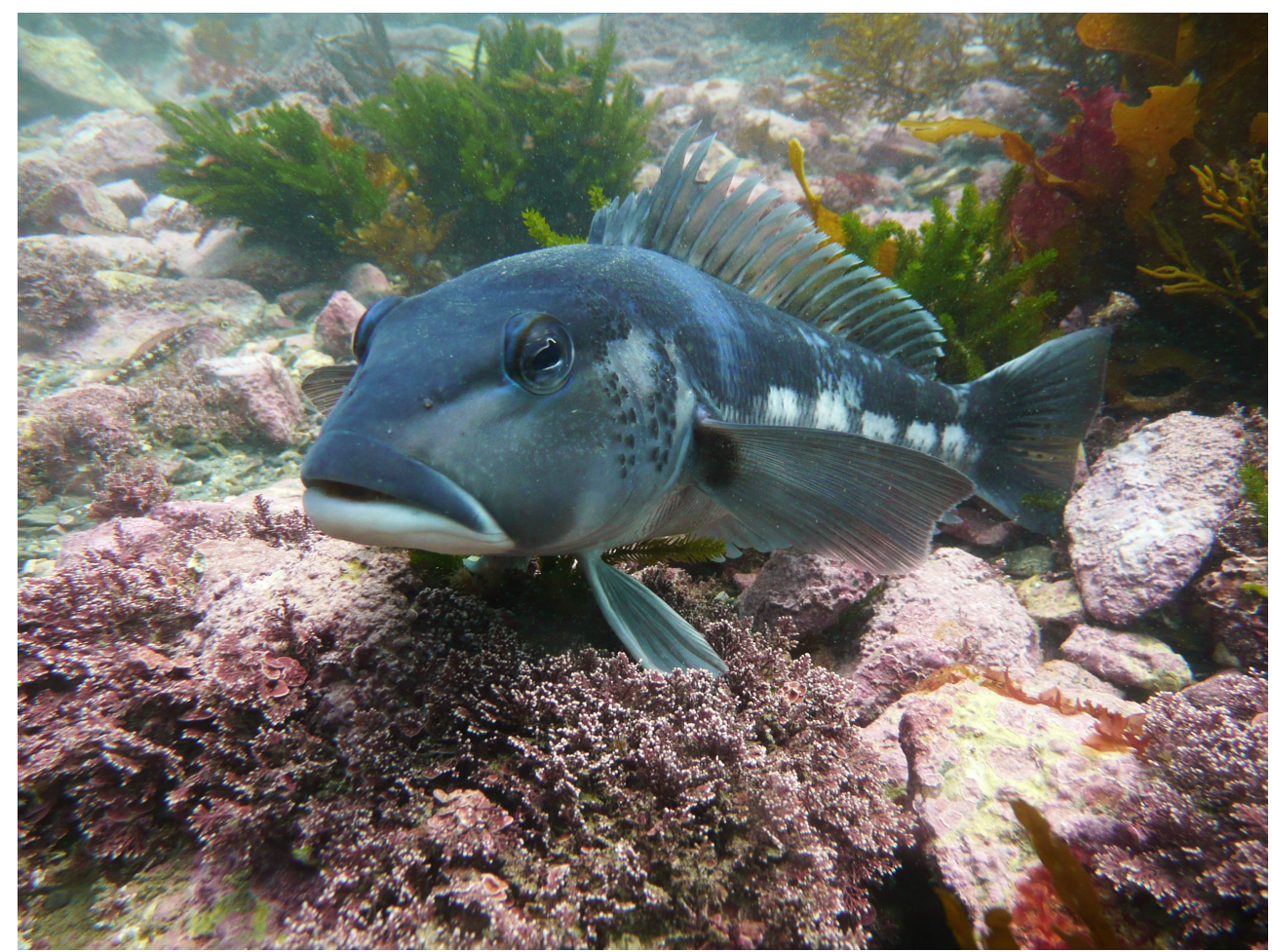

An adult blue cod makes a signature approach to an intruding diver within the Taputeranga Marine Reserve, Wellington. Photo by Jennifer Howe 


\begin{abstract}
This thesis primarily addresses the genetic population structure of blue cod (Parapercis colias) in the New Zealand Exclusive Economic Zone, within which approximately 2800 Tonnes of the endemic fish are harvested annually. Several regions with traditionally healthy blue cod stocks have recently experienced localised depletion due to over-exploitation. This highlights the importance for a clearer understanding of the genetic structure of the species in order to maximise the potential for the fishery to be managed sustainably. Also covered within this thesis are characteristics of the blue cod's mitochondrial genome, and development of a set of genetic tools that can improve the level of understanding for several important fisheries species in New Zealand waters.
\end{abstract}

Chapter two focuses on the characterisation of the blue cod mitochondrial genome, with the use of second-generation sequencing providing the first fully documented sequence for this species. The blue cod mitochondrial genome is identical in organisation to several other documented fish species' mitochondrial genomes, with no unexpected results. Also dealt with in Chapter two is the development and implementation of a set of generic control region primers, designed primarily for use on commercially important inshore New Zealand fish species. Nine of the eleven species which the primer was tested on had the targeted region successfully amplified, though heteroplasmy may be present in at least four species.

Chapter three reports the bulk of this research, with the phylogeographic structure of blue cod investigated. Samples were taken from the pectoral and pelvic fins of blue cod from 14 sites around New Zealand. A total of 475 sequences were taken from the hypervariable 5' end of the control region, with each sequence $491 \mathrm{bp}$ in length. The null hypothesis of genetic homogeneity throughout their distribution was rejected, with significant differentiation observed between mainland New Zealand and Chatham Island samples. While pairwise differences between mainland New Zealand sampling sites was limited, a significant trend of isolation by distance was observed. A demographic population expansion occurred more steeply and more recently in mainland populations, with a slower growth curve in Chatham Island populations. With a trend of isolation by distance present between mainland sampling sites, it is suggested that further investigations are made, utilising genetic markers capable of resolving deeper patterns of genetic structure within the population (e.g. microsatellites, SNP's).

Finally, Chapter four summarises and contextualises the results from the research components of this thesis, discussing management implications and potential threats to both the commercial and recreational blue cod fishery. A key area of focus for this section is the genetic and demographic risk that the population may face with continued targeting of larger individuals, given the biological trait of protogynous hermaphroditism in the species. 


\section{Preface and Acknowledgements}

While I never intended to spend longer at university that absolutely necessary, a love of the ocean and a willingness to learn about how it works has led me to the production of this thesis. During my time as an undergraduate at Victoria University of Wellington I spent many hours free-diving and spearfishing in the surrounding waters, reaping the rewards of my labour with food for friends and family alike. The ocean is a place I enjoy spare time, gather thoughts, and will forever have the utmost respect for. While at heart I am conservation minded, I appreciate the bountiful resources that live in our oceans, and understand that many people must survive off what their waters are able to provide, both financially and fundamentally. This thesis is written with respect to the commercial, recreational and social perspectives of the continuous debate that surrounds our fisheries, within both national and international waters. They are ours to enjoy, preserve, and protect.

Firstly and most importantly, I would like to thank my supervisor, Dr Peter Ritchie. Following a harmless chat about spearfishing, I suddenly found myself enrolled, and beginning a Masters of Science under his supervision, on my most feared topicgenetics. Over the ensuing 20 months I have enjoyed unselfish and dedicated support, and I have absolutely no doubt that I would not have been able to complete what you are now reading without Peter's unwavering support and guidance. I also owe greatly to the support of the entire Ritchie research group, especially Sebastian Hernandez, Andrea Varela, Monica Gruber, Henry Lane, Jack Du, and also to Luke Thomas, Bridget Johnson, Jennifer Howe and Will Arlidge, and in the School of Biological Sciences. Thank you for your comments, lab assistance, and general banter- it is greatly appreciated.

Further thanks to the members of the Ministry of Fisheries Southern Inshore Working Group, in particular Stephen Brouwer and Glen Carbines for sample collection, advice, and superior knowledge on both blue cod and the wider commercial fishing environment. Collection of over 800 samples takes a considerable amount of organisation and commitment. Thanks to Glen Carbines and Stock Monitoring Services, Russel Cole and NIWA, Gary Wilson and Otago University, Dan Urlich, Thomas Wansbone, Paul Knight, Simon Warden, Samual Clark, Froth Lacey, Graeme Sinclair and Gone Fishin', James Strong, Daniela Diaz Guisado, Sebastian Hernandez, Bennet McComish, Akaroa Fish and Dive Charters, Tommo and Kaikoura Fishing Tours, and others I may have missed. Thank you to Juliet Burton for the cover illustration.

As a recipient of the Masters by Thesis Scholarship, the financial support provided by Victoria University of Wellington has been profound. Without this assistance, far less time would have been able to be spent on research, and I thank you very much for the generous support you have shown me.

In the wider world, a special thank-you to Tabitha Newton for her unwavering support, advice, encouragement, and knowledge. Also, many thanks to my friends and family for helping and encouraging me over the last two years, especially those I have lived with- James Roach, Monica Hamlyn-Crawshaw, Suzannah Newton, and Thomas Wansbone. Thank you. 


\section{Table of Contents}

\begin{tabular}{lr} 
Abstract & Page \\
Preface and Acknowledgements & iii \\
Table of Contents & iv \\
List of Tables & v \\
List of Figures & vii \\
\hline
\end{tabular}

\section{Chapter One}

General Introduction $\quad 1$

1.1 Overview of New Zealand fisheries 1

1.2 Importance of genetic variation for fisheries management 2

$\begin{array}{ll}1.3 & \text { Detecting genetic variation }\end{array}$

1.4 Physical oceanographic processes 7

1.5 Genetic structure of New Zealand teleost species 9

$\begin{array}{lll}1.6 & \text { Study species: blue cod (Parapercis colias) } & 12\end{array}$

$\begin{array}{lll}1.7 & \text { Thesis aims } & 15\end{array}$

\section{Chapter Two}

The Mitochondrial Genome of Parapercis colias and development of a set of nonspecific fish primers

2.1.1 Mitochondrial genome analysis of Parapercis colias 16

$\begin{array}{ll}\text { 2.1.2 Development of control region primers } & 17\end{array}$

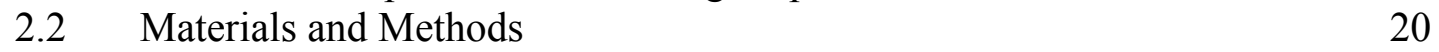

2.2.1 Whole mitochondrial genome sequencing of Parapercis colias 20

2.2.2 Control region primer development 20

2.2.3 Control region primer development strategy 21

$\begin{array}{lll}2.3 & \text { Results } & 24\end{array}$

2.3.1 Mitochondrial genome of Parapercis colias 24

2.3.2 Control region primer development 26

$\begin{array}{lll}2.4 & \text { Discussion } & 30\end{array}$

\section{Chapter Three}

The phylogeographic structure of New Zealand blue cod (Parapercis colias) based on mitochondrial DNA control region sequences 43

$\begin{array}{lll}3.1 & \text { Introduction } & 43\end{array}$

3.2 Materials and methods 46

3.2.1 Sample collection and DNA sequencing 46

$\begin{array}{lll}3.2 .2 & \text { Genetic analysis } & 47\end{array}$

$\begin{array}{lll}3.2 .3 & \text { Demographic history }\end{array}$

$\begin{array}{lll}3.3 & \text { Results } & 50\end{array}$

$\begin{array}{lll}3.4 & \text { Discussion } & 60\end{array}$

$\begin{array}{lll}3.4 .1 & \text { Population structure } & 60\end{array}$

3.4.2 Historical demography 62 


\section{Chapter Four}

General Discussion

66

4.1

General

66

4.2

Management suggestions

67

References

71 


\section{List of Tables}

\section{Chapter Two}

The Mitochondrial Genome of Parapercis colias and development of a set of nonspecific fish primers

2.1 Species included in study, TACC and recreational importance 21

$\begin{array}{ll}2.2 & \text { Control region statistics for each species } \\ 27\end{array}$

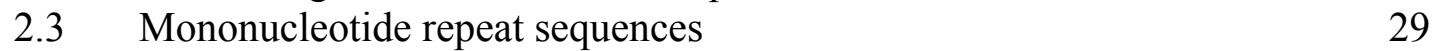

2.4 Coding regions for mitochondrial genome of Parapercis colias 34

2.5 Mitochondrial genome sequence for Parapercis colias 35

\section{Chapter Three}

The phylogeographic structure of New Zealand blue cod (Parapercis colias) based on mitochondrial DNA control region sequences

3.1 Genetic variation between sampled sites 51

3.2 AMOVA between regions in New Zealand 55

$\begin{array}{ll}3.3 & \text { Population expansion estimates } \\ \end{array}$

\section{List of Figures}

\section{Chapter One}

\section{General Introduction}

1.1 Three types of population structure 4

1.2 New Zealand coastal currents 8

$\begin{array}{lll}1.3 & \text { Blue cod quota management areas in New Zealand } & 13\end{array}$

\section{Chapter Two}

The Mitochondrial Genome of Parapercis colias and development of a set of nonspecific fish primers

2.1 Example of sequence overlap coverage 17

$\begin{array}{lll}2.2 & \text { Typical vertebrate mitochondrial DNA arrangement } & 23\end{array}$

2.3 The complete mitochondrial genome arrangement of Parapercis colias 25

2.4 Control region and flanking regions of Parapercis colias mitochondrial DNA

2.5 Control region and flanking regions of Polyprion oxygeneios mitochondrial DNA

\section{Chapter Three}

The phylogeographic structure of New Zealand blue cod (Parapercis colias) based on mitochondrial DNA control region sequences

3.1 Sample sites and haplotype variation $\quad 52$

3.2 Minimum spanning tree of haplotypes 53

3.3 Isolation by distance between mainland sampling sites 56

$\begin{array}{ll}3.4 & \text { Variation in genetic diversity with latitude } \\ 3.57\end{array}$

$\begin{array}{lll}3.5 & \text { Mismatch distribution } & 58\end{array}$

$\begin{array}{lll}3.6 & \text { Bayesian skyline plots } & 59\end{array}$ 


\section{CHAPTER ONE}

\section{GENERAL INTRODUCTION}

\subsection{Overview of New Zealand fisheries}

The New Zealand seafood industry represents the fourth largest export component of the New Zealand economy, totalling nearly NZ\$1.5 billion annually (www.stats.govt.nz, 2011). Despite its comparatively small geographic size, New Zealand has the fourth largest Exclusive Economic Zone (EEZ) in the world (4.4 million $\mathrm{km}^{2}$ ), an area approximately fourteen times the size of the land. At least 130 species are caught within the New Zealand EEZ, generating over 600,000 metric tonnes $(\mathrm{T})$ of seafood annually, of which a large proportion is exported to foreign countries. Preservation of this lucrative resource is of high importance.

In the 1980's, concerns that some fisheries in New Zealand were being harvested to a point that there was a risk of depletion in some areas saw the introduction of the Quota Management System (QMS). The QMS recognises separate management areas for each fishery species within the EEZ, called quota management areas (QMA), each of which has its own total allowable catch (TAC) for the fishing year. Commercial fishers wishing to catch fish within a QMA must have access to quota, which is traded as individual transferable quota (ITQ). Stock assessment models are used to determine the TAC, but the ITQ is a percentage of the total allowable commercial catch (TACC) for which each fisher owning quota is entitled to catch and trade for that fishing year. This allows management authorities to change the amount of fish that are removed from a QMA, though the proportion of the catch allocated to the fisher will not differ. The New Zealand QMS aims to keep catch levels as close to the maximum 
sustainable yield (MSY) as possible, though a cautionary approach is often used to minimise the likelihood of over-harvesting a stock (Lock \& Leslie, 2007).

Setting of QMAs in New Zealand is done through stock assessment models, which are based on knowledge of the biological stock structure of each species (Connor, 2001). As a result, 636 individual QMAs are present in New Zealand waters, each of which is seen as an individual stock. Quinn and Deriso (1999) define a stock is an 'aggregate of fish in a population which can be managed as a discrete unit'. Genetic markers have been used for several decades to identify discrete genetic stocks (Ihssen et al., 1981; Carvalho \& Hauser, 1994; Begg et al., 1999; Hebert et al., 2004). When genetic information is lacking, and stock structure of a species is poorly understood, it is safest to incorporate a management system that separates the fishery into distinct fishing areas, such as QMAs. If a species is incorrectly assumed to comprise only one genetic unit, but it is actually comprised of several genetic units, then there is a risk of local depletion and loss of genetic diversity (Carvalho \& Hauser, 1994). Genetic discreteness usually implies some restriction of migration, often in conjunction with spatial separation. In the circumstance that suitable habitat for a species is continuous, it is less likely that populations will exhibit population structure, instead forming a single panmictic population (MacLean and Evans, 1981). The ability to identify the level of population structure that exists in wild fish species is now proving extremely useful for sustainable management, often allowing a better understanding as to how discrete populations may react to harvest pressure.

\subsection{Importance of genetic variation for fisheries management}

Genetic variation in wild populations is constantly changing, as it experiences the forces of selection and genetic drift. Natural variables such as disease and predation commonly cause a reductions in population size and hence an increase in drift, which reduces genetic variation. This can be enhanced by the effects of fishing pressure (Hauser et al., 2002; Allendorf et al., 2008). Industrial scale fishing can cause three types of change to natural genetic diversity. Firstly, genetic variation is likely to decrease as population size is reduced. Inherently, this reduces the evolutionary potential of the population, as there is less genetic variation on which selection can act in response to environmental changes and other interactive pressures. In turn, this also increases the risk of inbreeding depression, which may reduce the biological 
productivity of the populations through reduced reproductive viability. The second major change that can result from fishing pressure is a disruption to population subdivision. Population structure is important as it allows segments of a population to diversify, adapt locally to different pressures, and become reservoirs of unique genetic traits. These population segments can evolve independently, and are termed evolutionarily significant units (ESUs). An ESU could ultimately lead to speciation. The third impact resulting from fishing pressure is the potential for selective genetic change. Harvesting of a species based on size restrictions may mean that only large individuals are removed from the fishery. This can cause selection for individuals that reproduce early and at a small size, decreasing the average size of fish in the population. The number of individuals required to maintain levels of genetic variation has been considered (Franklin, 1980), though it is likely to be directly proportional to the number of individuals whom are harvested from the population, relative to the total size. Higher harvest levels assumingly require higher population sizes in order to conserve genetic variation. Connectivity however, can negate the effects of differentiation by maintaining genetic homogeneity between populations.

Connectivity can occur during various stages of an organism's life history, with both larval and adult dispersal common in marine organisms

The primary goal for fisheries genetics studies is to identify discrete genetic stock units, as this forms the basis of stock assessment models. These studies typically begin with the null hypothesis of a single panmictic unit. From a management perspective, a genetically homogeneous unit is the simplest to manage, as individuals mate randomly throughout the distribution of the species, meaning the risk of localised depletion is low. As described by Laikre et al. (2005), panmixia is the first of three broad levels of population structure, with a species typically assigned to one of these, though in some cases more (see fig 1.1). The second form of population structure that a species may exhibit is 'continuous change', whereby the genetic composition of individuals changes continuously through space. This is essentially a pattern of 'isolation by distance' (Wright, 1943), where the more geographically isolated two individuals are from one another, the less similar they are genetically. Thirdly, 'distinct populations' is the presence of discrete genetic units in a species. This occurs when gene flow between the populations is so low, or even non-existent, that populations have evolved independently to one another, and differences are 
detected in genetic studies. It may be possible for a species to fit into more than one of these categories. For example: a species that is distributed on a large mainland site, and also on smaller islands, may show isolation by distance on the mainland, with mainland sites genetically distinct from the island population.
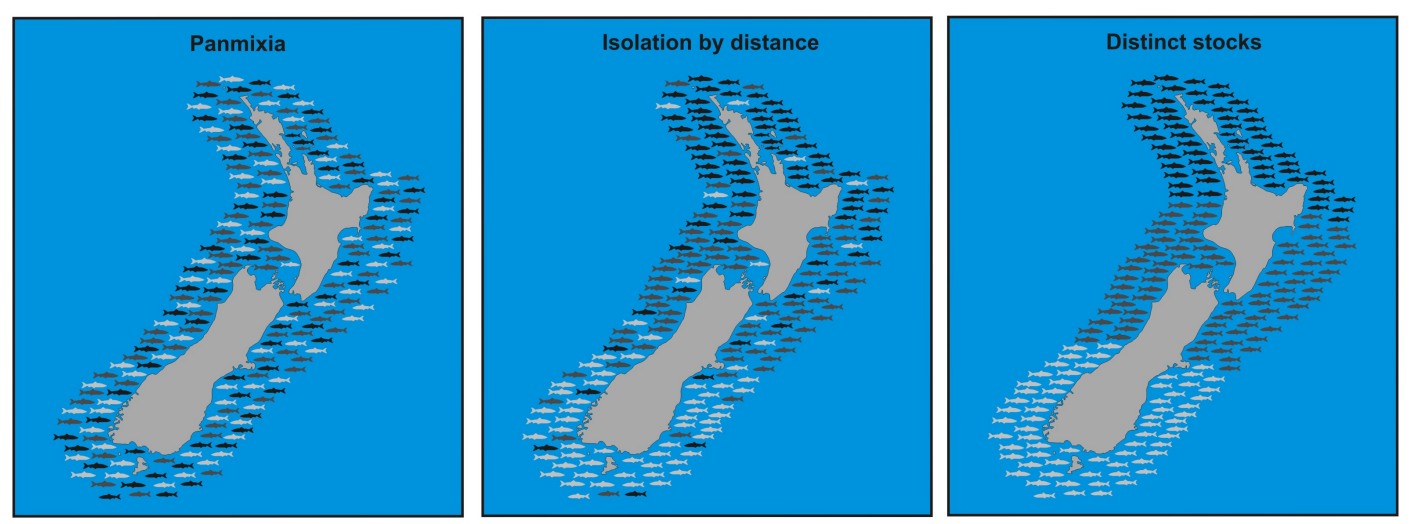

FIGURE 1.1: Three broad types of population structure, as adapted from Laikre et al. (2005). Shown are representations of homogeneous population structure (panmixia, left), continuous variation (IBD; centre), and genetically distinct stocks (right).

Determination of population genetic structure relies on the use of appropriate molecular markers. Ross et al. (2009) reviewed genetic studies of marine plant and invertebrate species in New Zealand, identifying a common genetic break either side of the Cook Strait. The break was attributed to both biological and physical processes, which together restricted gene flow between North and South Island populations.

Gene flow among marine populations can occur via a number of different mechanisms. Many marine organisms have a sedentary adult phase, which typically have a very low power of dispersal. Some sedentary species, however, have a pelagic larval phase, which for many represents the only opportunity for dispersal. For example, Haliotis iris, the New Zealand Black-foot Paua is a benthic mollusc which typically moves a very small distance throughout its adult lifetime (Poore, 1972), though larvae are pelagic for up to 8 days (Moss \& Tong, 1992). Long distance dispersal by organisms during their pelagic larval phase is common (Ward \& Elliot, 2001; Burridge \& Smolenski, 2003; Miller et al., 2011), though distance travelled is thought to be closely linked to their pelagic larval duration (PLD) (Siegel et al., 2003). A positive correlation is commonly observed between a species' PLD and 
levels of connectivity between geographically isolated populations (Shanks, 2009). As well as PLD, migration throughout the water column by larvae is common, with larvae able to alter their position in the water column significantly to match preferences for dispersal direction, distance and predator avoidance ( Leis, 2007; Irisson et al., 2009). Alongside biological factors, physical factors such as tidal patterns, wind, wave action and oceanographic currents contribute significantly to dispersal patterns in pelagic larvae (Cowen \& Sponaugle, 2009). There is mounting evidence, however, which suggests that dispersal distance in species with short PLDs is a 'spiky, stochastic curve' for which distance travelled is a combination of PLD, and timing of events that aid transport, such as storms and periodically strong currents (Siegel et al., 2003; Siegel et al., 2008; Selkoe \& Toonen, 2011). Larval dispersal and gene flow between marine populations is a complex set of bio-physical interactions.

The highly migratory nature of many fish species is regularly suggested as a cause for low levels of genetic structure (e.g. Smith et al., 1996; Burridge \& Smolenski, 2003). Though geographically separate populations of hoki (Macruronus novaenelandiae) are known to exist (Livingston \& Schofield, 1995), spawning aggregations allow genetic exchange between populations (Smith et al., 1996). As well as this longdistance dispersal in adult hoki, a PLD of approximately 7 months is further likely to contribute to genetic continuity around New Zealand. The presence of long-ranging dispersal characteristics does not always imply that a species will exhibit low levels of population structure, or panmixia. Atlantic bluefin tuna (Thunnus thynnus), a species with extremely high potential for dispersal, display significant genetic variation in both time and space, even within relatively confined areas of the Mediterranean Sea (Riccioni et al., 2010). Similarly, limited-ranging behaviour and territoriality of many reef species is often used to explain high levels of genetic structure (e.g. Hickey et al., 2009). Territoriality can cause low movement, with individuals unwilling to disperse any great distance from a defended range, restricting gene flow between spatially separated populations.

Just how much gene flow is required to maintain population homogeneity is a complex topic. Genetic homogeneity, a factor of the number of migrants, is more easily achieved than ecological homogeneity, which is a factor of the proportion of migrants moving from one population to another (Cowen et al., 2000). Theory 
suggests that 'one-migrant-per-generation' (Mills \& Allendorf, 1996) is sufficient to keep populations genetically homogeneous. It is therefore possible for both rare, long distance dispersal events, and infrequent episodic events to maintain connectivity between geographically isolated populations.

\subsection{Detecting genetic variation}

The use of molecular genetic techniques to detect population structure is of particular importance in fisheries management. Many different methods for detecting differentiation are available, all of which range in cost, ease of design and use, and their ability to detect and resolve subtle patterns of genetic differentiation. Popular in early genetic studies because of their relative low cost, allozymes (protein) are rarely used today because of their lack of resolving power compared to most modern markers (Smith \& Johnston, 1985).

Mitochondrial DNA (mtDNA) is popular marker, and it has been used in large number of genetic studies over the past three decades (e.g. Graves et al., 1984; Magoulas et al., 1996; Ward \& Elliot, 2001; Will, 2009). In most species, mtDNA is maternally inherited and evolves at a rapid rate, potentially 5-10 times faster than nuclear DNA in some vertebrate species (Vawter \& Brown, 1986). A suitable level of statistical resolution from mtDNA in marine genetic studies is reliant on a suitably large sample size because of the levels of variability, and the often widespread distribution of haplotypes (Carvalho \& Hauser, 1994). The cost of utilising and analysing mtDNA markers is relatively cheap, and they are straightforward to develop. MtDNA can be used to calculate the effective population size $\left(N_{e}\right)$, though the estimate will be one quarter of the $N_{e}$ of a nuclear gene because of the maternal inheritance of mtDNA (Carvalho \& Hauser, 1994). This can be further complicated in teleost species because many are hermaphroditic at some point in their life history. Simultaneous hermaphrodites, as well as protogynous hermaphrodites who mature as females and reproduce prior to sex inversion, will pass on their mtDNA. This will mean that the quarter $N_{e}$ will not apply to these species. The issue of variable $N_{e}$ among fish has received little attention, though it seems a particularly important consideration when calculating the effective population size of species and comparing estimates of levels of genetic variation, especially those that are commercially important. 
Nuclear DNA markers such as microsatellites, and more recently single nucleotide polymorphisms (SNPs), have become the preferred method for detecting fine scale levels of genetic structure. However, these methodologies can be relatively expensive and difficult to develop. Microsatellite loci sample multiple genomic locations, and so are often able to detect higher levels of genetic differentiation than single locus mtDNA. Because they are non-coding, variation will be independent of natural selection (except when a nearby gene is under selection), and they are particularly useful for describing the patterns of gene flow and differentiation caused by genetic drift. SNPs have fewer alleles than microsatellites, though a significantly larger number of loci can be developed, enabling them to detect more subtle patterns of variation and discover gene regions under selection (Brumfield et al., 2003). The high cost of identifying and screening for SNPs is a limiting factor in their application to fisheries genetics.

As long as the region of DNA targeted is neutral and sample size is sufficiently large, the simplest molecular tools will give a reasonable assessment of a population's structure. Markers like mtDNA can be used as a guide for the application of more complex methodological approaches (e.g. Dammannagoda et al., 2011; Mach et al., 2011; Miller et al., 2011).

\subsection{Physical oceanographic processes}

The physical oceanographic processes have an important role to play in shaping population genetic variation. New Zealand's coastal environment is very complex, comprising both warm sub-tropical currents from the north, and cold semi-polar currents from the Southern Ocean (fig. 1.2, see Heath, 1985). From the northwest, the Tasman front (TF) splits down both the east and west coasts, forming the East and West Auckland Currents (EAUC, WAUC), both of which meander south whilst remaining close to the coastline. The East Cape Eddy (ECE) breaks off the south flowing EAUC in the Auckland/Bay of Plenty region, before the EAUC becomes the East Cape Current (ECC) south of East Cape. An important rock lobster larval retention eddy, the Wairarapa Eddy (WE), splits off the ECC (Chiswell \& Booth, 1999) south of Hawke Bay. The ECC flows south as far as the Wairarapa, where it is forced eastward to the Chatham Islands by the north flowing Wairarapa Coastal 
Current (WCC). On the west coast, the WAUC flows south as far as the Waikato region, before colliding with the north flowing West Coast Current (WC), which begins near Hokitika/Westport in the South Island. The D'Urville Current (DUC) parts from the WC, flowing through the Cook Strait and continuing toward the Chatham Islands. From Fiordland, the Southland Current (SC) is generated from the sub-tropical convergence current (STC), and traces the coastline towards Otago, flowing through Foveaux Strait and continuing up the east coast of the South Island. Once at the Chatham Rise, the SC branches off towards the Chatham Islands. See Heath (1985) for further information.

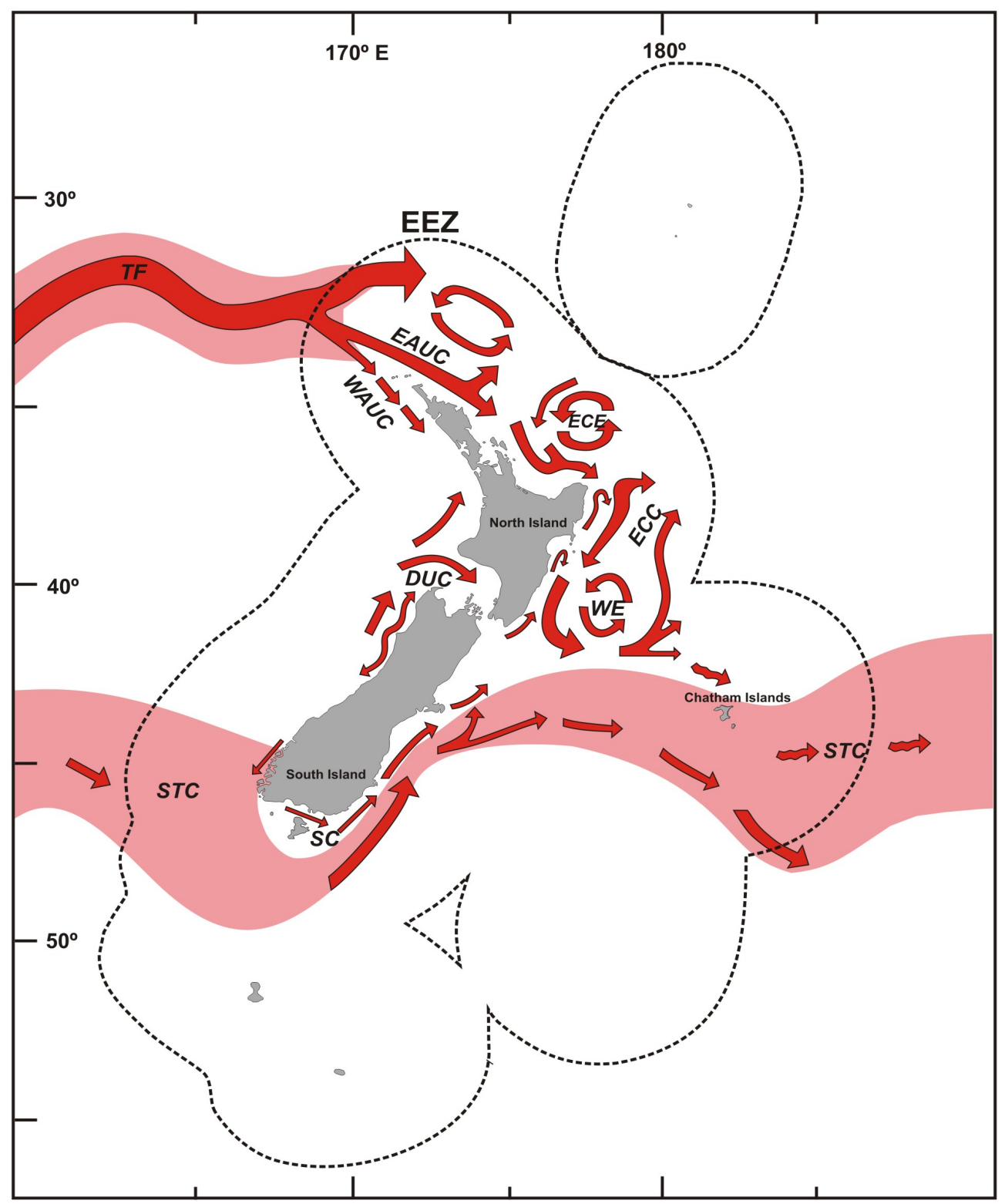

FIGURE 1.2: Schematic reconstruction of surface currents around the New Zealand exclusive economic zone (EEZ) and coastline. Included in the diagram is the Tasman Front (TF), East Auckland Current 
(EAUC), Eest Auckland Current (WAUC), East Cape Eddy (ECE), East Cape Current (ECC), Wairarapa Eddy (WE), D'Urville Current (DUC), Sub-tropical Convergence (STC) and Southland Current (SC). Adapted from Heath (1985), and Chiswell (2009).

\subsection{Genetic structure of New Zealand teleost species}

At least $30 \%$ of the 136 species included in the New Zealand QMS are inshore fish species, and together make up an important part of the commercial fishing industry. Of these, genetic population structure is well understood for snapper, tarakihi and yellowtail kingfish (Bernal-Ramirez et al., 2003; Burridge \& Smolenski, 2003; Miller et al., 2011), though some biological and ecological evidence for stock structure in bluenose, hapuku, and several species of warehou does exist (Smith \& Johnston, 1985; Bagley et al., 1998; Beentjes \& Francis, 1999; Horn et al., 2001; Horn, 2003). Further genetic information in many of these fisheries would benefit management considerably, helping to shape management decisions. The development of generic PCR primers (e.g. control region) for regions of fish mtDNA would help establish a set of molecular tools for genetic surveys to be conducted on a range of important species.

While few genetic studies currently exist on commercially important New Zealand fish species (inshore and offshore), what follows is a brief summation of the studies that have reported mtDNA and microsatellite data and analysis.

\section{Hoki (Macruronus novaezelandiae)}

Using mtDNA markers, no evidence exists for genetically differentiated populations. This is attributed to long-distance migratory behaviour, and transport of larvae and juveniles between spawning sites and adult areas via coastal currents (Smith et al., 1996). As an example, Smith et al. (1996) explains that larvae and juveniles hatched at spawning sites on the west coast of the South Island are likely transported to east coast nursery and adult feeding areas via the Westland and D'Urville currents (fig 1.1). Hoki have an extremely long PLD and juvenile pelagic phase (seven months; May \& Blaber, 1989), and when combined with extensive migratory behaviour and spawning aggregations, overlap and gene flow between populations seems plausible. Despite population overlap, geographically isolated populations are managed as discrete units. Such management results from evidence that fish in different 
geographical locations grow and mature at different rates, making some areas more vulnerable to exploitation than others. There is, however, some limited evidence suggesting that at least two separate stocks of Hoki exist (Livingston and Schofield, 1996). Livingston and Schofield (1996) suggest Cook Strait and west coast spawners may be generated from different stocks, with the west coast stock possibly being linked to fish in the Auckland and Campbell Islands. Evidence for this is limited to morphometric analysis, with no genetic evidence to back up the hypothesis. The study of Smith et al. (1996) also showed a lack of population structure between Tasmanian and New Zealand populations.

\section{Orange_Roughy (Hoplostethus atlanticus)}

Similar stock structuring patterns in orange roughy were found in two separate studies published in 1996 and 1997. Smith et al. (1996) found evidence for three geographically isolated populations using mtDNA markers (Smith et al., 1996). Gene flow between sites on the west coast of the South Island and eastern coast population on the Chatham Rise and Richie Bank is common, with no differentiation between sites. Three stocks of orange roughy were identified-Southern: Puysegur-Waitaki region; 2. Northern: eastern Richie Bank-West coast-Chatham rise; 3. Western: Challenger plateau. The Western stock is the only population of orange roughy that exists without gene flow from other sampled sites. Stock structure was also identified in a study conducted by Smith and Benson (1997), finding two separate stocks on the east coast of New Zealand. This study included more extensive sampling in a smaller area. Two regions were chosen (Chatham Rise, east coast), from which 15 sample sites were identified. Results showed no differentiation within sample sites at the two main locations, though significant differentiation between the two nearest sampling sites at each location. This evidence does not entirely agree with Smith et al. (1996), as there is an expectation of connectivity between these two areas, which together with the west coast, form the Northern stock. Smith and Benson (1997) explain a theme of temporal differentiation in orange roughy stocks, which may explain disagreement with the previous study. Given behavioural characteristics of orange roughy (e.g. spawning aggregations), sampling protocol may prove important in differentiation of stocks. Together, the two papers prove a degree of stock structure in one of New Zealand's most important fisheries species, though it is certainly an area that would benefit from clarification. 


\section{Snapper (Pagrus auratus)}

Snapper in New Zealand exhibit a high degree of population structure. Microsatellite analysis identified genetic differentiation of populations in the north and south, with a Tasman Bay stock significantly differentiated to all northern populations (BernalRamirez et al., 2003). Bernal-Ramirez et al. (2003) used opposing oceanographic processes to explain this result, with larvae from west coast populations inhibited from reaching Tasman Bay by both the Taranaki and D'Urville currents. Northeastern populations are genetically distinct, except for a small similarity between west coast populations and upper north-east populations. Despite its close proximity to East Cape populations, Hawkes Bay populations are genetically heterogeneous, and are actually more closely related to west coast and upper northeast populations, than they are to East Cape fish. Bernal-Ramirez et al. (2003) hypothesised that this genetic break was due to the Wairarapa eddy, as it reaches its northern parameter near Hawke Bay, restricting flow of Hawke Bay larvae north and instead circulating them in the eddy south. The north-eastern population remains one genetic unit, ranging from East Cape to Doubtless Bay in the far north east. This separates New Zealand Snapper into what Bernal-Ramirez et al. (2003) consider three main stocks units; 1. Tasman Bay; 2. West coast; 3 . North east.

\section{Tarakihi (Nemadactylus macropterus)}

Tarakihi extend around all of the New Zealand coastline, as well as South Australia. Despite this broad range, no genetic sub-division was found between four distant locations either side of the Tasman Sea, using microsatellite analysis (Burridge and Smolenski, 2003). Possessing an extremely long pelagic larval phase (seven months), and travelling great distances as mature adults in search of food, the biology of tarakihi supports high levels of gene flow adult populations, and a lack of stock structure (Annala, 1987). Because of this, management from a fisheries perspective is relatively simple, as the safety net of re-stocking populations is substantial given the event an area is over-exploited.

\section{Yellowtail kingfish (Seriola lalandi)}

Yellowtail kingfish are present in waters of both New Zealand and Australia, and are wide-ranging and particularly capable swimmers. Miller et al. (2011) failed to detect 
significant population structure between New Zealand and east-Australian populations using mtDNA and microsatellite markers, with strong migratory tendencies used to justify the connectivity. Differentiation between west-Australian and all eastAustralian and New Zealand populations indicates population structure does exist, but vast bodies of water are required to stem gene flow of this highly migratory species.

\subsection{Study species: blue cod (Parapercis colias)}

Blue cod is widely considered the most important recreational fishery in the South Island, with areas such as the Marlborough Sounds, Otago, and Stewart Island especially popular recreational fisheries. Blue cod is popular for its medium texture white flesh and sporting qualities, caught by recreational anglers using hook and line, and sometimes speared. The recreational catch is estimated to be over $700 \mathrm{~T}$, with at least $75 \%$ of that coming from South Island waters (Bradford, 1998). Commercially, blue cod is regularly the holder of one of the ten largest TACC of inshore teleost species (www.fs.fish.govt.nz, 2011). In 2010/11 blue cod TACC was 2,681,496kg, though not all of this allowance was reported caught. The blue cod fishery is currently managed as eight QMAs (fig 1.3), with the largest takes coming from the Southland and Chatham Island fisheries $(\mathrm{BCO} 4,5)$. As is often the case, these QMAs were set with no prior knowledge of stock structure when blue cod was first introduced to the QMS in 1986. There have been no studies of its genetic stock structure, but current management takes the precautionary approach by separating the fishery into the eight FMAs.

Aspects of the biology of blue cod make it particularly susceptible to overexploitation. The Marlborough Sounds fishery has recently had catch limit reductions and closure of several areas to all forms of blue cod fishing because research and recreational catch reporting suggested some localised stock depletion (Ministry of Fisheries, 2008). The Marlborough Sounds stock decline was largely considered the result of recreational pressure. Commercial quota cuts to the country's key blue cod fishery, the Southland region (BCO 5), are also beginning to be implemented, suggesting a widespread decline in heavily fished blue cod stocks. The cut is reported to have resulted from significantly reduced catch per unit of effort (CPUE) reports by commercial fishers, though many in the industry agreed with the decision (Mackay, 2011). 


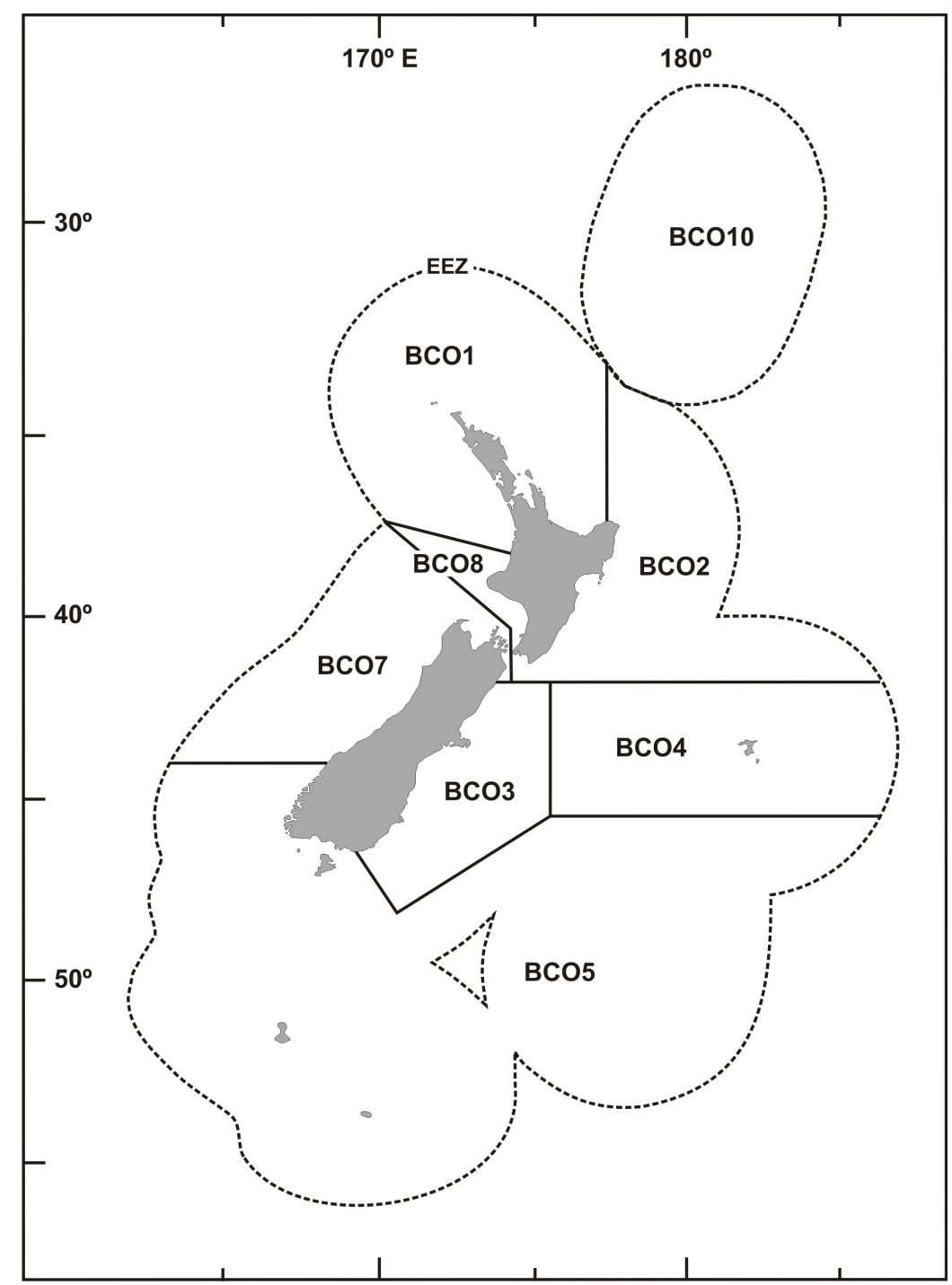

FIGURE 1.3: Blue cod (BCO) quota management areas as identified in the New Zealand quota management system.

Blue cod are distributed throughout the New Zealand coastal environment over or near rocky reefs, and are commonly found to depths of $150 \mathrm{~m}$. Trawl catches sometimes report catches of blue cod to depths of 350m (Warren et al., 1997). Blue cod are far greater in abundance in more southern latitudes, with the bulk of the commercial fishery targeting these areas.

Spawning season varies throughout the country, with Southland (BCO 5) fish spawning between November and January (Carbines, 2003), and Northland fish between September and January (Mutch, 1983). Carbines (2003) outlines that the length of the spawning season, and development of multiple stages of oogenesis as 
strong evidence for the idea that blue cod are multiple spawners. The eggs of blue cod are planktonic for approximately 5 days, followed by a further 5 days as pelagic larvae (Robertson, 1973; Henderson, 2009). Information regarding settlement onto reefs is not well understood, though Carbines (2003) notes that juvenile blue cod are commonly observed in very shallow $(<15 \mathrm{~m})$ open reefs and sandy areas.

Blue cod are protogynous hermaphrodites, with the majority of fish beginning life as females, before undergoing sexual inversion to become males. While this occurs in most fish, some begin life as primary males, which are fish born as males that are not female at any stage in their lives (Carbines, 2003). Age and size at maturity is highly variable around the country, with northern (BCO 1) fish younger and smaller at maturity than southern (BCO 5) fish ( Mutch, 1983; Carbines, 2003). Males in Northland (BCO 1) mature at approximately 110-190mm total length (TL) at around 2-3 years of age (Mutch, 1983), while Southland fish may not mature until approximately 260-280mm TL, at 4-6 years old. In Southland, the length at which sexual inversion occurs is inconsistent, though most common between $280 \mathrm{~mm}$ and $320 \mathrm{~mm}$ TL, at an age of approximately 5-6 years (Carbines, 2003). Blue cod can reach over $50 \mathrm{~cm}$ in length, and live for a maximum of approximately 18 years (Carbines, 2004; Carbines et al., 2004).

Adult blue cod are often found on the edge of rocky outcrops near sandy areas (Pers. obs., 2010; Carbines, 2003), and adult males appear to be highly territorial, as well as defending a small number (3-5) of mature females (Mutch, 1983). Mutch (1983) also noted that the size of the territory and number of females defended is related positively to the size of the male defending the territory. Juvenile fish may co-inhabit areas with adults, assumed to exist because of the different dietary requirements at the respective ages. Adult movement of blue cod appears to be minimal, though in rare circumstances, long-distance dispersal does occur. Tagging studies indicate that over an 18 month period, $60 \%$ of fish move less than $1 \mathrm{~km}$ (Carbines, 1999). Despite this, Carbines (1999) also found one fish moved 156km during the same period of time. Other tagging studies suggest similar patterns, with many individuals not moving more than 100m from their tagged location (Mace \& Johnston, 1983; Cole et al., 2000; Carbines, 2003; Carbines \& McKenzie, 2004;). 
When considering aspects of blue cod biology such as low PLD, limited movement by both juvenile and adult fish, a prediction of a moderate to high level of population structure seems justified. Sampling of blue cod from throughout the New Zealand coastal environment, including the offshore Chatham Islands, will allow for the first time a description of the patterns of genetic variation between various sites.

\subsection{Thesis Aims}

The overall goal of this research was to develop a mtDNA marker for blue cod and use it to determine the level of genetic variation and structure around New Zealand. The first research component of this thesis (Chapter two) follows the characterisation of the entire mtDNA genome for blue cod, as well as development of a set of generic primers for the amplification of the mtDNA control region of several commercially important New Zealand fish species. Only the cytochrome $c$ oxidase gene (Ward, 2005) and control region (Chapter three) of blue cod has been sequenced to date. Species included for primer development have varied biological and ecological characteristics, each are part of the New Zealand QMS, and most are also important recreational fish. The second aim of this chapter was to amplify and sequence a section of the mtDNA genome that contained the control region, following which more specific primers for individual species are developed for use in future fisheries genetic studies.

Chapter three is an investigation of the population genetic structure of the blue cod (Parapercis colias) in New Zealand. Mitochondrial DNA markers were used to determine the levels of genetic variation, patterns of genetic connectivity, effective population size and approximation of times since population expansion.

Chapter four is a general discussion section, focusing on results from this research and placing them in the context of existing research. 


\section{CHAPTER TWO}

\section{THE MITOCHONDRIAL GENOME OF PARAPERCIS COLIAS AND DEVELOPMENT OF A SET OF NON- SPECIFIC FISH PRIMERS}

\subsection{INTRODUCTION}

\subsubsection{Mitochondrial genome analysis of Parapercis colias}

Mitochondrial DNA has been used for phylogeographic and phylogenetic studies both within and between species for many years because genes on this molecule have a higher mutation rate (Brown et al., 1979) compared to nuclear DNA ( Saccone et al., 1987; Bowen et al., 2006; Hickey et al., 2009). Characterisation of the entire mtDNA genome has become more common for many species, and the organisation of the molecule sometimes differs between relatively closely related organisms (Árnason et al., 1993). Comparisons of mtDNA gene order have been useful for determining highorder relationships among species, as well as for use in closer relationship analysis such as identifying the point at which reproductive compatibility ceases between two different genomes (Árnason \& Gullberg, 1993).

Traditional approaches for sequencing genomes such as entire mtDNA have typically relied on Sanger chain-termination sequencing (Sanger et al., 1977), which enable 500-700 bp length reads. However, recent developments in DNA sequencing technology, so-called second-generation techniques, have vastly improved the number of sequence reads that can be generated. Second-generation sequencing machines produce very large numbers of reads, though they are shorter than the first-generation 
sequencing techniques. However, if enough sequence reads can be produced then the overlaps among them can be found and put together as an assembly of a genomic region. This has been particularly helpful for generating whole genome sequences of the mtDNA because it is usually only about $16,000 \mathrm{bp}$ long. With the help of previously sequenced genomes held in the GenBank database, the raw sequence data can be assembled and aligned using information from a closely related organism (see McComish et al., 2010). McComish et al. (2010) noted four different types of secondgeneration sequencing machines are currently available, and capable of producing up to 114 million reads, each ranging from 35-150 nucleotides long, in a single run. The read length and volume of sequence information that can be generated is constantly increasing with improving technology. This allows very large portions of genomes to be sequenced relatively quickly, and eliminates the need to use polymerase chain reaction (PCR) to target smaller regions of DNA such as individual genes. Further, second generation sequencing has been shown to allow identification of characteristics of some genomes not able to be detected using traditional PCR techniques (McComish et al., 2010). This technology provides a highly effective way to sequence whole mtDNA genomes from a range of New Zealand fish species, and allows generic PCR primers to been designed.
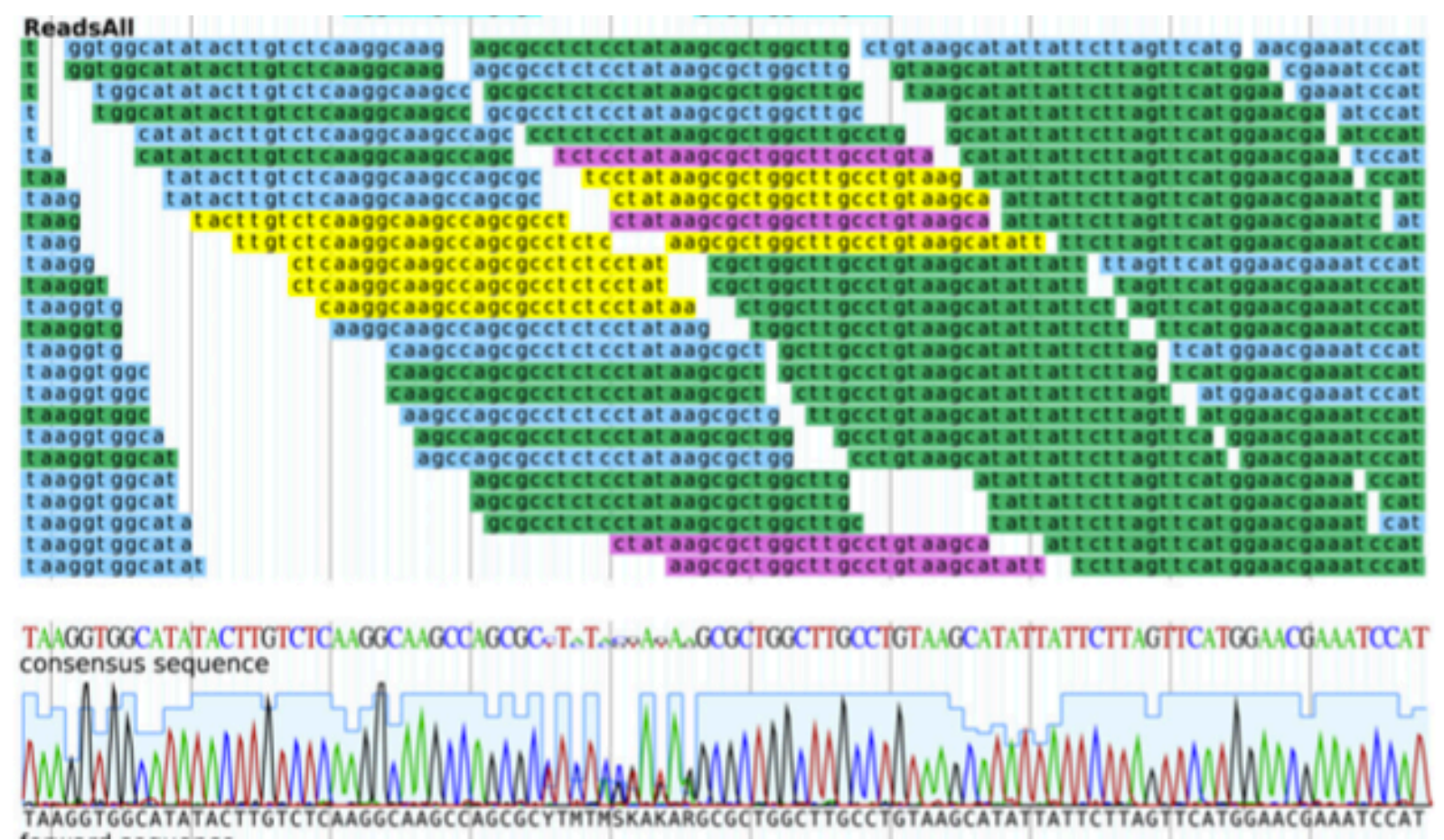

FIGURE 2.1: Example of short (27bp) reads generated by an Illumina Genome Analyzer. Based on overlapping of sequence reads, a consensus sequences is generated (below). Taken from McComish et al. (2010). 


\subsubsection{Development of control region primers}

The primary goal of genetics in fisheries management is to identify discrete stocks, or genetic groups that should be managed separately. Mitochondrial DNA has been used to identify fish stocks for over three decades, and several gene regions have been used. The control region is typically the most variable region of mtDNA, and therefore can potentially provide the best level of resolution for population-level studies. Slower evolving genes such as COX 1 are also well suited to inter-species comparisons and this region has been particularly useful as a 'DNA barcoding' marker for species (Ward et al., 2005). Some nuclear DNA markers, such as microsatellites and single nucleotide polymorphism (SNP's), are capable of providing higher levels of resolution, but their development is much more technically challenging and it can be very expensive. Nuclear genes typically evolve at a slower rate than those on the mitochondrial genome, but in combination, nuclear and mtDNA sequences can together reveal the often complex patterns of differentiation within and among populations (Vawter \& Brown, 1986; Broderick et al., 2011). Mitochondrial DNA gives a unique perspective of the structure of genetic variation within and among populations because it is maternally inherited, and it does not undergo recombination. Hence, a range of phylogenetic techniques can be applied at the population level, as well as a selection of population genetic analysis techniques. Another key advantage is the ability to adapt mtDNA primers for application across a broad range of species. Mitochondrial DNA can be used as the first step to exploring levels of genetic differentiation within a population or fisheries stock (Moritz et al. 1987). If differentiation is detected within mtDNA, then more complex nuclear markers may or may not need to be used to resolve the finer-scale patterns of structure.

The CR is an area of the mitochondrial genome that is known to evolve at a rapid rate, with higher levels of variability than most other mitochondrial genome regions (Saccone et al., 1987). In the vertebrate mtDNA genome, the CR is approximately $1 \mathrm{~kb}$ in length, flanked either side by tRNA-Pro at the 5' end, and tRNA-Phe at the 3 '. It is the relaxed functional constraints in parts of the CR which allow it to evolve at a much faster rate than the average mitochondrial sequence (Brown, 1985). In vertebrates, the 5' and 3' ends of the CR are most variable, with a conserved region 
between these two regions, often referred to as the centrally conserved domain (CCD) (Brown et al.,1986; Saccone et al., 1987). Of the two flanking regions, the sequence ranging from Proline transfer RNA region (tRNA-Pro), through to the CCD (usually between 450-550bp) appears to be the most variable, and is regularly used in population genetic studies (Hyper-variable region 1, HRVI) (Nagata et al.1998; Pourkazemi et al.1999; Aboim et al. 2005).

There has been very little CR primer development for New Zealand fish species, and very few phylogeographic studies. The development of mtDNA markers for amplification of the CR in a range of inshore New Zealand fish species would open up possibilities for stock structure research, and add to the dataset of genetic information for New Zealand commercial fish species. Generic primers are available for amplification of comparatively conserved regions of the mtDNA genome, such as COX 1 (e.g. Ward et al., 2005), though to date there is a lack of primer sets available for amplification of the CR, especially for southern hemisphere fish species.

The overall aim of the study was to sequence the entire mtDNA genome of the blue cod and develop a set of primers to amplify the mtDNA CR across a selection of inshore New Zealand fish species. Firstly, the second-generation sequencing techniques have been applied to a blue cod DNA sample, and the entire mtDNA genome has been recovered from the resulting sequence information. Secondly, a set of PCR primers have been developed for amplifying of the control region of a range of fish species. 


\subsection{MATERIALS AND METHODS}

\subsubsection{Whole mitochondrial genome sequencing of Parapercis colias}

For second-generation sequencing of the blue cod (Parapercis colias) mtDNA genome, high quality DNA was extracted using the phenol-chloroform method. Samples were taken from the pelvic fin of two individuals (ACH 1, ACH 3) from the Akaroa Harbour, Canterbury, New Zealand. DNA concentrations of at least $500 \mathrm{ng} / \mu \mathrm{L}$, with high purity levels $(260 / 280>2.00)$ were aimed for, and DNA suspended in TE buffer. Sequences were generated on an Illumina Genome Analyzer at the Beijing Genomics Institute, China. Because of the small quantity of samples, mate-paired DNA libraries were constructed, each of which had insert sizes of 200 base pairs (bp). The Solexa-Pipeline method was implemented, with $58.27 \mathrm{~Gb}$ of raw data generated from a single run. Each of the reads produced by the Illumina machine are $100 \mathrm{bp}$ long, though bases at either end of the read are lower quality, thus were trimmed to around $75 \mathrm{bp}$. To minimize the likelihood of incorrectly aligning sequence reads, any reads with $\mathrm{N}$ bases (i.e. base not able to be distinguished), reads with greater than $20 \%$ of bases low quality, suspected contamination reads, and duplication reads generated by PCR while constructing the library were all discarded.

Following initial filtering as described above, sequence reads were imported as FASTA files into Geneious 5.4 (Drummond et al., 2010), and alignments made based on consensus read overlaps. Once the sequence had been aligned, annotation of the molecule was performed based on the previously described mtDNA genome of Psenes cyanaphrys, the species that produced the most similar CR sequence during a BLAST search.

\subsubsection{Control region primer development}

\section{General}

Species used in this study were chosen based on several factors: availability, commercial and recreational importance, planned genetic projects, stock structure knowledge and unresolved stock problems. All of the species listed are part of the New Zealand Quota Management System (QMS), and most represent important recreational fisheries, including snapper, blue cod, kahawai and hapuka which are of particular significance to recreational anglers. 
TABLE 2.1: The list of species included in this study, along with their commercial abbreviation tag (e.g. BCO, blue cod), Total allowable commercial catch (TACC), and recreational importance as judged by colleagues and the author.

\begin{tabular}{lcc}
\hline \multicolumn{1}{c}{ Species } & TACC (T) & Recreational importance \\
\hline Blue Cod (BCO) & 2,681 & High \\
Blue Moki (MOK) & 608 & Low \\
Blue Warehou (WAR) & 4,513 & Low \\
Butterfish (BUT) & 162 & Low \\
Hapuka (HPB) & 2,181 & High \\
Jack Mackerel (JMA) & 60,574 & Low \\
Kahawhai (KAH) & 2,728 & High \\
Red Gurnard (GUR) & 5,181 & Moderate-high \\
Snapper (SNA) & 6,357 & High \\
Stargazer (STA) & 5,456 & Low \\
Tarakihi (TAR) & 6,439 & Moderate-high \\
\hline
\end{tabular}

\subsubsection{Control region primer development strategy}

The CR was targeted by designing primers for conserved regions in the flanking cytochrome $b$ and 12S-rRNA genes, and these were used to generate a sequence spanning across the entire CR. Once the full sequence of this segment had been obtained, internal primers were designed specifically to target the CR in a range of species. In this study, primers located within cytochrome $b$ and near the 5 ' end of the control region were used to develop a unique primer in the tRNA-Pro region, a the 5', end of the CR. This primer was then paired with a 12S-rRNA primer, and the resulting sequence used to design a primer to the 3' end of the CR, within tRNA-Phe. These are then paired for amplification of the entire CR (see fig. 2.2).

First the cytochrome $b$ and 12S-rRNA genes of Parapercis colias were sequenced using the following primer pairs; (1) L-Cytb-BCO (5'GTAAACTACGGATGACTGATTCG) with H16500 (5'-GCCCTGAAATAGGAACCAGA) (Kai et al., 2004); and H-12S-BCO (5'-GCACCGCCAAGTCCTTTGGG) with H-tRNA-Pro-BCO (5'-GAGCGCCGGTCTTGTAAACCGG). H-tRNA-Thr$\mathrm{BCO}$ was designed from the initial sequences of primer pair one, which spanned from near the middle of the cytochrome- $b$ gene, into the conserved tRNA-Pro. All PCRs contained $67 \mathrm{mM}$ Tris- $\mathrm{HCl} \mathrm{pH} 8.8,16 \mathrm{mM}\left(\mathrm{NH}_{4}\right)_{2} \mathrm{SO}_{4}, 1.5 \mathrm{mM} \mathrm{MgCl}_{2}, 200 \mu \mathrm{M}$ of each dNTP's, and $0.5 \mu \mathrm{M}$ of each primer, $0.6 \mu \mathrm{g} / \mu \mathrm{L}$ Bovine Serum Albumin (BSA), 1 unit of BIOTAQ ${ }^{\mathrm{TM}}$ DNA Polymerase (Bioline), and $1 \mu \mathrm{L}$ of template DNA. 
Thermocycling conditions were $94^{\circ} \mathrm{C}$ for 30 seconds, $55^{\circ} \mathrm{C}$ for 30 seconds, $72^{\circ} \mathrm{C}$ for 45 seconds for 35 cycles, followed by a final extension of $72^{\circ} \mathrm{C}$ for 10 minutes. The resulting PCR products were purified with ExoSAP-IT (Amersham Parmacia Biotech, Japan) and the DNA sequence was determined using an ABI 3730 Genetic Analyser (service provided by Massey University NZ, and Macrogen Incorporated, Korea). DNA sequences were edited and aligned in Geneious V 5.3.4 (Drummond et al., 2010), using the default parameters. The resulting $1248 \mathrm{bp}$ and $1264 \mathrm{bp}$ sequences were used to design primers in the tRNA-Pro and tRNA-Phe regions. The second primer, which was developed for use in conjunction with H-tRNA-Pro-BCO to produce an approximately $900 \mathrm{bp}$ sequence spanning the CR, is H-tRNA-Phe-FISH (5'-CTTAACATCTTCAGTGTTATGC). In order to generate the entire CR sequence for all species, both primers were used for sequencing, and resulting sequences trimmed and a reverse compliment strand generated, before a contiguous sequence was generated.

In preparation for population genetic studies on Parapercis colias, Polyprion oxygeneios and Pagrus auratus, further primers were designed to amplify the control region. For $P$. colias, and $P$. auratus, primers were designed to target the approximately $500 \mathrm{bp}$ long HRVI segment of the control region (P. colias: H-CCDCR-BCO; 5'-AGAACGCTCGGCATGTTGGGT-3'; P. auratus: L19-tRNA-ProSnapper; 5'-CACCATTGGCTCCCAAAGC-3', H17-tRNA-Pro-Snapper; 5'GCTTTCTAGGGCCCATC-3'). For $P$. colias, this primer was paired with the earlier designed H-tRNA-Pro-BCO. Results from the use of this primer can be found in Chapter three of this thesis. $P$. oxygeneios $\mathrm{CR}$ amplification was conducted using a more specific primer located in the tRNA-Pro region (H-tRNA-Pro-HPB; 5'CCTACCCCTAACTCCCAAAGC-3') and paired with the H-tRNA-Phe-FISH. 


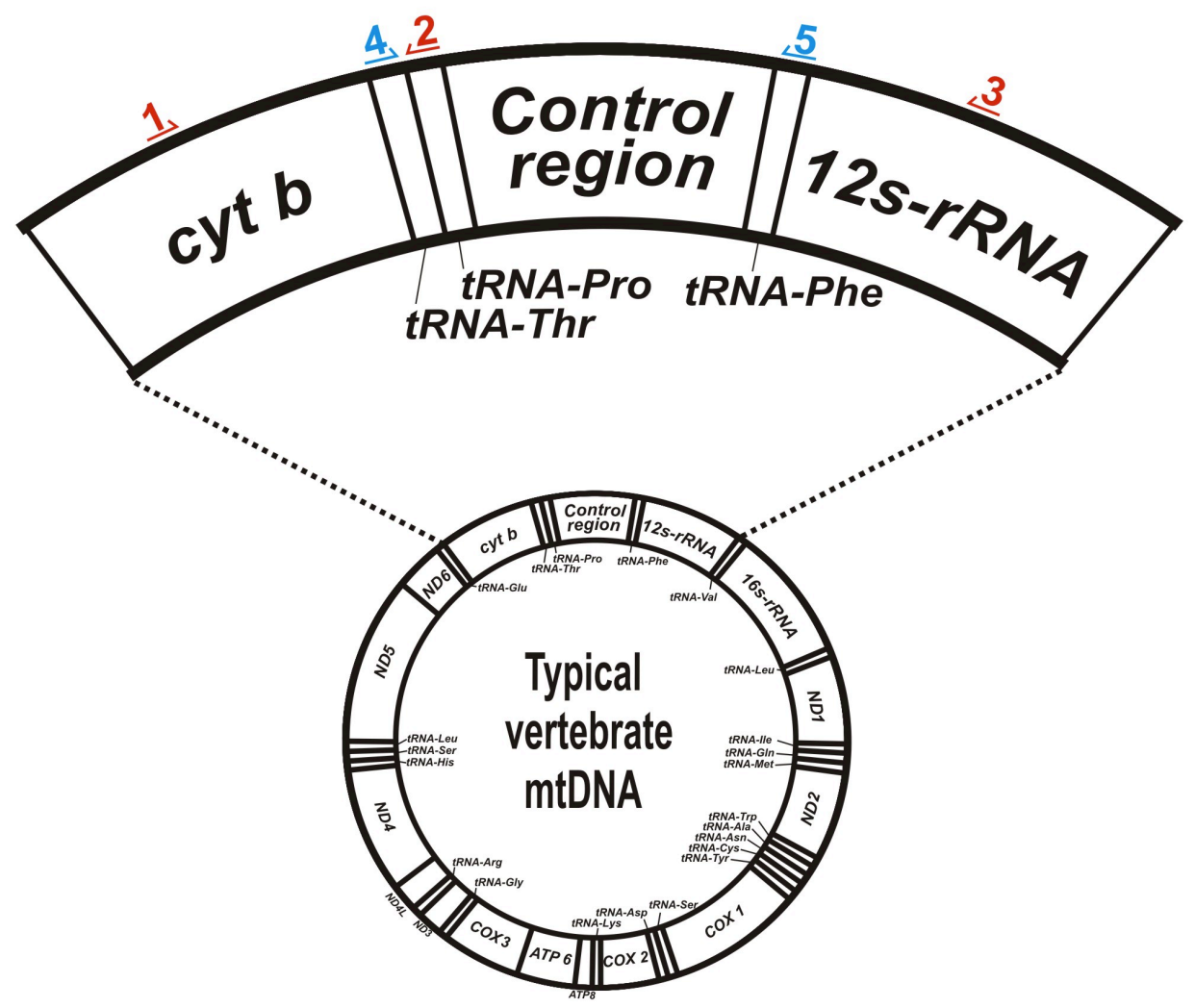

FIGURE 2.2: Typical vertebrate (lower section), with targeted region or mtDNA shown (upper section). Primer combinations 1 (L-Cytb-BCO, 5'-GTAAACTACGGATGAC-TGATTCG) \& 2 (H16500, 5'GCCCTGAAATAGG-AACCAGA) and 3 (H-12S-BCO, 5'-GCACCGC-CAAGTCCTTTGGG) \& 4 (H-tRNA-Pro-BCO, 5'-GAGCGCCGGTCTTGTAAACCGG) used initially to extract sequences of control region flanking regions for specific primer development. Primers 4 and 5 (H-tRNA-Phe-FISH, 5'-CTTAACATCTTCAGTGTTATGC) could then be used to sequence the control region of inshore New Zealand fish species 


\subsection{RESULTS}

\subsubsection{Mitochondrial genome of Parapercis colias}

In total, over 10 million read pairs were generated using the Illumina Genome Analyzer, with an average base coverage of 11.9 nucleotides (base coverage is the number of sequence reads which account for a single base position-see fig. 2.1). The minimum coverage of any base was one, with a maximum coverage of 34 . In order to map the entire mtDNA genome, 2,148 reads were required, and despite strict parameters for inclusion in the analysis, this is considered a relatively low number (Pers. Comm. McComish, 2010).

The assembled mitochondrial genome of $P$. colias (individual ACH 3) was 16,631bp in length, with base frequencies of $\mathrm{A}=27 \%, \mathrm{C}=28.2 \%, \mathrm{G}=17 \%, \mathrm{~T}=27.8 \%$ $(\mathrm{GC}=45.2 \%)$. The molecule contained the standard set of genes, including 13 proteincoding genes, 2 ribosomal RNA genes, and 21 tRNA genes (fig. 2.3). With the exception of COI and ND6, all protein-coding genes begin with the standard ATG start codon. COI begins with GTG, and ND6 with CTA. The gene end codon of TAA and TAC were only observed in 6 of 13 protein-coding genes. Mitochondrial genome gene composition and structure was the same as the typical fish arrangement, however no full mtDNA genomes are currently available from congeneric species for comparison (e.g. Xanthichthys auromarginatus, Auxis rochei, Beryx decadactylus, Oreochromis niloticus).

Confidence in the alignment of the final sequence is based on the depth of coverage for each nucleotide position, and should be at least two sequence reads (i.e. coverage $\geq 2$ ). In some parts of the $P$. colias mtDNA genome, only one sequence read was available. In particular, a small (20 bp) gap at the 5' end of 16S rRNA was not covered by any reads on initial inspection. While the gap was filled after further analysis, it is possible there are some errors in the draft sequence, and the $20 \mathrm{bp}$ read should be viewed with caution. In the future, PCR amplification and sequencing of the lower coverage regions will enable these regions to be verified. 
While only two individuals were sequenced, some basic analysis of the differences between the two sequences is possible. The coverage of $\mathrm{ACH} 3$ was better than $\mathrm{ACH}$ 1 , which required several small gaps to be covered by the sequence of ACH 3. This may be a result of a reduced quality of DNA extraction. A total of 23 single nucleotide polymorphisms are present between the two sequences. Cytochrome $b$ and the control region have the most polymorphic sites between the two samples, with five, and ND2, ND4 have four each. The only other regions to any polymorphic sites were 16S rRNA, ND1 and ND5.

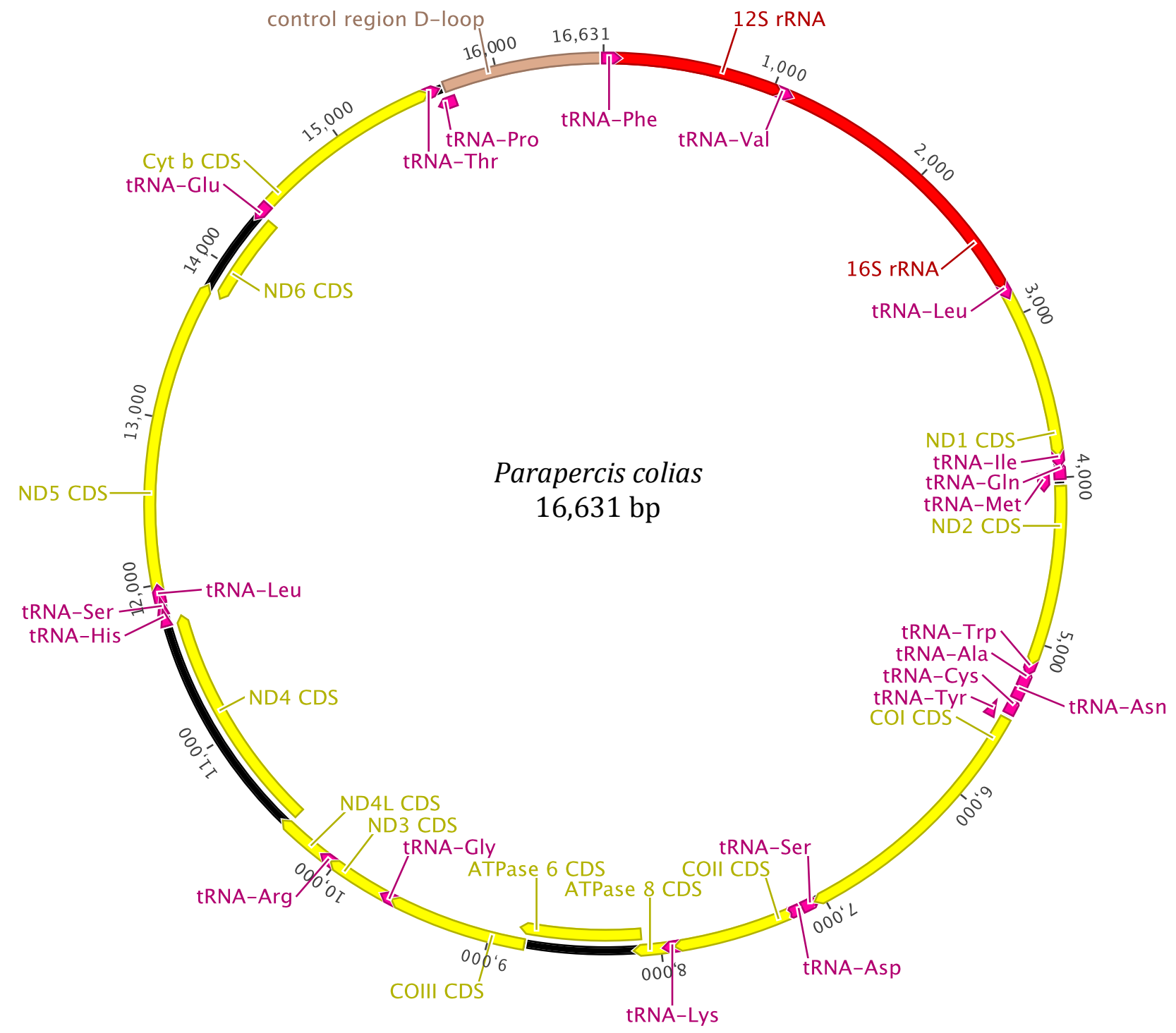

FIGURE 2.3: Complete mitochondrial genome of $P$. colias (ACH 3). Arrowheads indicate direction of transcription. 


\subsubsection{Control region primer development}

The total length of CR sequences in all the species sampled ranged from $836 \mathrm{bp}$ in Nemadactylus macropterus, to 1354 bp in Pagrus auratus, with an average length of $867 \mathrm{bp}$ (table 2.2). All sequences were AT rich (>60\%). The base composition of each sequence is shown in table 2.2. When sequencing from only one direction (H-tRNAPro), five of 11 species failed to produce readable sequences across the entire CR. In these cases, both directions were sequenced and put together to span the entire CR. In some of the species a $T_{11-12}$ mononucleotide tract within the CCD appears responsible for the appearance of a double sequence read (putative heteroplasmy) and the degradation of the signal strength approximately 500-550bp from the 5' end of the CR. However, P. oxygeneios, T. symmetricus, L. ciliaris and N. macropterus were the four species in which sequencing was able to progress through the mononucleotide tract, presumably because these species had between one and three substitutional changes within the middle of the mononucleotide repeat, which created replication stability (Table 2.3). The only unusual sequence was that of Pagrus auratus, which, despite the insertion of a $\mathrm{C}$ nucleotide between a $\mathrm{T}_{9}$ and $\mathrm{T}_{5}$ polynucleotide tract, still gave a double sequence signal. Neither of the primer pairs developed in this study successfully amplified the CR from the DNA of Seriolella brama and Arripis trutta.

The most likely explanation for the double sequences that appear after the mononucleotide repeat is that polymerase slippage is occurring, causing two sequences, one or more bases pairs out of synchrony. This could have arisen by mitochondrial heteroplasmy within the fish cell, as the replicating polymerase slips and generates length-different copies of the mitochondrial genome, or it could be generated during the PCR and sequencing process. The origins of this sequence variation could be further investigated using clones of the PCR product, which are each derived from individual sequence products. If the sequences derived from single PCR products show one sequence result, then the slippage and multiple length genomes are most likely within cell heteroplasmy. In some species there are only a maximum of $\mathrm{T}_{6}$ repeats within one tract because a substitution has occurred making the mononucleotide repeat imperfect. This presumably enables the polymerase to read through the repeat, without stalling, and adding or subtracting a repeat unit. For species with this type of presumptive heteroplasmy, new CR primers designed to an internal part of the CR would avoid amplifying the repeat. For example, in blue cod, 
the internal primer is located within the $\mathrm{CCD}$, and when combined with the tRNA-Pro primer, a 590bp long sequence is generated. 

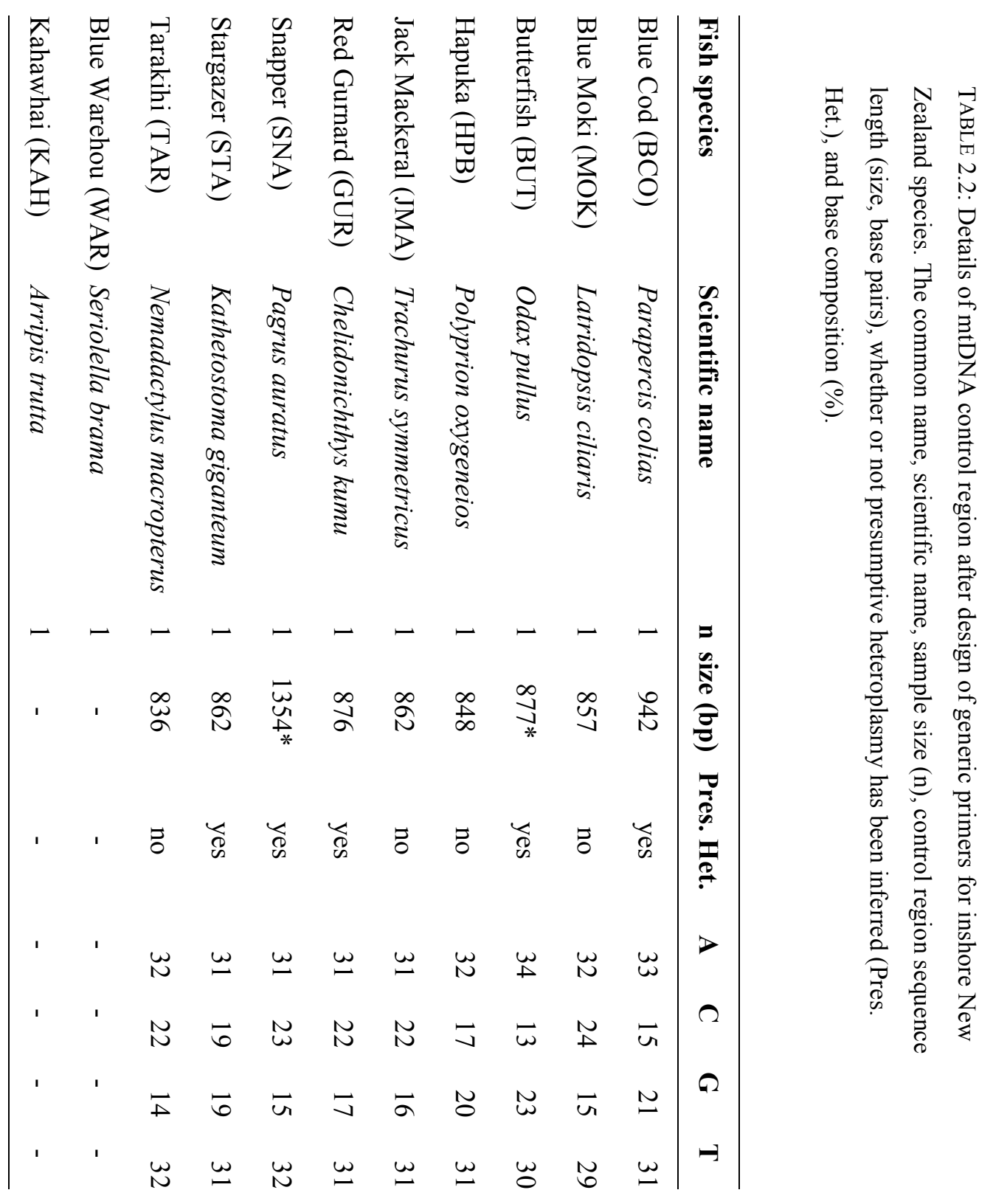


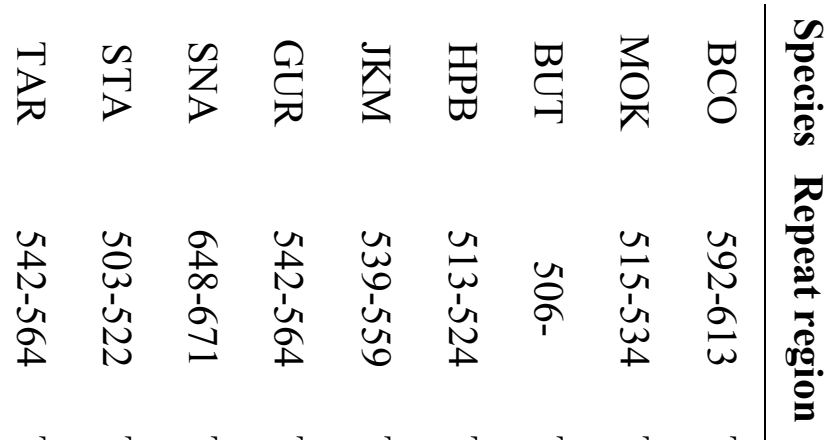

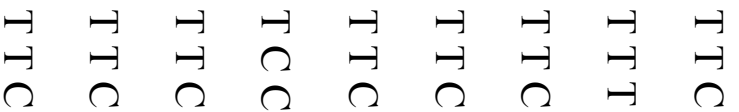

$$
\begin{aligned}
& \begin{array}{lllllllll}
-1 & \ddots & \Omega & -1 & -1 & -1 & -1 & -1 & \ddots
\end{array} \\
& \Omega \Omega \rightarrow \Omega \Omega \Omega \Omega \Omega \Omega \\
& \text { Ө }
\end{aligned}
$$

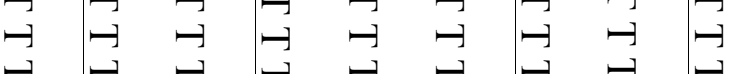

$$
\begin{aligned}
& \exists \text { H }
\end{aligned}
$$

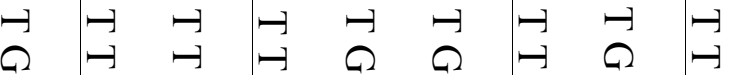

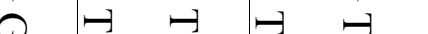

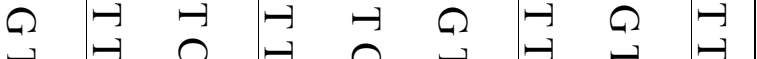

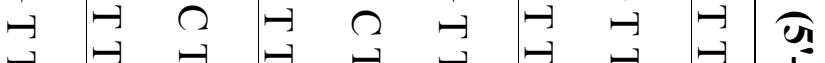

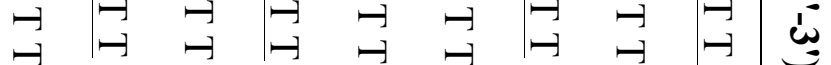

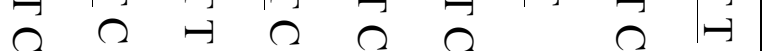

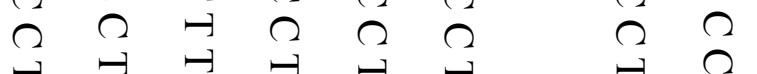

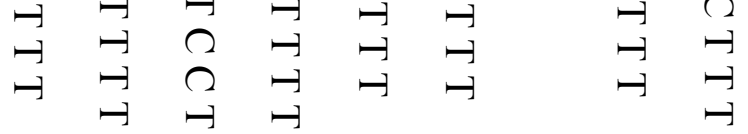

$$
\begin{aligned}
& \dashv \stackrel{-}{-}
\end{aligned}
$$

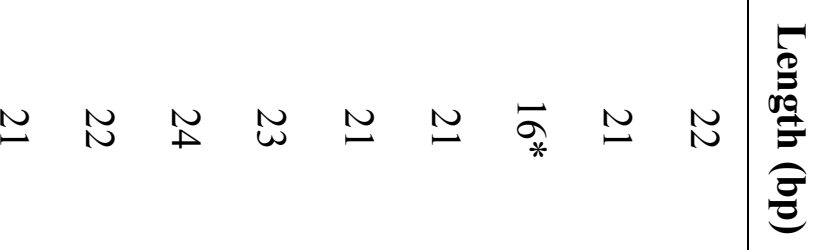

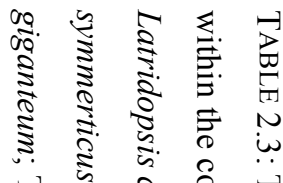

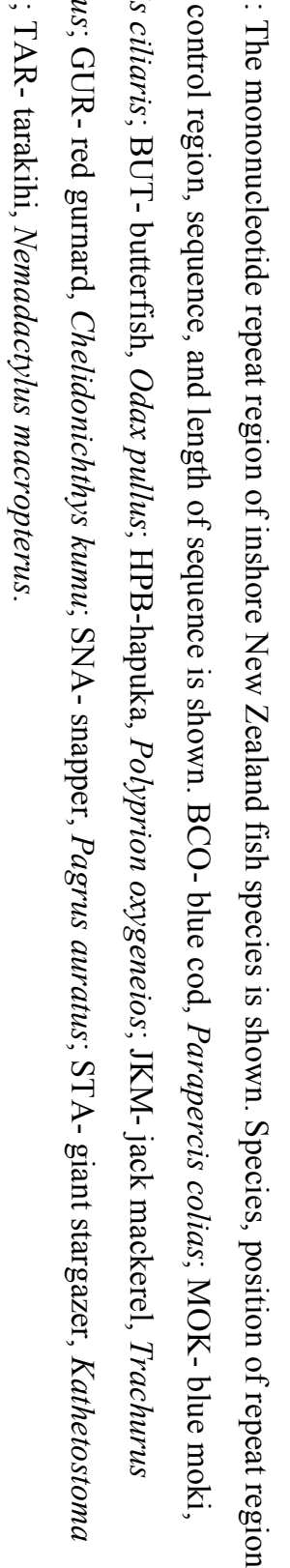




\section{DISCUSSION}

The whole mitochondrial genome of Parapercis colias is identical to the typical organisation found in many fish species (Catanese et al., 2008; Miya et al., 2003; Yang et al., 2009), though it could not be compared to any congeneric species because none have been documented. This study makes available, for the first time, an entire mtDNA genome from the Pinguipedidae family, and future analyses of a closely related species may uncover some interesting phylogenetic patterns and taxonomic changes. Genetic investigations into other Parapercis species have been reported in the literature, though none of these studies have sequenced the entire mtDNA genome of the species (Kai et al., 2004). Also, Prolatilus jugularis, a species that is found off the coast of Chile, has extremely similar morphological characteristics, and is found in habitats similar to that of $P$. colias. Currently no genetic studies have been conducted on this species and the potentially interesting evolutionary relationships between $P$. juglaris and $P$. colias cannot be investigated. Further investigation of these species may reveal an interesting taxonomic relationship.

Development of a set of generic primers for the ribosomal S7 gene in fishes (Chow \& Hazama, 1998) has enabled many genetic studies (e.g. Lavoué et al., 2003; Schelly, Salzburger et al., 2006), with the conservation of the sequence within the region making application across many species relatively simple. Though several nonspecific fish mtDNA primers have been reported (Ivanova et al., 2007; Ward et al., 2005), the more conserved level of sequence variation of the cytochrome $c$ oxidase 1 gene means it has been less useful for population genetic studies compared to more variable regions such as the control region.

Mitochondrial DNA heteroplasmy is common in the control region of fishes (Arnason \& Rand, 1992; Brown et al., 1992), and it has been confirmed in Atlantic cod (Gadus morhua) and white sturgeon (Acipenser transmontanus) using PCR cloning techniques. Based on a comparison to other fish studies, it seems likely that the double sequences found after the poly- $\mathrm{T}$ tract in the present study were heteroplasmy at the cellular level. The HVRI region is the most variable segment of the control region (Nagata et al., 1998; Pourkazemi et al., 1999; Aboim et al., 2005) and development of primers to target this specific area of the mtDNA genome will 
generate enough variation for statistically robust population genetic inferences (e.g. Chapter three of this thesis). This primer strategy would also avoid the problematic mononucleotide repeat region, but still generate 450-600 base pairs of data for each species.

Using 'universal primers' to generate initial data sets to explore population structure is a common approach in the literature, and is often followed by a development of more specific primers for larger surveys. For example, Roeder et al. (2002) designed a set of universal mtDNA primers for all penguins species, setting up the technical framework for other researchers to conducted population genetic studies (e.g. Jouventin et al., 2006). The development of universal CR primers for New Zealand fish species will allow similar studies to follow. In the case of blue cod (P. colias), hapuka (Polyprion oxygeneios) and snapper (Pagrus auratus), more specific primers have been developed for amplification of the CR. From these, a population genetic study of blue cod in New Zealand has been conducted, and is reported in Chapter three of this thesis. Two of my colleagues in the Victoria University of Wellington School of Biological Sciences are currently completing similar analyses on hapuka and snapper, with results expected in the next 12 months.

A set of generic inshore fish mtDNA primers have been reported in this chapter. As these are taken up by future researchers, the genetic population structure of each species can be determined and used to inform managers and fisheries scientists about fisheries stock structure. Levels of genetic variation and stock differentiation can provide an indication as to how a population or area may respond to harvest pressure, especially when coupled with existing biological parameters such as age at maturity and growth rate. Furthermore, the determination of genetic stock structure will enable stock assessment models to be properly matched to natural biological variation within a fishery, and align with natural areas of stock productivity. 


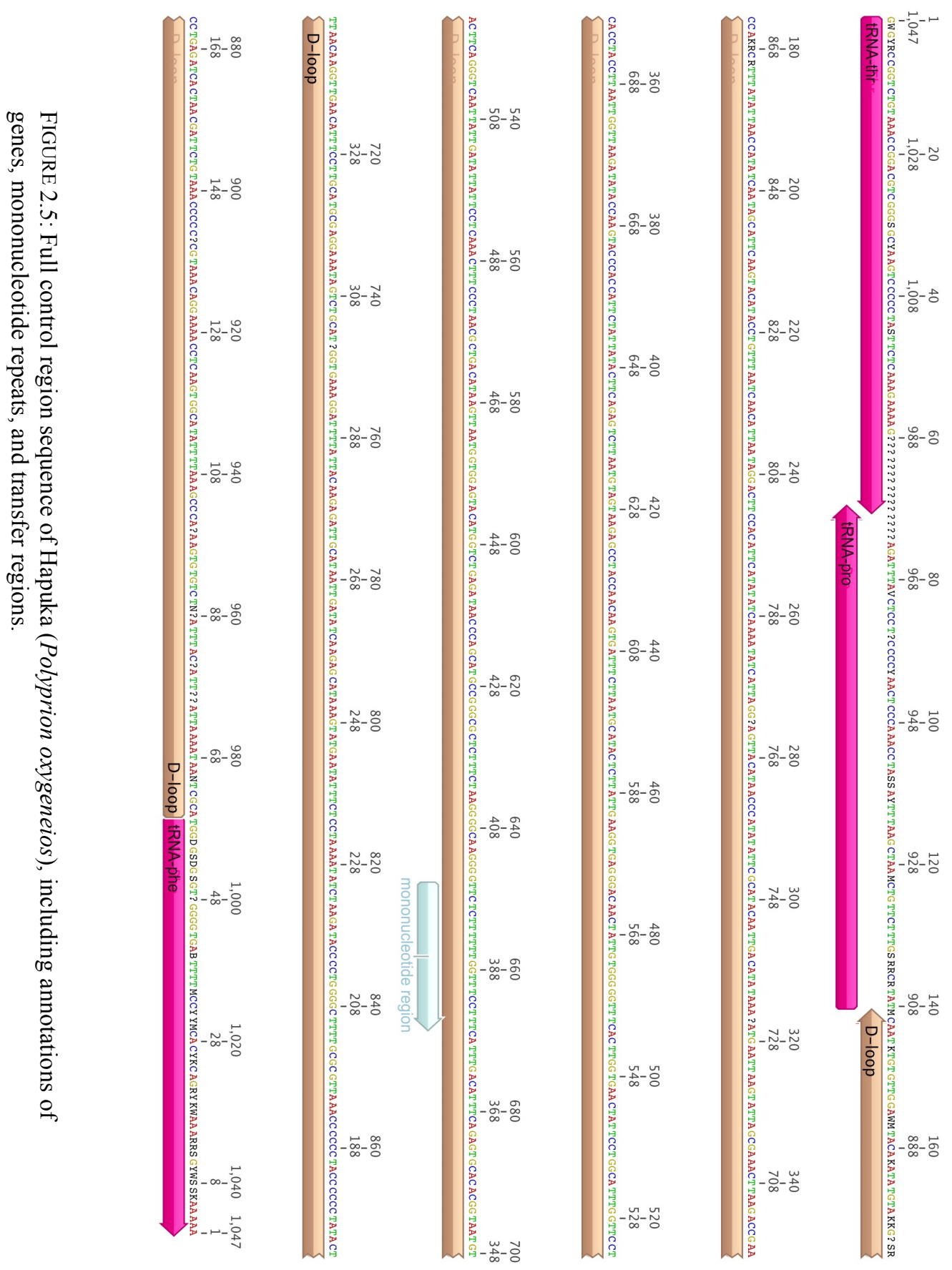


TABLE 2.4: Regions of $P$. colias mtDNA genome.

\begin{tabular}{ccc}
\hline Starts & Stops & Region/gene \\
\hline 0 & 68 & tRNA-Phe \\
68 & 1029 & 12S rRNA \\
1029 & 1101 & tRNA-Val \\
1101 & 2799 & 16S rRNA \\
2800 & 2873 & tRNA-Leu \\
2873 & 3848 & ND1 CDS \\
3852 & 3922 & tRNA-Ile \\
3922 & 3993 & tRNA-Gln \\
3992 & 4062 & tRNA-Met \\
4063 & 5109 & ND2 CDS \\
5109 & 5180 & tRNA-Trp \\
5181 & 5250 & tRNA-Ala \\
5252 & 5325 & tRNA-Asn \\
5358 & 5423 & tRNA-Cys \\
5422 & 5492 & tRNA-Tyr \\
5493 & 7039 & COI CDS \\
7044 & 7115 & tRNA-Ser \\
7126 & 7198 & tRNA-Asp \\
7204 & 7895 & COII CDS \\
7895 & 7969 & tRNA-Lys \\
7970 & 8138 & ATPase 8 CDS \\
8128 & 8811 & ATPase 6 CDS \\
8811 & 9596 & COIII CDS \\
9596 & 9667 & tRNA-Gly \\
9667 & 10016 & ND3 CDS \\
10016 & 10086 & tRNA-Arg \\
10089 & 10386 & ND4L CDS \\
10379 & 11769 & ND4 CDS \\
11769 & 11838 & tRNA-His \\
11838 & 11908 & tRNA-Ser \\
11914 & 11987 & tRNA-Leu \\
11987 & 13826 & ND5 CDS \\
13822 & 14344 & ND6 CDS \\
14344 & 14413 & tRNA-Glu \\
14417 & 15558 & Cyt b CDS \\
15558 & 15629 & tRNA-Thr \\
15628 & 15698 & tRNA-Pro \\
15698 & 16631 & control region \\
\hline & &
\end{tabular}




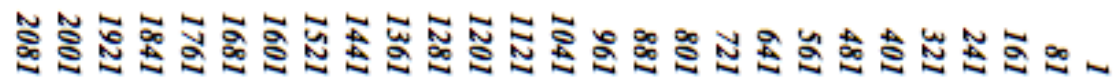

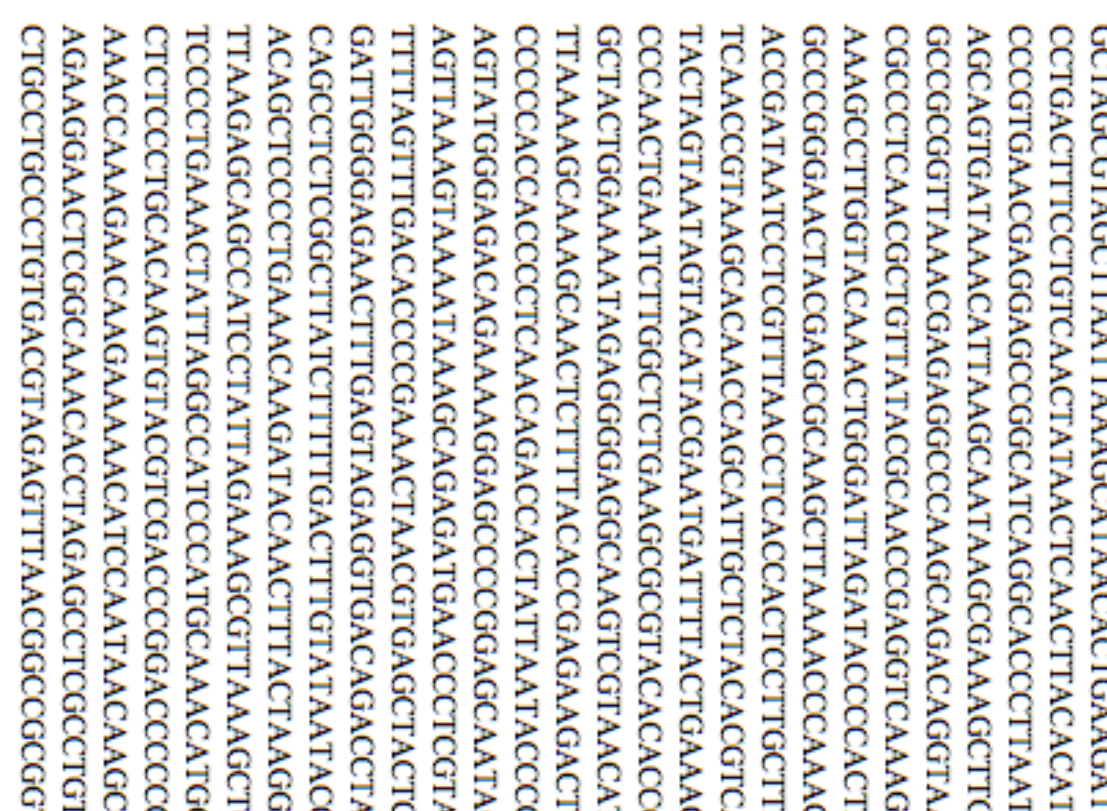

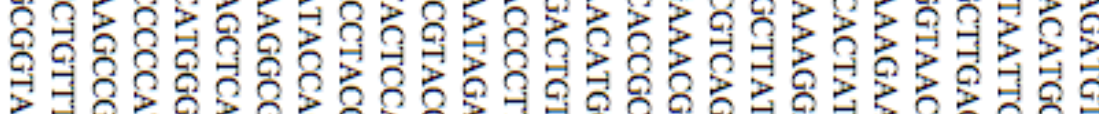

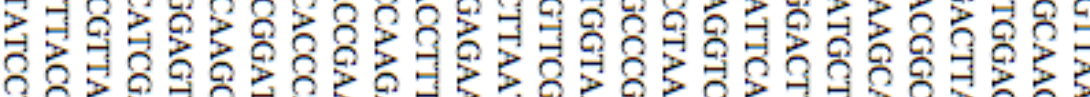

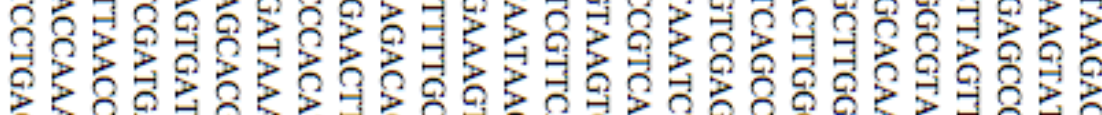

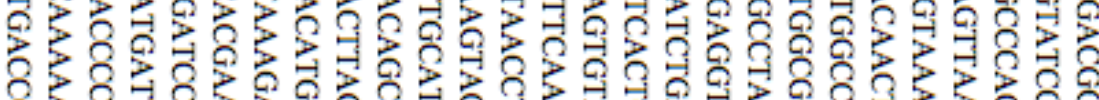

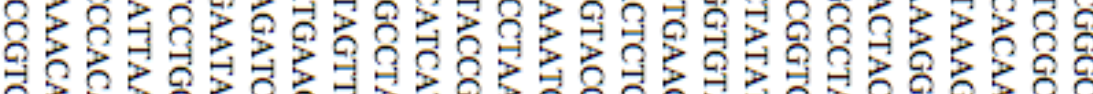

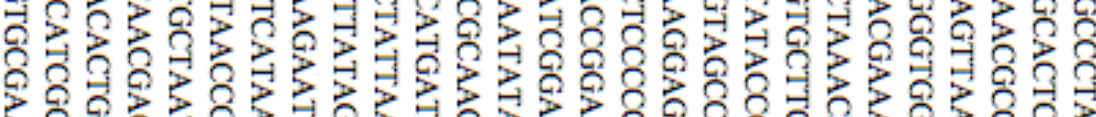

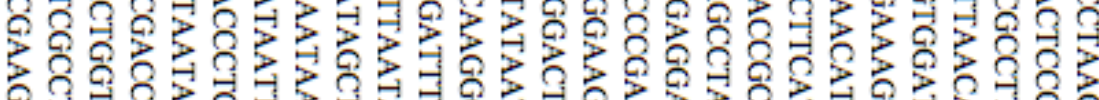

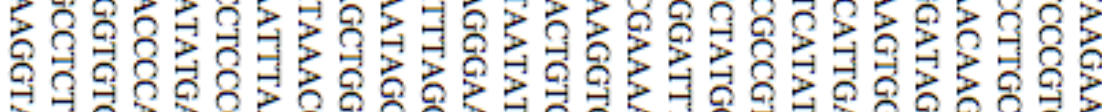

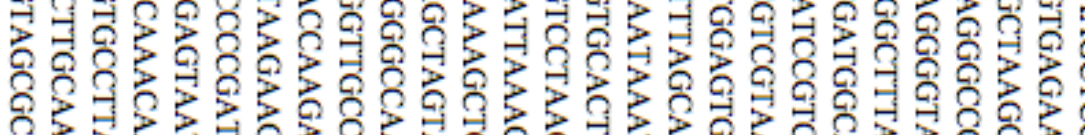

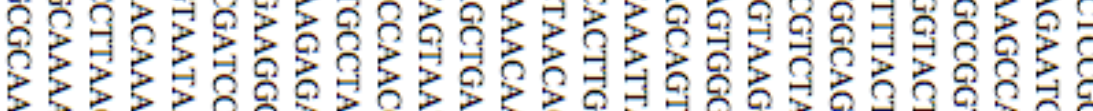

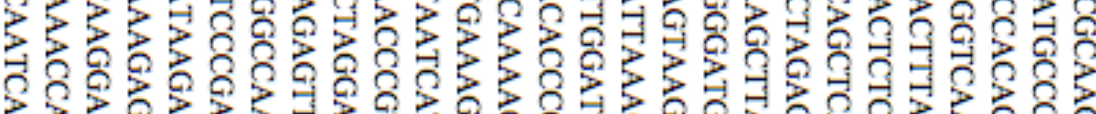

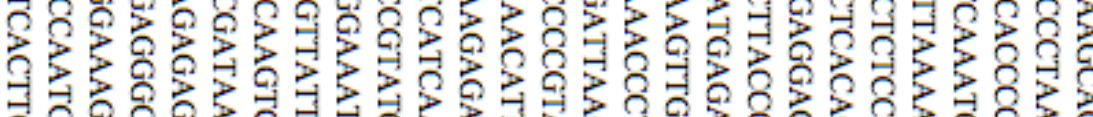

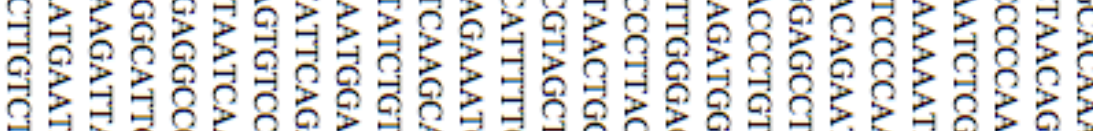

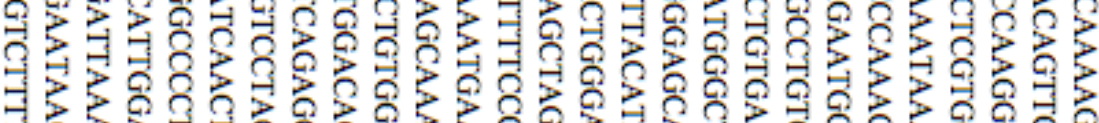

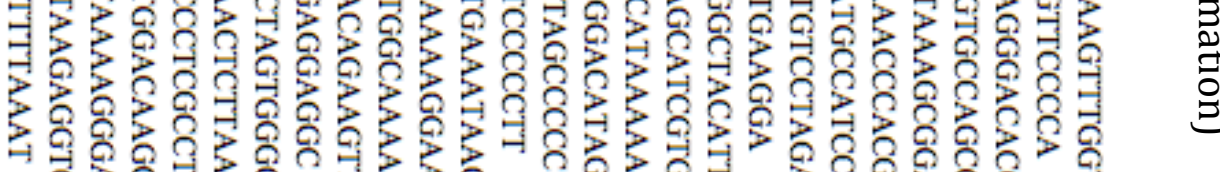

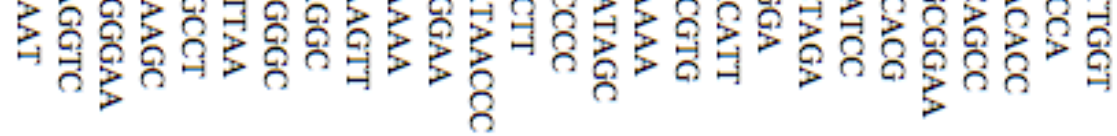




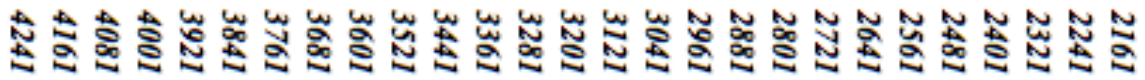

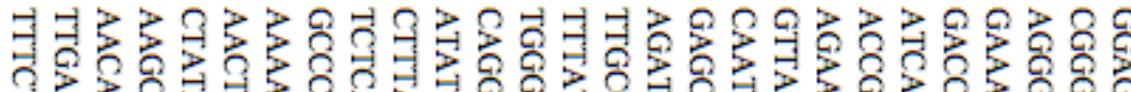
ว

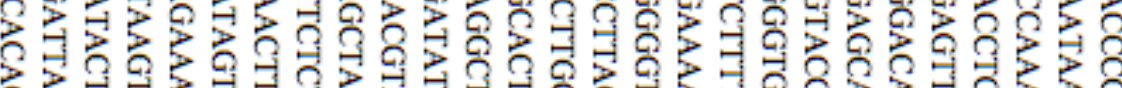

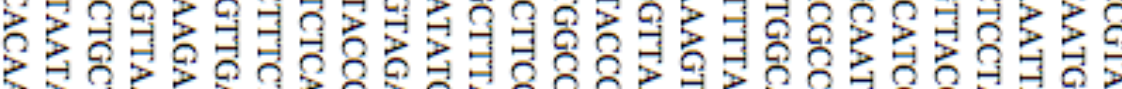

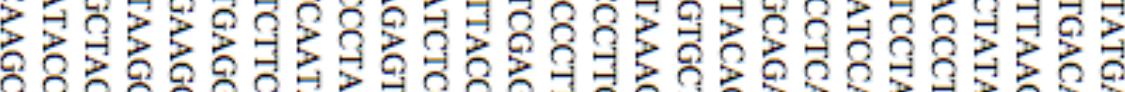

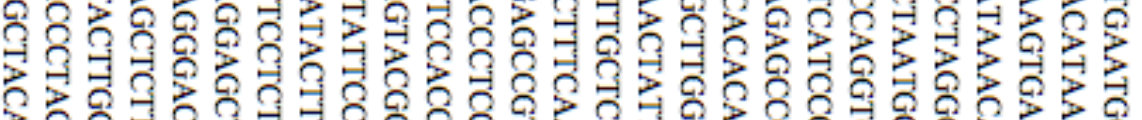

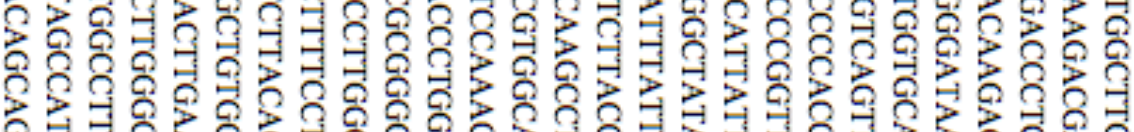

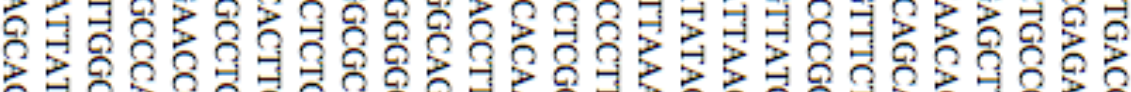
ว

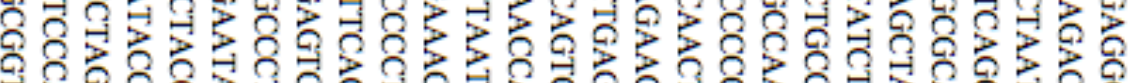

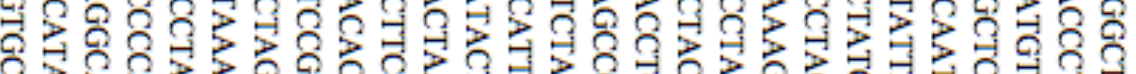

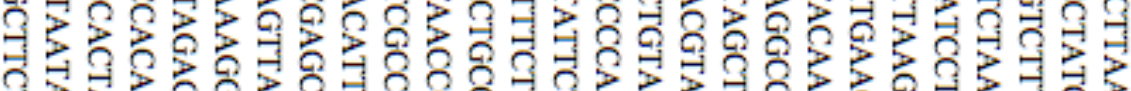

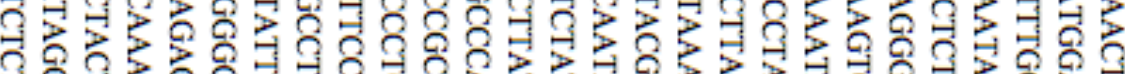

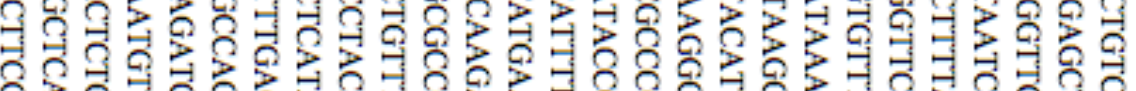

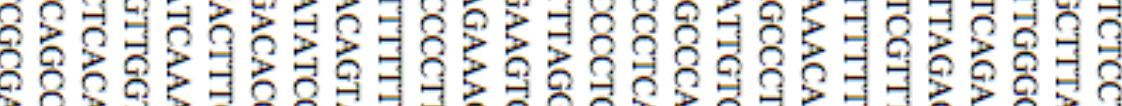

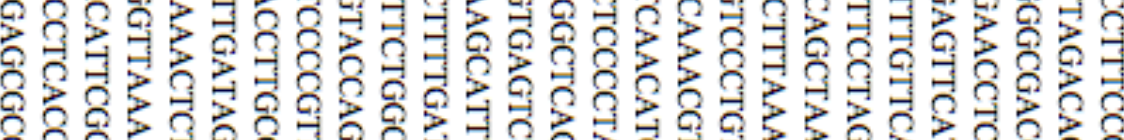

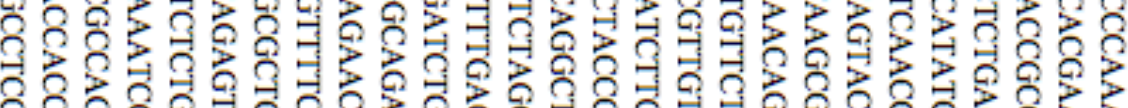

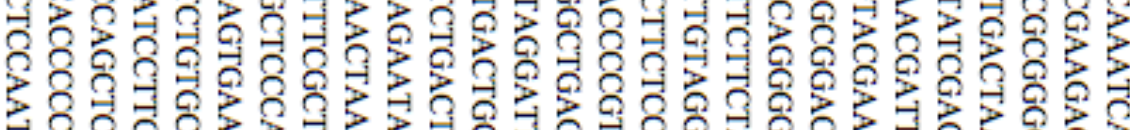

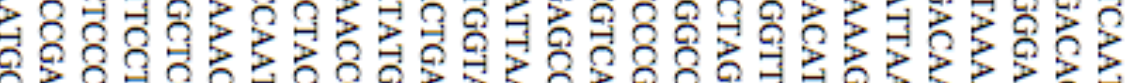

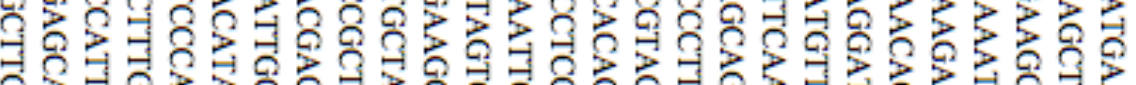

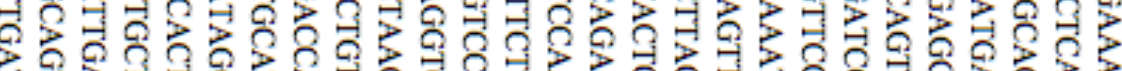

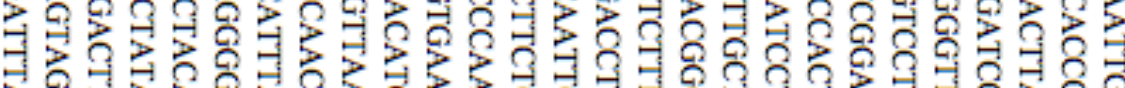

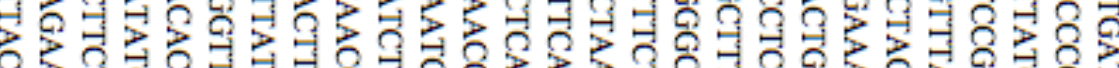

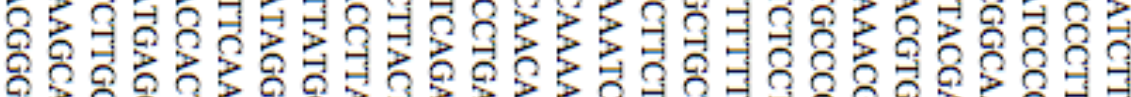

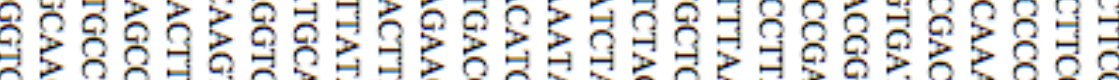

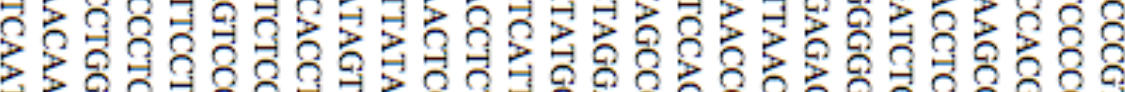

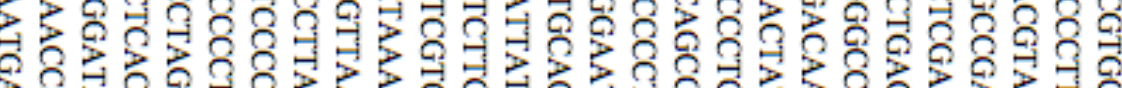

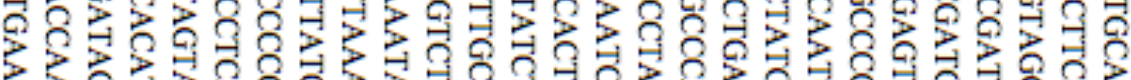

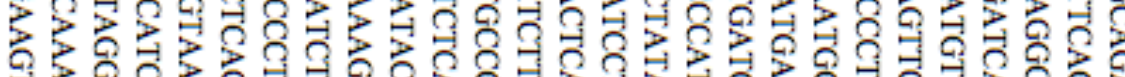

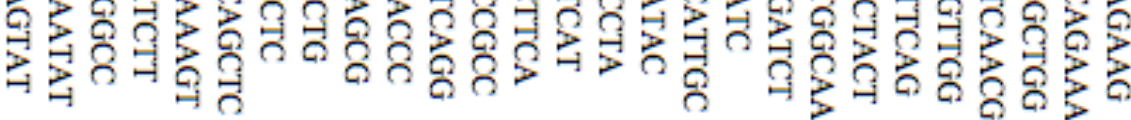

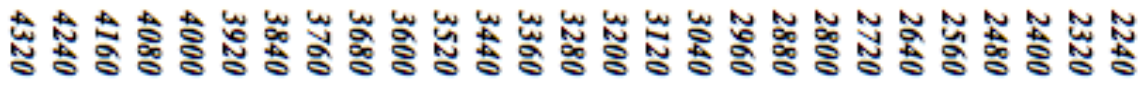




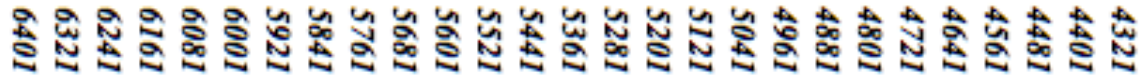

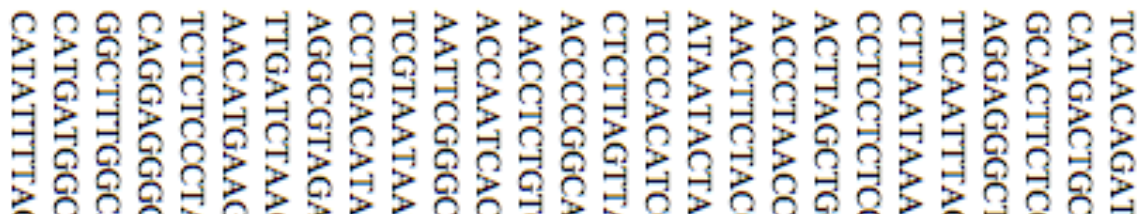

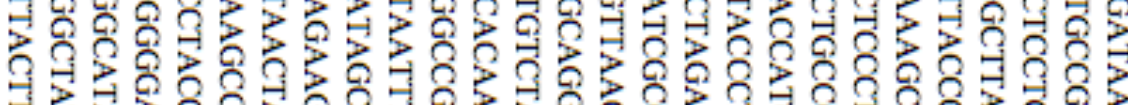

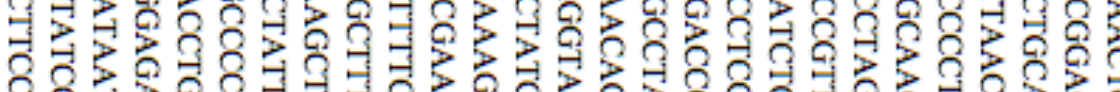

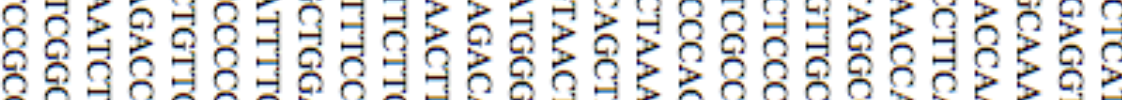

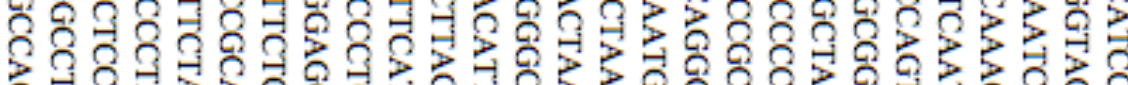

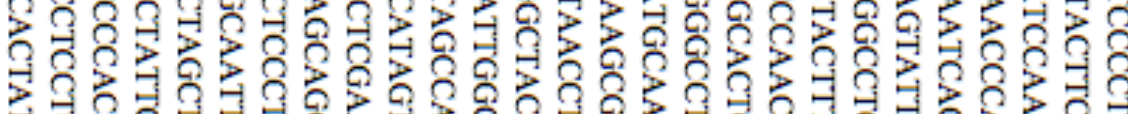

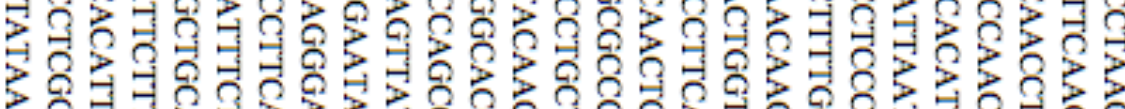

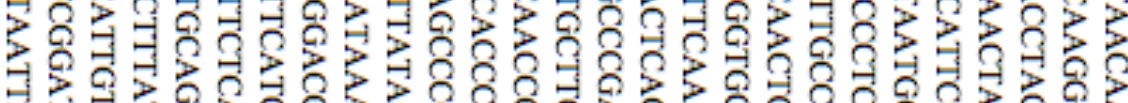

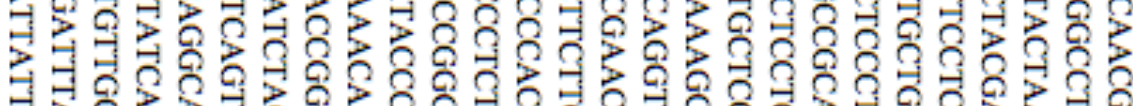

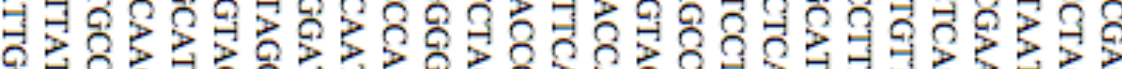

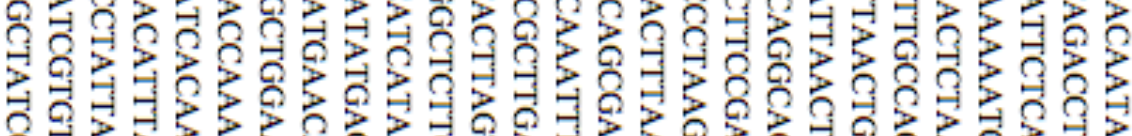

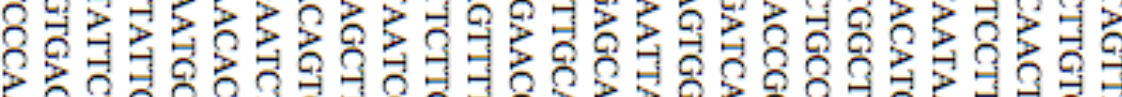

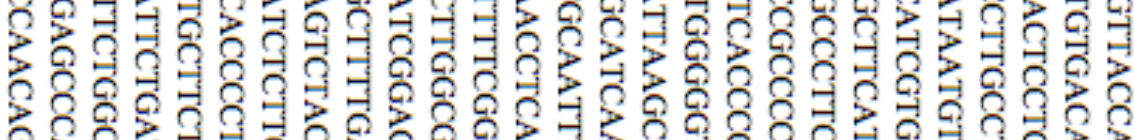
ว

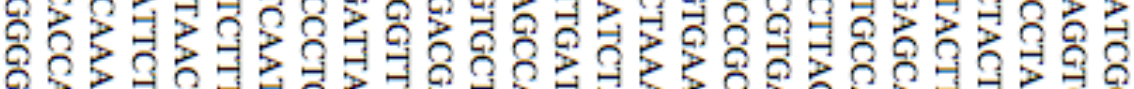

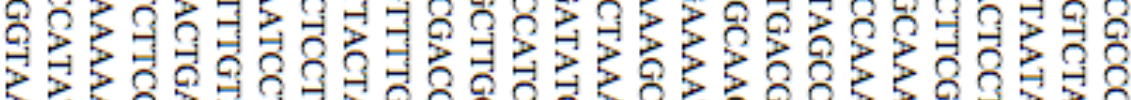

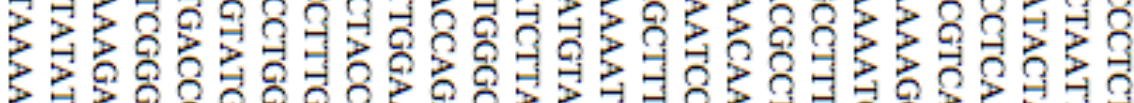

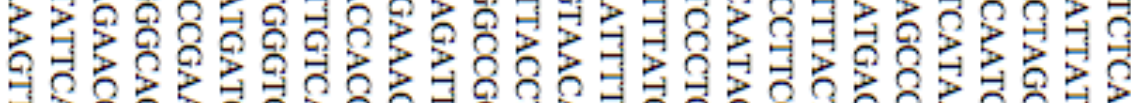

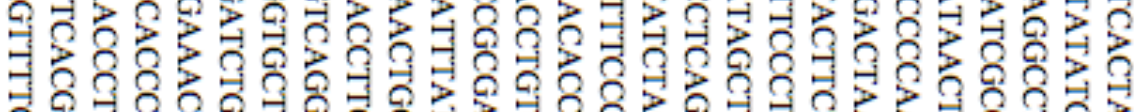

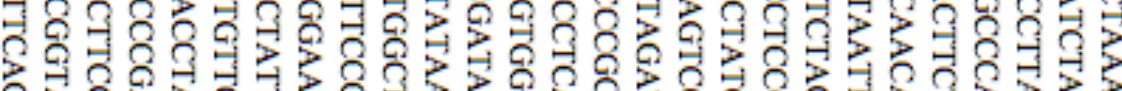

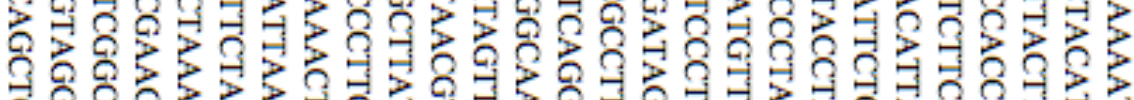

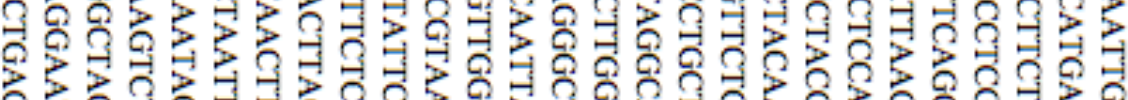

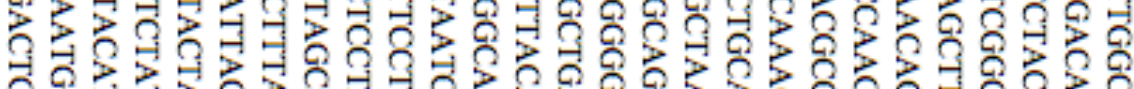

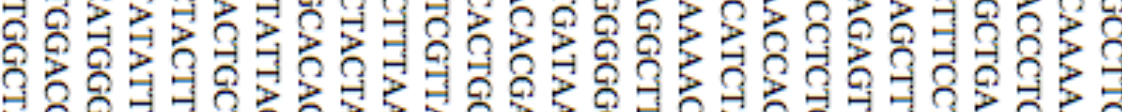

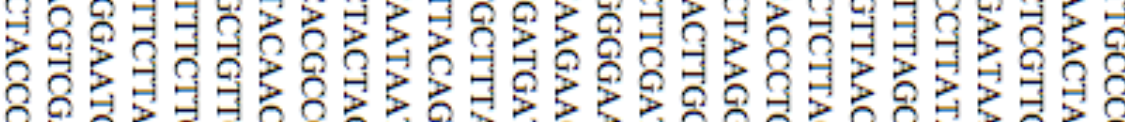

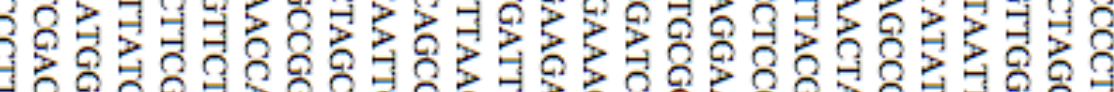

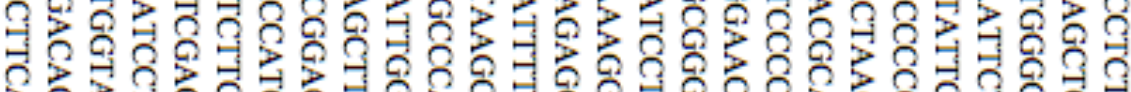

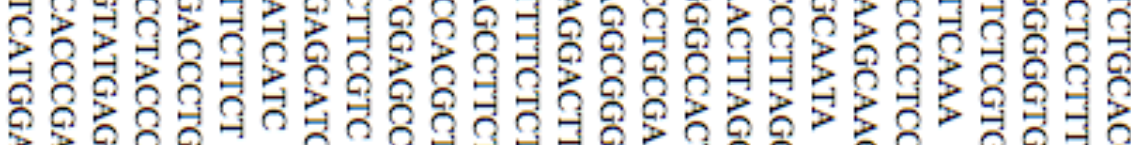

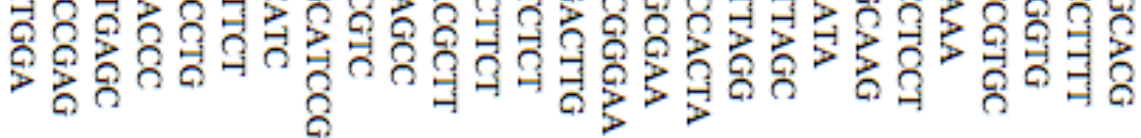

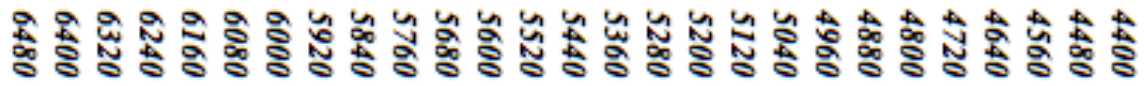




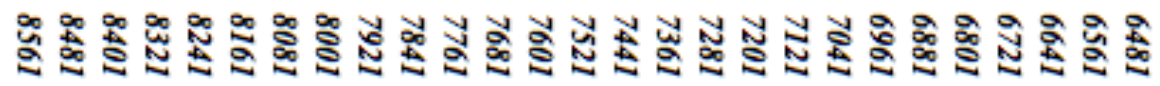

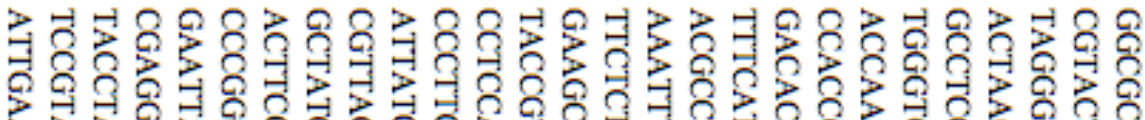

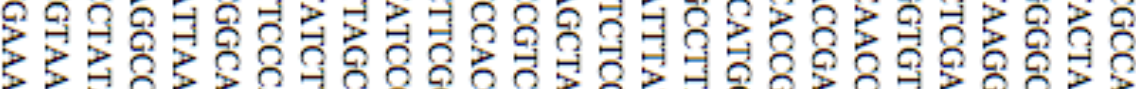

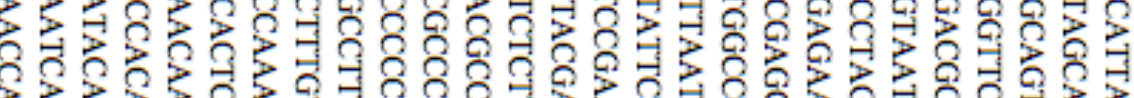

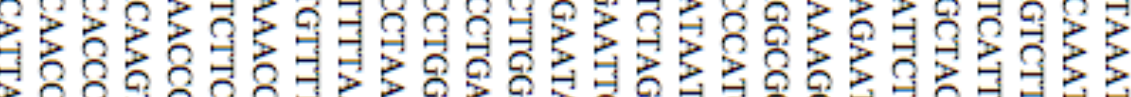

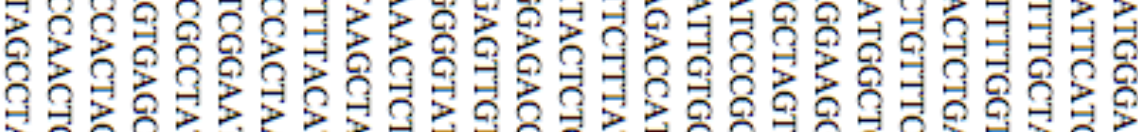

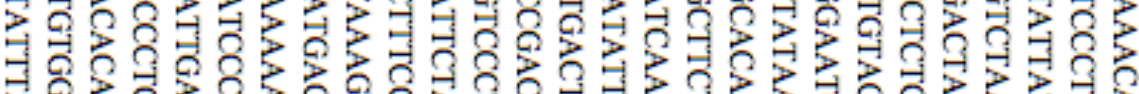

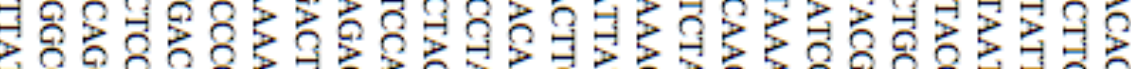

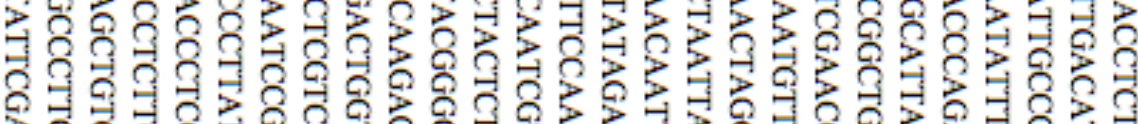
ว

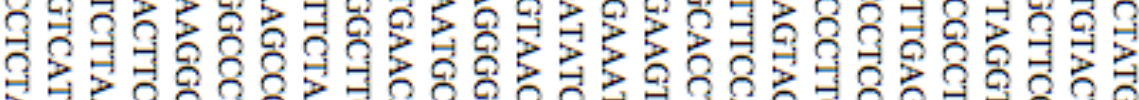

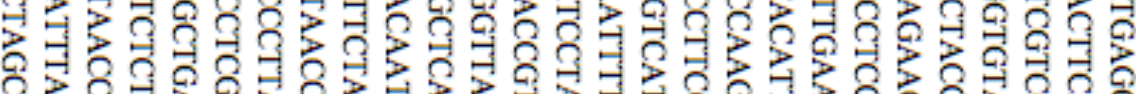

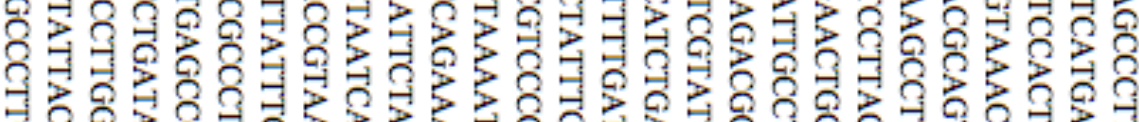

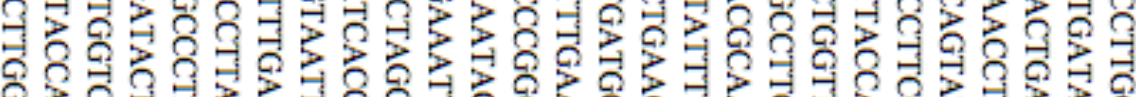

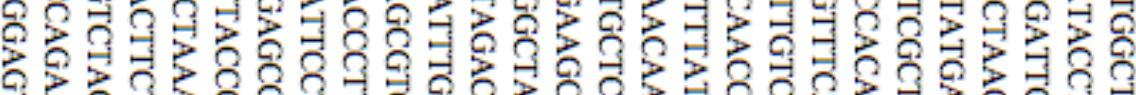

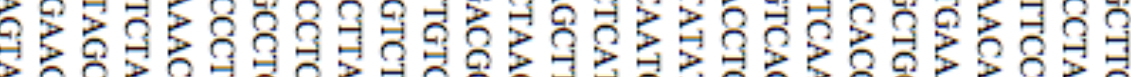

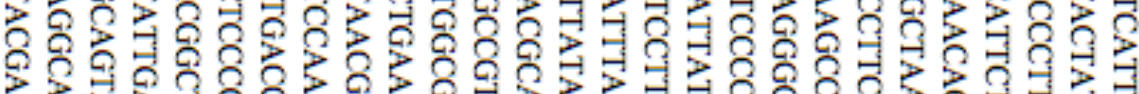
ไว

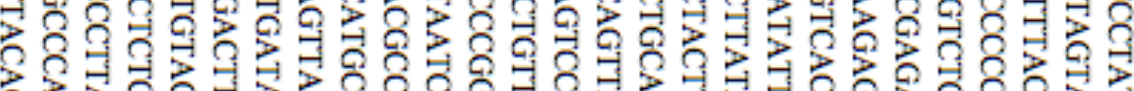

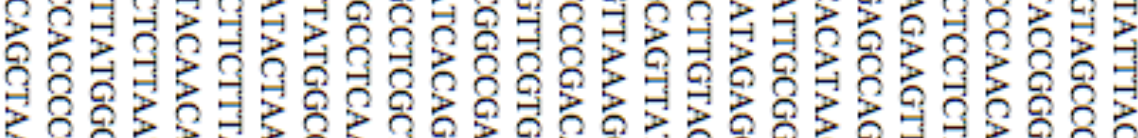

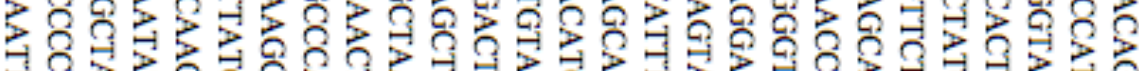

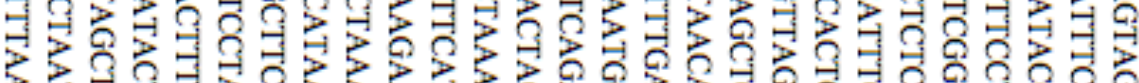
ว

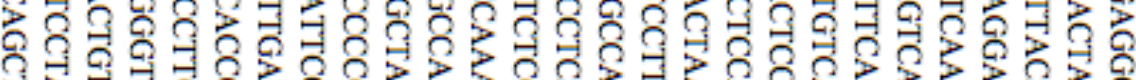

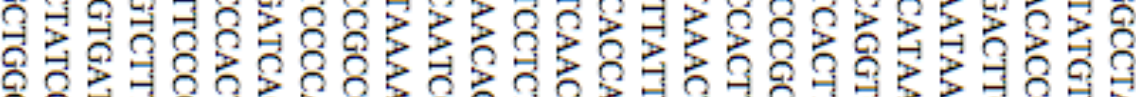

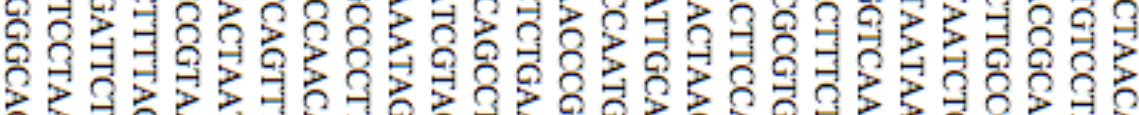

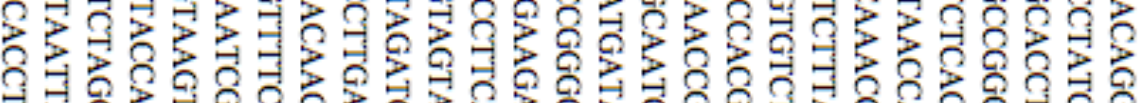

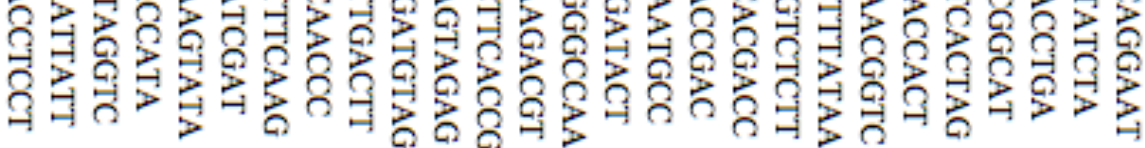

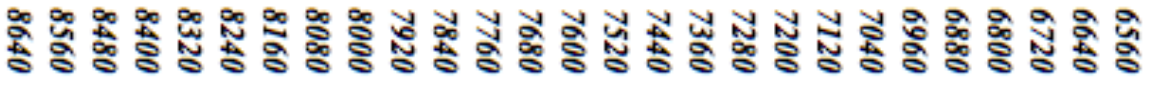




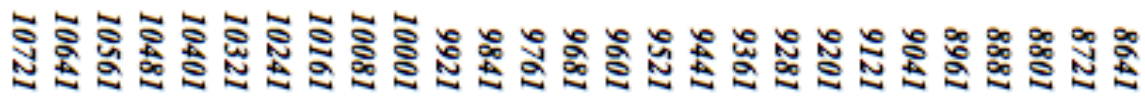

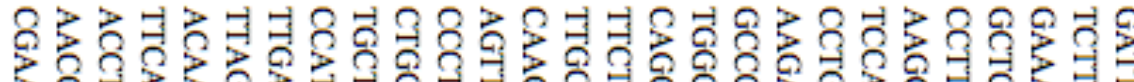

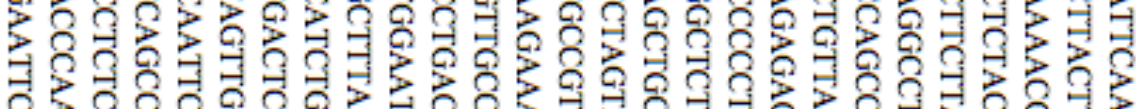

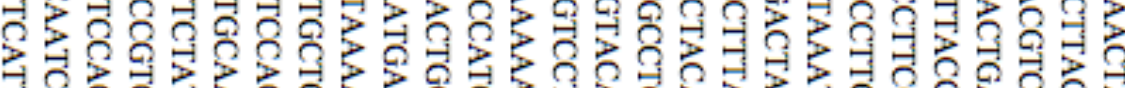

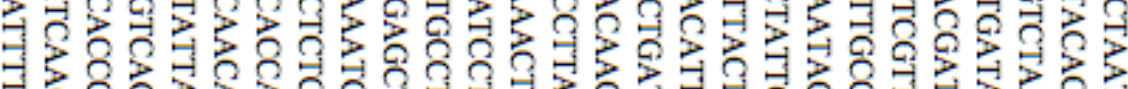

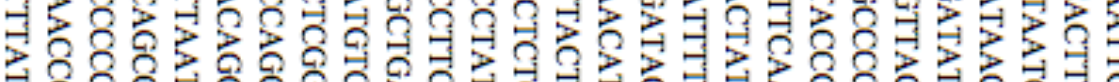

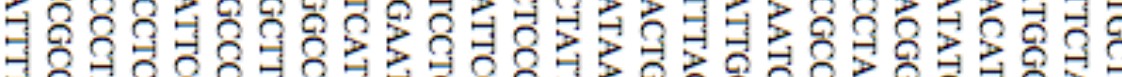

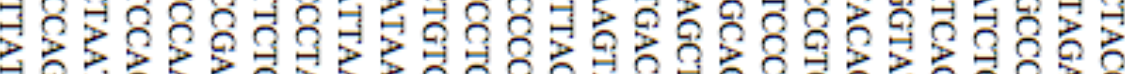

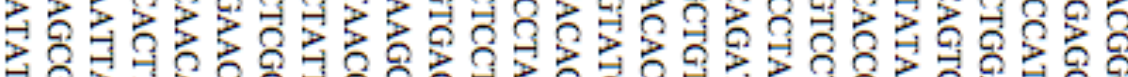

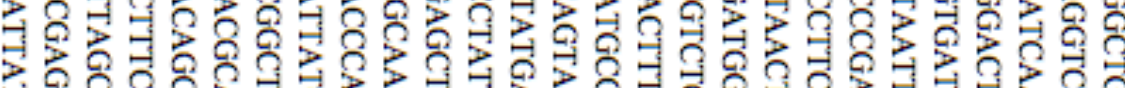

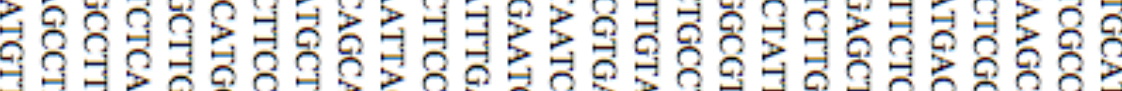

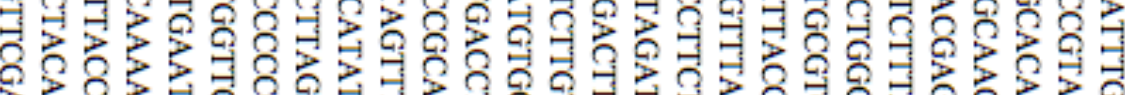

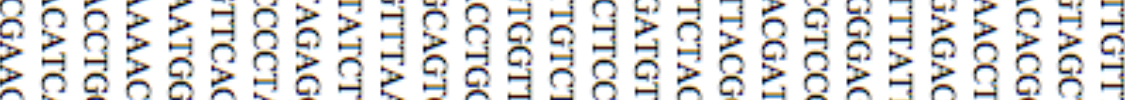

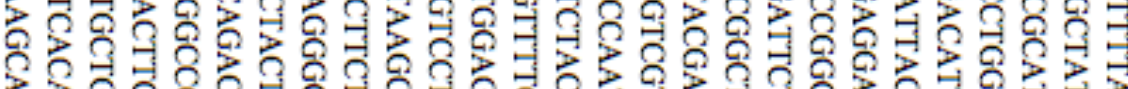

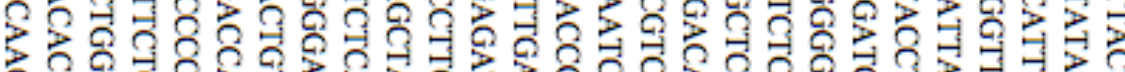

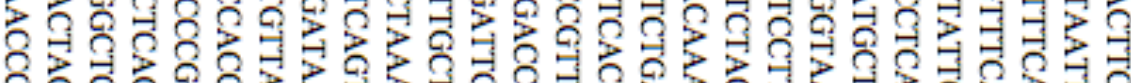

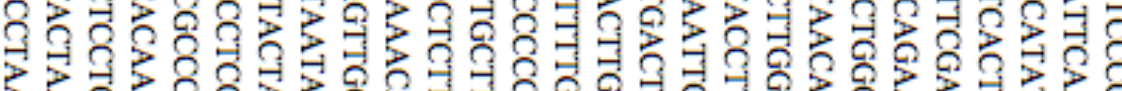

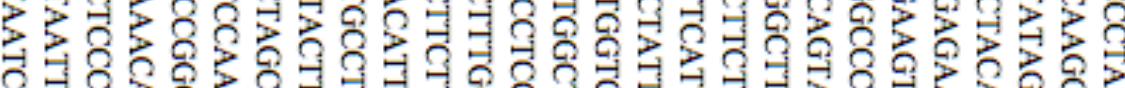

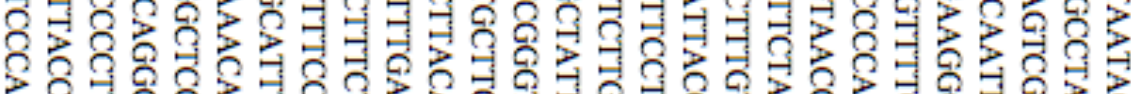

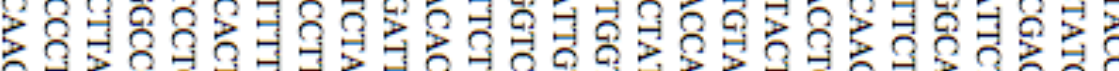

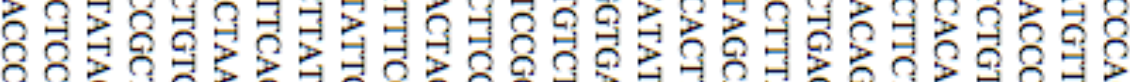

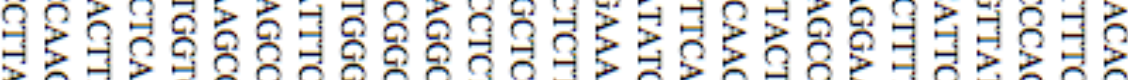

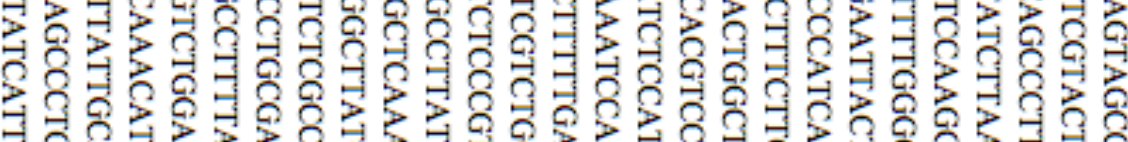

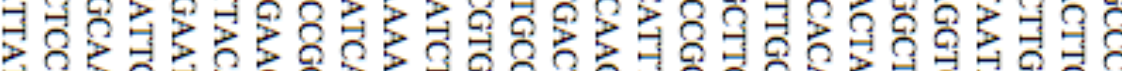

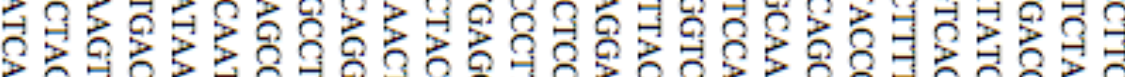

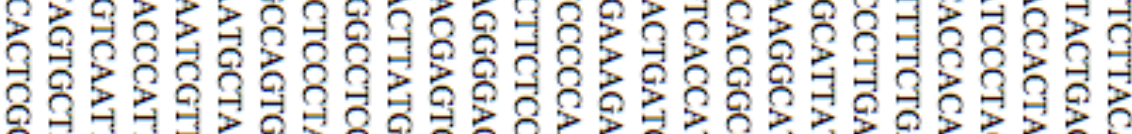

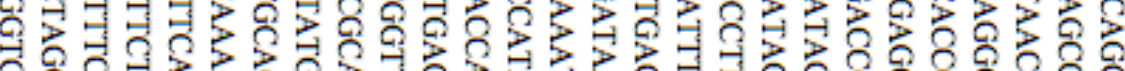

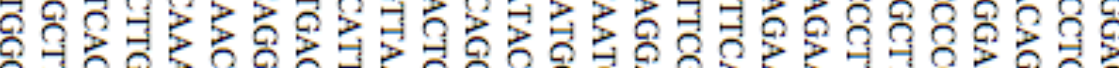

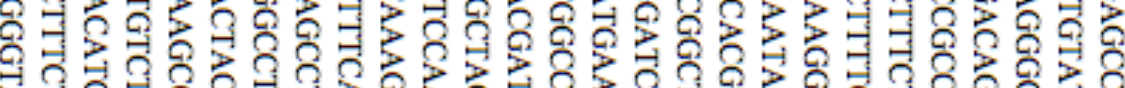

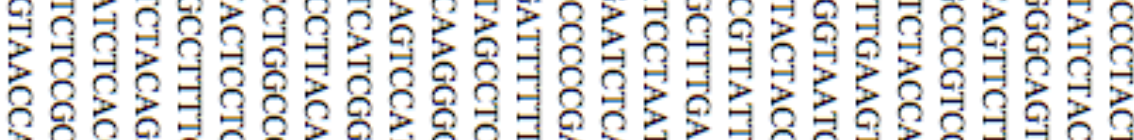

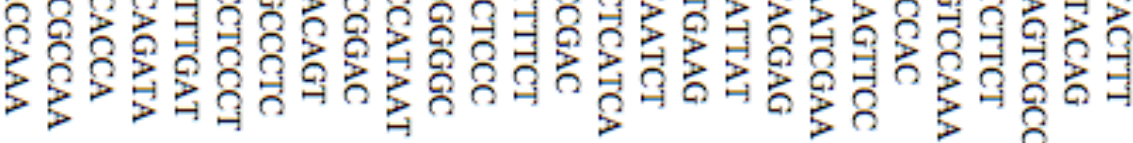

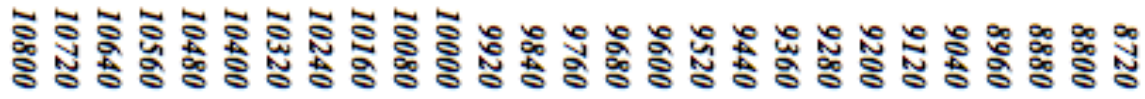




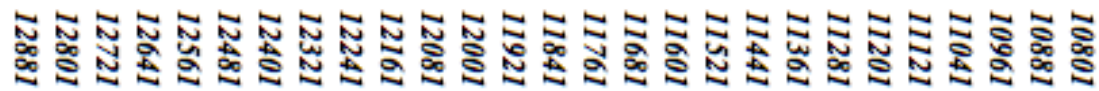

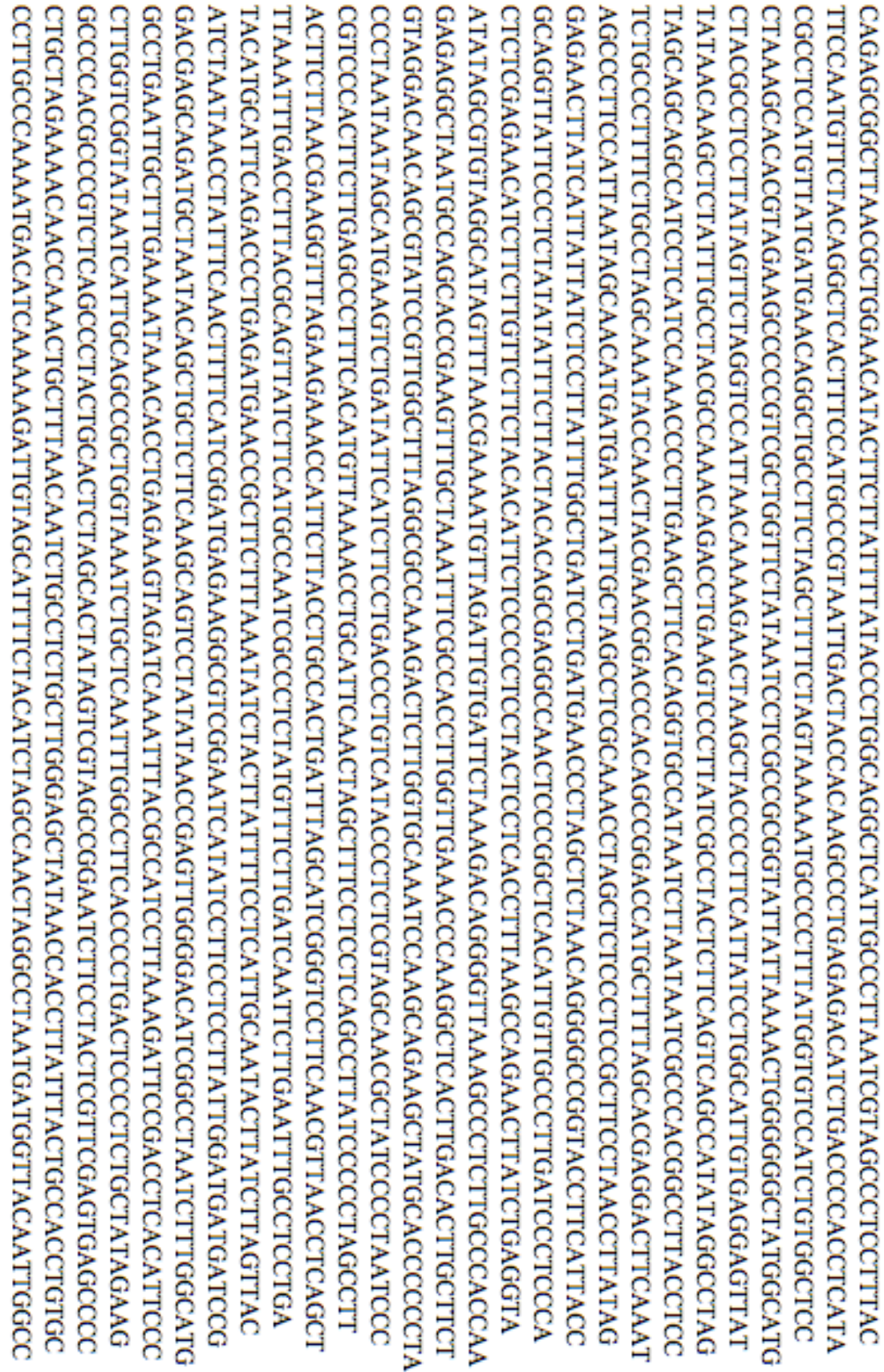

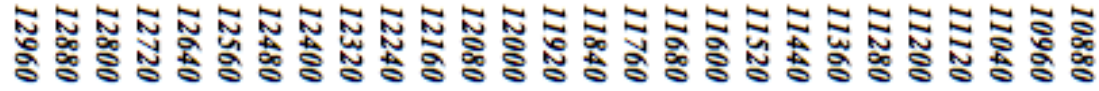




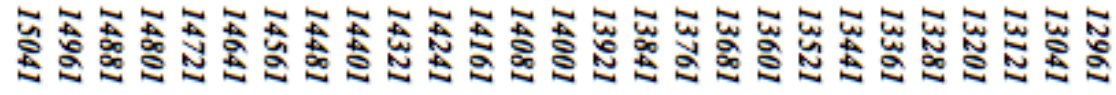

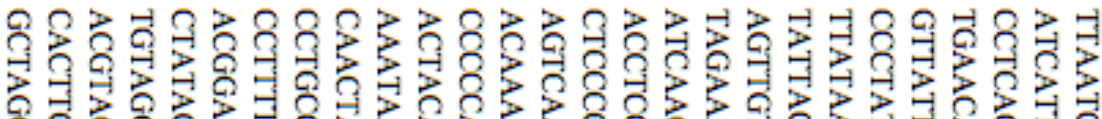

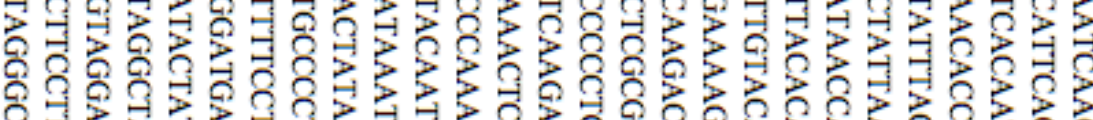

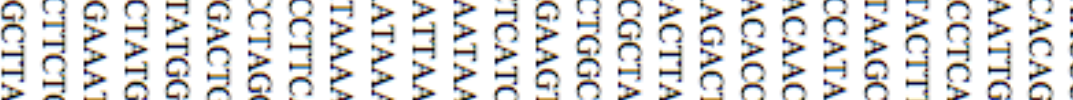

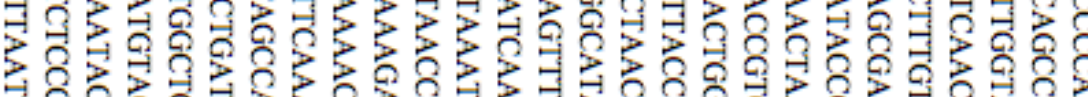

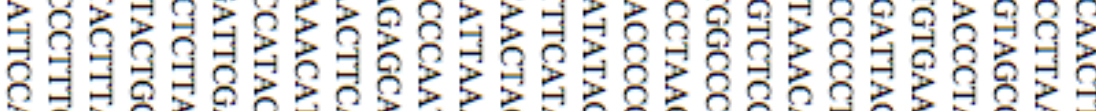

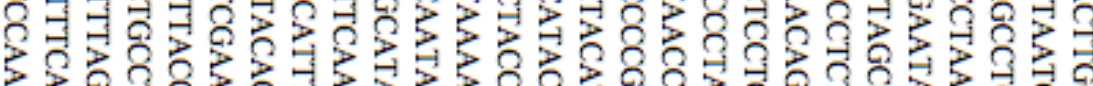

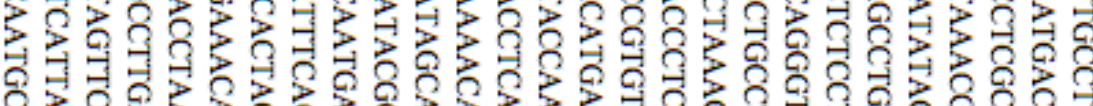

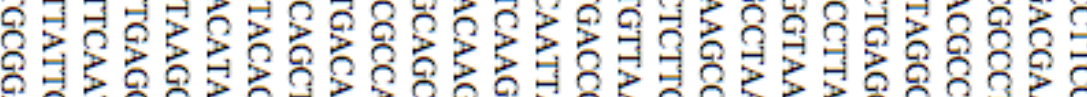

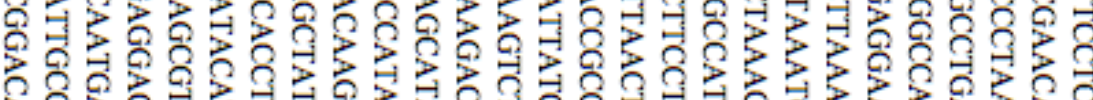

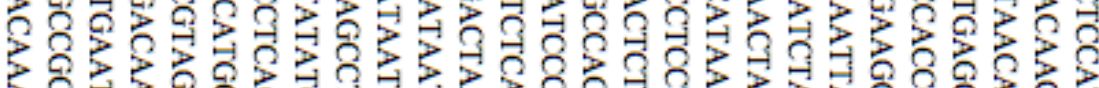

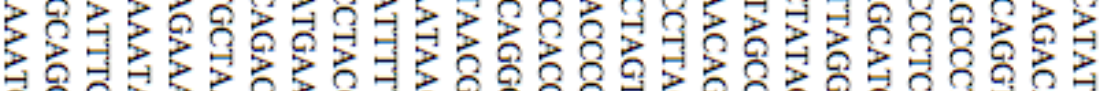

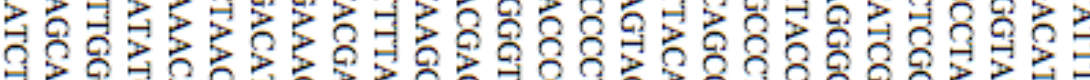

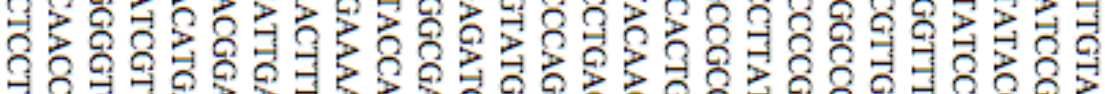

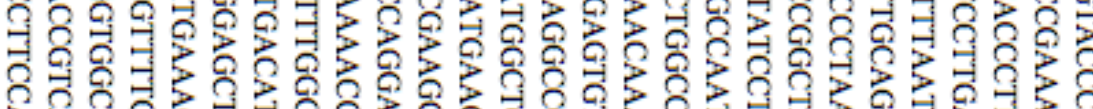

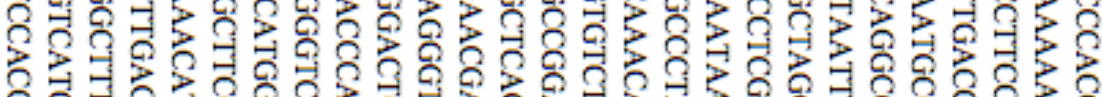

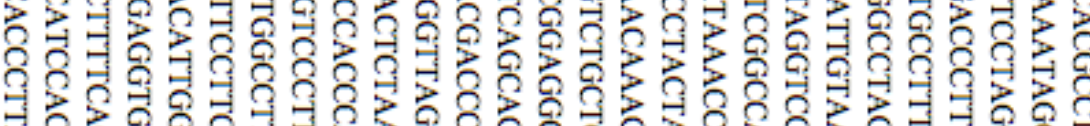

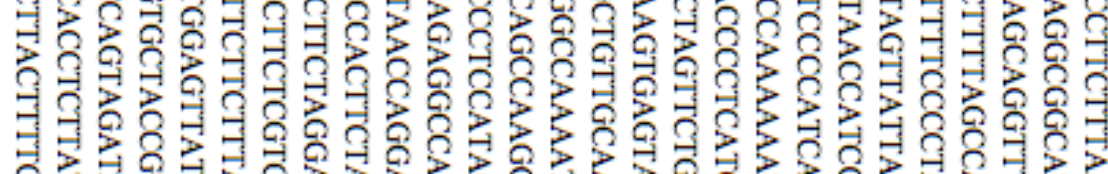

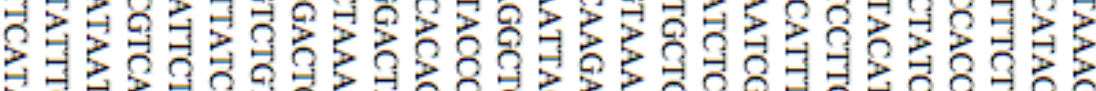

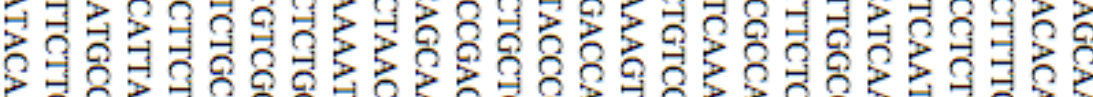

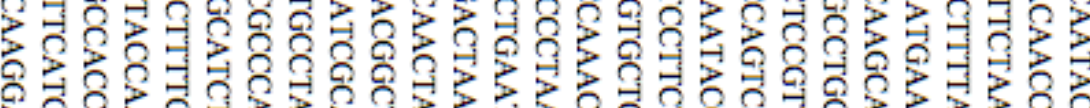

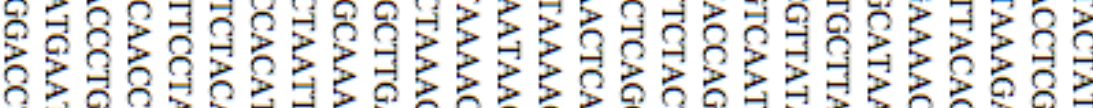

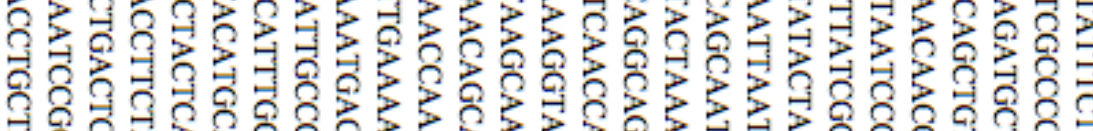

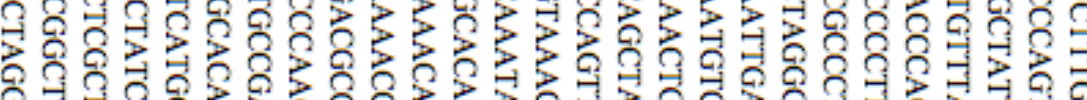

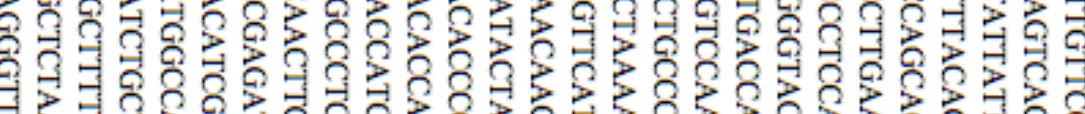

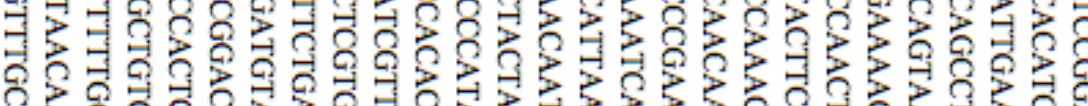

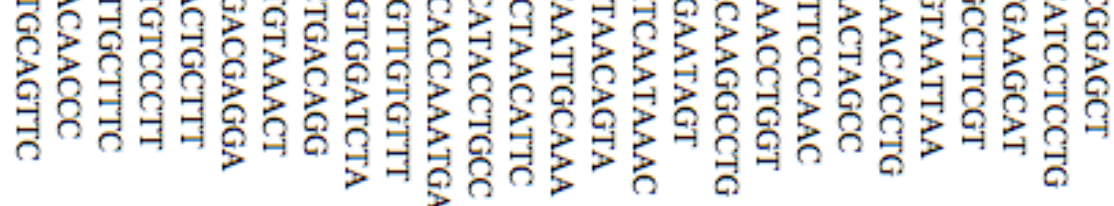

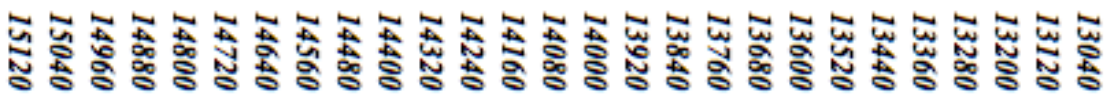




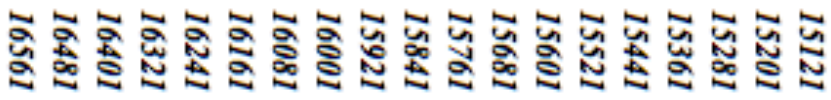

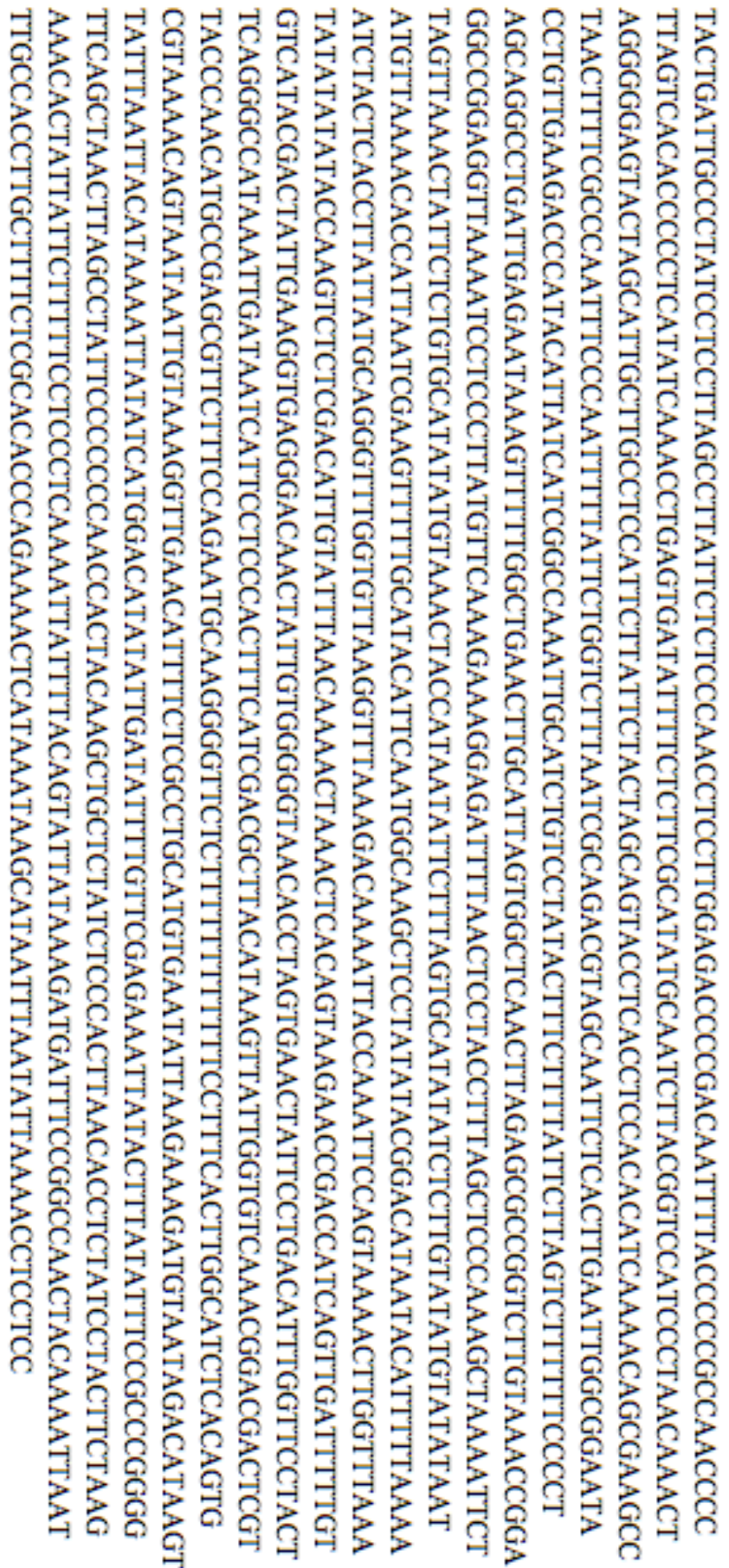

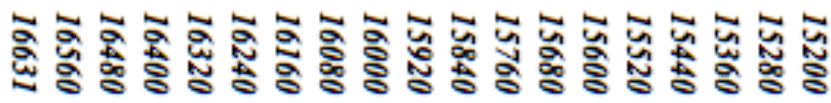




\section{CHAPTER THREE}

\section{THE PHYLOGEOGRAPHIC STRUCTURE OF NEW ZEALAND BLUE COD (PARAPERCIS COLIAS) BASED ON MITOCHONDRIAL DNA CONTROL REGION SEQUENCES}

\subsection{INTRODUCTION}

All species are typically structured into groups of individuals that are, to a greater or lesser extent, isolated from one another. Biotic and abiotic limitations to dispersal among groups will lead to genetic differences as a result of the evolutionary processes of genetic drift and selection. Understanding the genetic structure of marine populations is important for sustainable fisheries management, because breeding units can be identified and distinct genetic stocks can be managed separately (Ward \& Elliot, 2001). Modern fishing practices and pressure can be intense enough to cause at least one of three types of genetic change: alter genetic subdivision, change levels of genetic diversity, or cause selective genetic changes (Frankham et al., 1999; Allendorf et al., 2008). While any of these changes can occur naturally within wild populations, unsustainable harvest strategies may prove detrimental to the genetic and demographic condition of the fishery. As genetic information is gained, both on single species and fish populations in general, predicting changes that may occur in wild populations as a result of harvesting becomes simpler, and appropriate management allowances can be made accordingly. 
Fisheries management has used several different types of genetic markers to describe stock structure, including allozymes, mitochondrial DNA (mtDNA) and DNA microsatellites (Smith \& Johnston, 1985; Aboim et al. 2005; Miller et al., 2011). Mitochondrial DNA has been one of the most popular markers because it is relatively easy to collect data, gene content is conserved across a wide range of species, and it is often highly variable within species (Galter et al., 2009). The mitochondrial genome is typically inherited from females and it does not undergo recombination, which means that all genes act like a single locus and share the same history. Matrilinear inheritance reduces the effective population size to a quarter of an equivalent nuclear locus, and hence mtDNA will be more sensitive to demographic change. However, a quarter effective population size will not apply to all fish species equally, because there are many species that change sex during their lifetime and so make a genetic contribution as both a female and a male (Nakamura et al. 2005). The genetic consequences of fishing pressure on a sex-changing fish species has received little attention, despite demographic impacts on populations being well understood (Alonzo \& Mangel, 2005).

Parapercis colias (blue cod) is endemic to New Zealand and is considered one of the most important recreational fish species. P. colias are protogynous hermaphrodites, and sex inversion may occur at lengths less than $20 \mathrm{~cm}$, though when a dominant male is removed from an area, a nearby female is likely to undergo rapid sex-change, with the majority of female sexual characteristics being lost immediately (Carbines, 2003; 2004). However, not all fish begin life as females, nor do all females change sex to males (Carbines, 2004). The potential effect of harvest pressure on a sequentially hermaphroditic fish species such as $P$. colias is considerable, with larger, targeted adults more likely to be males (See Coleman et al. 1996; Bhandari et al. 2004; Alonzo \& Mangel, 2005; Molloy et al. 2007). In terms of genetic markers for protogynous hermaphrodite species, it is possible for all individuals in the population to pass on their mtDNA, both as mature females and before becoming males. As a result, the genetically effective population size may only be a quarter that of a nuclear locus, and less sensitive to demographic change.

P. colias is found throughout coastal inshore waters over shallow reefs, typically in water depths less then $150 \mathrm{~m}$ (Anderson et al., 1998). Largely by default the fishery is 
currently managed as eight separate management units, with very little being known about stock structure of the species. Sustainability of $P$. colias stocks has recently been questioned, with commercial and recreational reductions in catch limits in key fishing areas of New Zealand due to concerns about local depletion.

The pelagic larval duration (PLD) of marine species is considered an important determining factor of the level of connectivity between locations (Selkoe \& Toonen, 2011), though for P. colias, little published evidence on PLD exists. Robertson (1973) estimates eggs float freely in the upper layers of the water column for around five days, followed by an assumed five day pelagic phase as larvae, before settling in relatively shallow coastal waters. This means P. colias' PLD is very short compared to many fish species (Victor \& Wellington, 2000). Tagging studies have suggested that juvenile fish move less than a kilometre on average before settling at a particular location (Carbines, 1999). Carbines (1999) also found, however, that tagged adults were capable of moving up to $156 \mathrm{~km}$ from their release site, suggesting long-range dispersal of adults occurs. Adult P. colias are territorial.

Several authors have proposed a high level of even localised stock structure in $P$. colias, due largely to the high territoriality and low PLD of the species (e.g. Carbines $\&$ McKenzie, 2004), though this has not been formally tested. In this study, the genetic variation of $P$. colias is examined throughout coastal sites of inshore New Zealand waters and the Chatham Islands, using mitochondrial DNA markers. Our aim was to determine the level of population diversity and differentiation using samples collected throughout New Zealand coastal waters. Special consideration is given to differentiation between previously identified genetic breaks in New Zealand's marine environment (Ross et al. 2009). 


\subsection{MATERIALS AND METHODS}

\subsubsection{Sample collection and DNA sequencing}

A total of 475 fin-clip samples of $P$. colias were collected from 14 locations around the coast of New Zealand between February 2010 and June 2011 (table 3.1; figure 3.1). Twelve of the sampling sites were from mainland sites (North, South and Stewart Island), and one site was on the Chatham Islands, which was classified as an offshore sampling site. Fish were sampled from catches taken by commercial vessels, during fishery surveys, or sampled by hook and line. Sampling of sex and age of fish was random. Non-destructive fin-clip samples were taken from the pectoral or pelvic fin of the fish and preserved in $85 \%$ Ethanol, and some live fish caught were returned to the ocean.

Total genomic DNA was extracted using a standard phenol-chloroform protocol (Sambrook et al., 1989). We initially used the PCR primers developed for Parapercis sexfaciata (Kai et al., 2004) to amplify the entire mtDNA control region sequence of $P$. colias. We then designed primers specifically for $P$. colias that amplified a $600 \mathrm{bp}$ portion of the control region from the tRNA-Pro (H-tRNA-PRO-BCO 5'-

GAGCGCCGGTCTTGTAAACCGG-3) to a site in the highly conserved central domain of the control region (H-CCD-CR-BCO 5'AGAACGCTCGGCATGTTGGGT-3’').

All PCRs consisted of $67 \mathrm{mM}$ Tris- $\mathrm{HCl} \mathrm{pH}$ 8.8, $16 \mathrm{mM}\left(\mathrm{NH}_{4}\right)_{2} \mathrm{SO}_{4}, 1.5 \mathrm{mM} \mathrm{MgCl}$, $200 \mu \mathrm{M}$ of each dNTP, $0.5 \mu \mathrm{M}$ of each primer, $0.6 \mu \mathrm{g} / \mu \mathrm{L}$ Bovine Serum Albumin (BSA), 1 unit of BIOTAQ ${ }^{\mathrm{TM}}$ DNA Polymerase (Bioline), and $1 \mu \mathrm{L}$ of template DNA. Thermocycling conditions were $94^{\circ} \mathrm{C}$ for 30 seconds, $55^{\circ} \mathrm{C}$ for 30 seconds, $72^{\circ} \mathrm{C}$ for 45 seconds for 35 cycles, followed by a final extension of $72^{\circ} \mathrm{C}$ for 10 minutes. The resulting PCR products were purified with ExoSAP-IT (Amersham Parmacia Biotech, Japan) and the DNA sequence was determined using an ABI 3730 Genetic Analyzer (service provided by Massey University NZ, and Macrogen Incorporated, Korea). DNA sequences were edited and aligned in Geneious V 5.3.4 (Drummond et al., 2010), using the default parameters. 


\subsubsection{Genetic analysis}

Summary statistics such as the number of haplotypes $(\mathrm{H})$, haplotypic $(\mathrm{h})$ and nucleotide $(\pi)$ diversity, Fu's $F$ statistic, Fu and Li's $D^{*}$ statistic were calculated using Arlequin 3.0 (Excoffier et al., 2005). Population structure was evaluated using the fixation index ( $\Phi_{\mathrm{ST}}$; Excoffier et al. 1992) implemented in DnaSP 4.0 (Rozas et al., 2003) and statistical significance was assessed by permuting the data set 1000 times. Genetic discontinuity was estimated using two a priori assumptions of population structure. Firstly, each site was compared to all others in a pairwise comparison, which would show any genetic structure present within the sampling sites. Secondly, because of its isolation from the other sampling sites, the Chatham Island samples were compared to all mainland sites (grouped as one population).

A hierarchical analysis of molecular variance (AMOVA) was conducted using Arlequin 3.0 (Excoffier et al., 2005) to assess the levels of genetic differentiation $\left(\Phi_{\mathrm{CT}}\right)$ between regions (pooled sites). Statistical significance was assessed using 1000 permutations of the data set. The AMOVA was run under six different a priori expectations for population structure: (1) two regions, mainland New Zealand sites separated from the Chatham Islands; (2) two regions, sites organised into a North and South biogeographic regions relative to the $42^{\circ}$ latitude line (see Apte \& Gardner, 2002). The Chatham Islands were excluded from this analysis; (3) three regions, North Island and South Island New Zealand separated at the Cook Strait, and Chatham Island sampling sites; (4) two regions, North Island and Chatham Islands, excluding the South Island; (5) two regions, South Island and Chatham Islands, excluding the North Island; and (6) two regions, North Island and South Island, excluding the Chatham Islands.

A test for isolation-by-distance (IBD) was conducted using the regression of $\Phi_{\mathrm{ST}}(1-$ $\left.\Phi_{\mathrm{ST}}\right)^{-1}$ and measurements of geographic distance between sites $(\mathrm{km})$. Distances between sites were estimated using Google Earth 6.0 to calculate the shortest possible marine distances between coordinates. The exception to this was the Auckland and Ahipara sampling sites, which were combined to form the Northern (NOR) site because of low sample sizes. Latitudinal and longitudinal measurements were based on a point equidistant to the two sampling locations (35 50'45"S, $\left.174^{\circ} 4^{\prime} 35^{\prime \prime} \mathrm{E}\right)$. A Mantel's test was used to assess the significance of the regression analysis. Haplotype 
diversity, nucleotide diversity and the number of pairwise differences were plotted against site latitude to assess the relationship between sampling latitude and levels of genetic variation.

A Minimum Spanning Tree (MST) was calculated in Network V.3.1(Rohl, 2000), using the output generated by DnaSP 4.0 (Rozas et al., 2003), and re-drawn in CORELDraw. A MST visually represents each haplotype and its genetic similarity to other haplotypes, as well as the number of individuals that posses each haplotype.

\subsubsection{Demographic history}

Fu's $F_{\mathrm{S}}$ statistic was used to estimate demographic expansion, and will recover a large negative value from the data set if the population has undergone a recent population expansion (Liu et al., 2011). The distribution of pairwise nucleotide differences was calculated and plotted against the frequency of the haplotype using DnaSP 4.0. The data were fitted to a sudden expansion model (1,000 simulations) and associated raggedness index (Harpending, 1994) was calculated for all regions (North Island, South Island, Chatham Islands, and all populations). Following a recent demographic expansion, the distribution of pairwise differences will approximate a Poisson Distribution, while at constant size the curve is multimodal and erratic (Slatkin \& Hudson, 1991). The time since population expansion was estimated using the equation $t=\tau / 2 \mu$, where $t$ is time since divergence, $\mu$ is the rate of mutation per gene per generation, and $\tau$ is the mean age of mothers of the offspring produced by a cohort over its lifetime (Caswell, 2001). Following Bowen et al. (2006) and Mach et al. (2011), time since divergence was estimated allowing the mutation rate vary within the range of $2.0 \times 10^{-8}$ substitutions/site/year $(\mathrm{s} / \mathrm{s} / \mathrm{yr})$ through to a more conservative $5.0 \times 10^{-8} \mathrm{~s} / \mathrm{s} / \mathrm{yr}$. Mismatch distributions were only fitted to two data groups, with mainland lineage and Chatham Island lineages separated to allow for individual representation of the demographic history of each of the populations (fig. 3.5).

In addition, we used the Skyline plot method (Ho \& Shapiro, 2011) to estimate demographic history implemented in BEAST v1.6.1 (Drummond \& Rambaut, 2007). Bayesian skyline analyses with 10 groups were used to measure population size changes through time, in the Chatham Island and mainland New Zealand populations separately, and with all grouped together. The Marko Chain Monte Carlo (MCMC) 
simulations were run for $10^{7}$ iterations with a strict molecular clock, General Time Reversible (GTR) model and stepwise skyline model used. The first $10^{6}$ steps were excluded as the burn-in time. Following the procedure of Liu et al. (2011), two mutation rates were considered. This allows for the time dependency of molecular rate estimates, explained by Ho et al. (2005) to potentially be an order of magnitude faster than many estimates suggest. In allowance, the two rates used were $2.0 \times 10^{-8}$ $\mathrm{s} / \mathrm{s} / \mathrm{yr}$ and $2.0 \times 10^{-7} \mathrm{~s} / \mathrm{s} / \mathrm{yr}$, with latter considered a high rate for a reef fish (Bowen et al. 2006). Genealogies were sampled every $10^{3}$ iterations, and all other parameters remained in their default settings. Skyline plots of the tree file were generated using Tracer v1.5 (Drummond \& Rambaut, 2007). 


\subsection{RESULTS}

DNA sequence data from the mtDNA control region of $475 P$. colias individuals were aligned and the final data set was trimmed to a length of $493 \mathrm{bp}$. The aligned sequences had asymmetric base frequencies of $\pi_{\mathrm{A}}=0.329, \pi_{\mathrm{T}}=0.334, \pi_{\mathrm{G}}=0.185$ and $\pi_{\mathrm{C}}=0.152$, and there were two indels. There were 45 polymorphic sites and the overall $\pi$ was estimated to be 0.00602 . A total of 95 haplotypes were recorded and haplotypic diversity overall was 0.783 , with among site haplotypic diversity ranging from 0.684 to 0.968 between Puysegur Point and Wellington respectively. All sites were dominated by two main haplotypes found in over $60 \%$ of sampled individuals. There was a minimum of four mutational differences between these two haplotypes (H1 and H2), and the maximum between any two haplotypes was nine steps (Fig. 3.2). In the Chatham Islands samples, 64 sequences displayed 28 haplotypes, 20 of which are found in no other samples (private). Fu's $F$ statistic was also notably different in the Chatham Islands (Fu's $F=-28.251$ ), observed to be nearly five times the size of the next greatest, Kaikoura. 


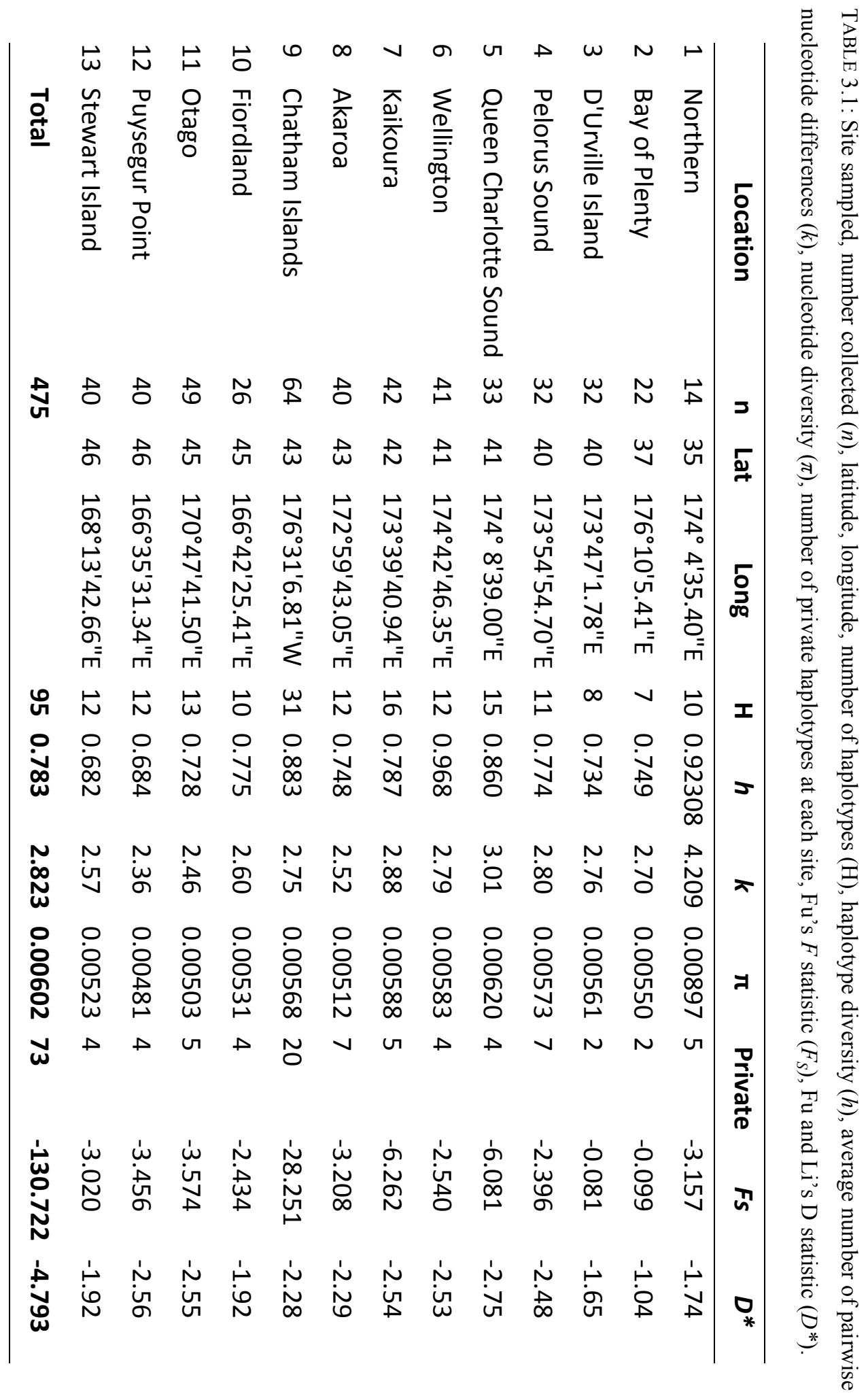




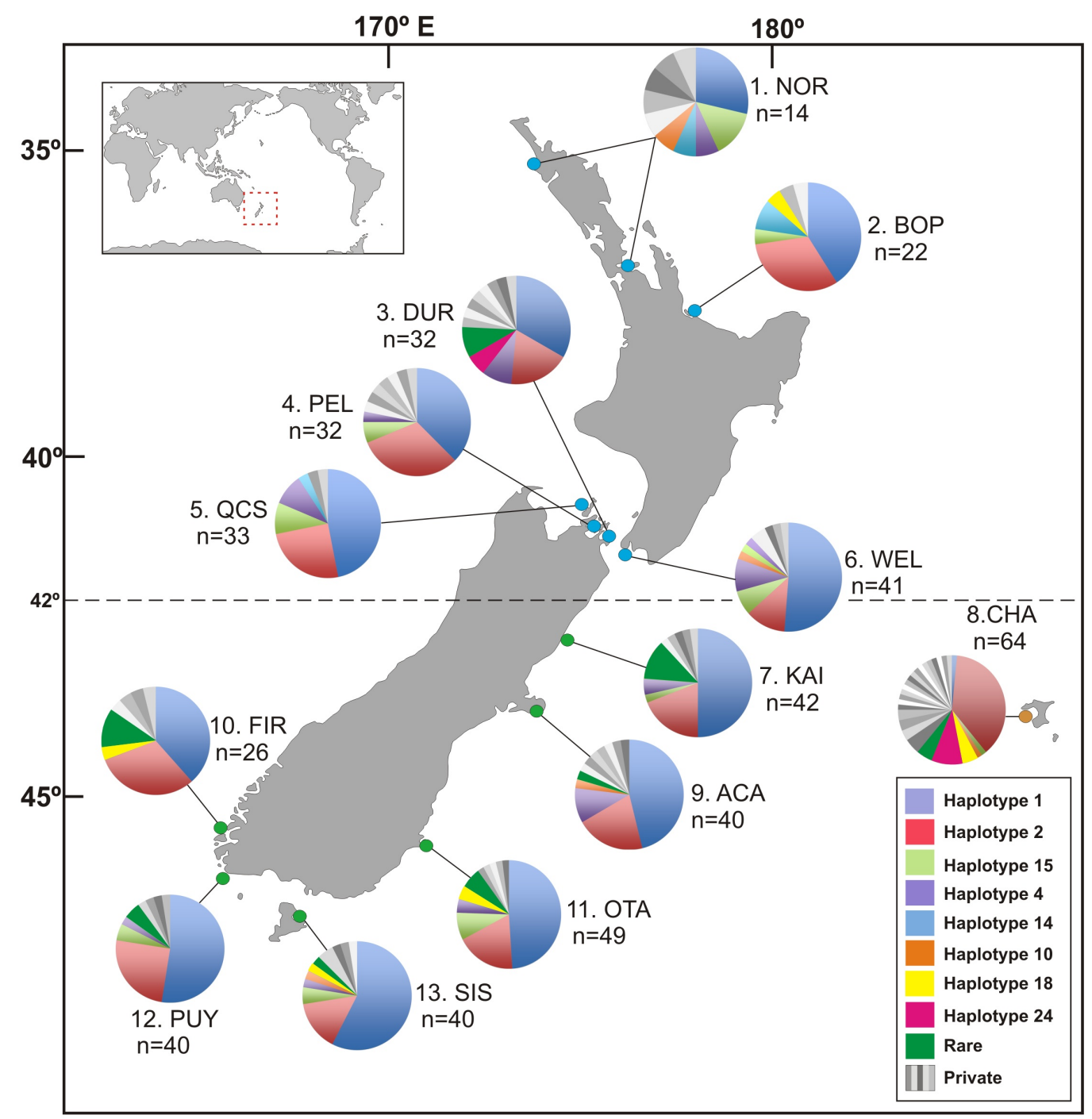

FIgURE 3.1: Sampled sites for Parapercis colias around the New Zealand coastline and the Chatham Islands. Within the pie charts, the eight most frequent haplotypes are shown individually, with rare (not private and not in the 8 most common) grouped into their own category, and private shown as shades of grey.

A minimum-spanning tree (MST) with all 95 haplotypes showed the presence of two dominant haplotypes (fig. 3.2). Haplotype frequencies within each site were calculated and they are shown on pie charts as a proportion of the total frequency within each site (fig. 3.1). Rare haplotypes (a frequency <0.05) that were present in at least one population were grouped into a 'rare' category. Despite many haplotypes being found in only one individual (private haplotypes), they were not grouped as to display sequence diversity at each site. From these two haplotypes, 60 are differentiated by a single substitution and branch off in a star-like arrangement 
(haplotypes were named H1-H95 according to order of discovery). Haplotype H1 is the most common haplotype in the sample set (40\%), but also the most common haplotype in all mainland New Zealand sites. The Chatham Islands shows a different pattern to mainland New Zealand. Only one individual (1.5\%) in the Chatham Islands possessed haplotype $\mathrm{H} 1$ and most individuals (37\%) had haplotype $\mathrm{H} 2$, compared to only $19 \%$ of individuals with that haplotype in the total data set. The Chatham Islands also showed greater $\pi$ than most other sites.

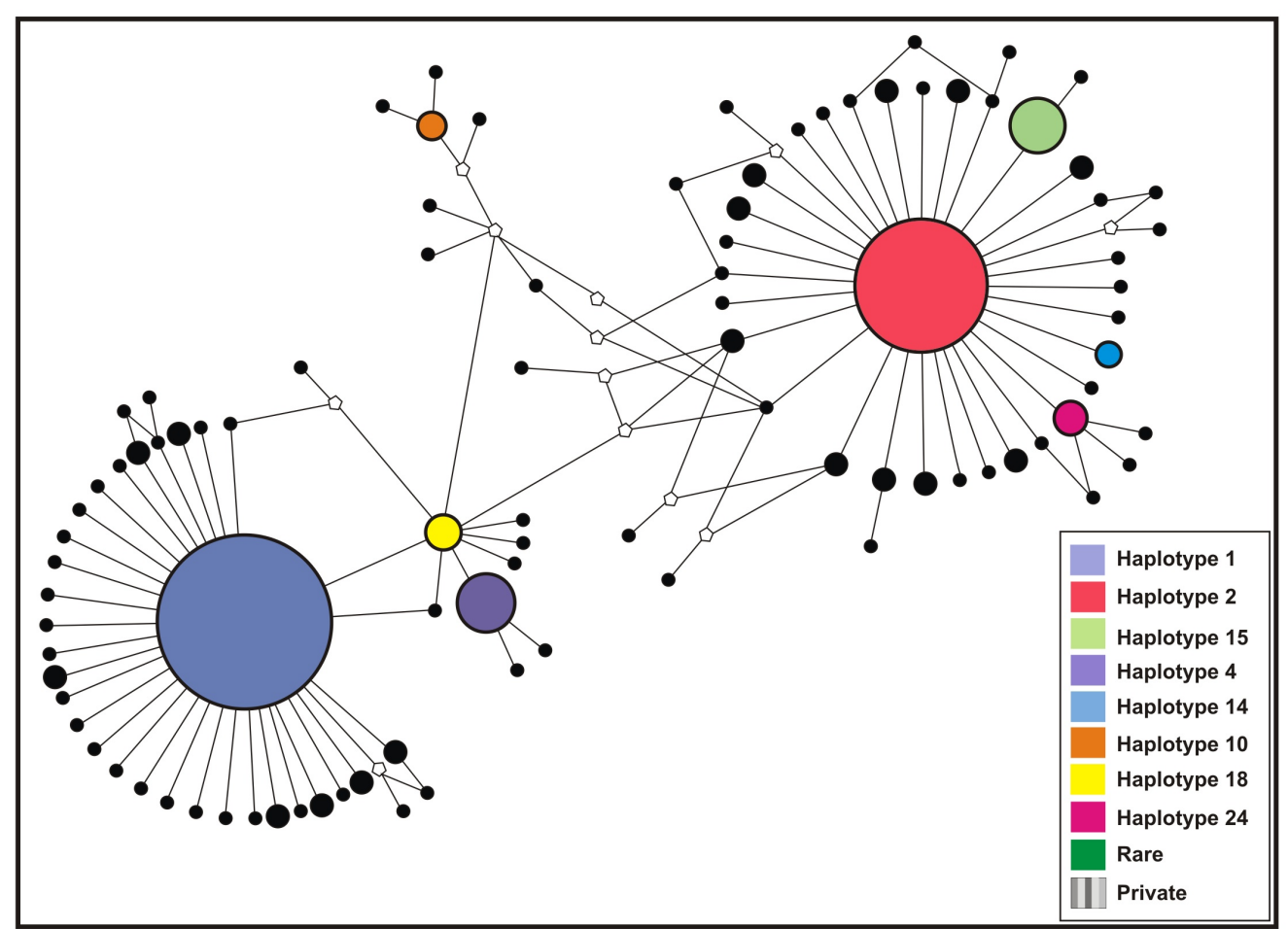

FIGURE 3.2: The unrooted minimum spanning tree depicts the relationships between all 95 haplotypes present in the sample. The circle size is relative to the number of individuals who posses the haplotype, while each internal branch is representative of a single substitutional change between the two adjacent circles (haplotypes). Haplotypes not represented in the sample are shown as hollow pentagons.

Haplotype frequencies varied among sites around mainland New Zealand. The general trend was that all sites possessed private haplotypes and were dominated by haplotype H1. Rare haplotypes (haplotypes which feature outside of the eight most common, though in at least two populations) were common throughout the southern sites. Interestingly, haplotype H24 was common at both the Chatham Islands (9\%) and Queen Charlotte Sound (6\%) sites, but were not at any other site. 
There was a significant level of genetic differentiation between mainland New Zealand sites and the Chatham Islands, with pairwise $\Phi_{\mathrm{ST}}$ indicating that all mainland sites are significantly different from the Chatham Islands. The most closely related site to the Chatham Islands was the Bay of Plenty $\left(\Phi_{\mathrm{ST}}=0.0956\right)$, and the least related site was Stewart Island $\left(\Phi_{\mathrm{ST}}=0.2072\right)$. The presence of inter-site genetic structure is limited around mainland New Zealand, with only one $\Phi_{\mathrm{ST}}$ value greater than 0.05 (BOP-STE=0.0571). Bay of Plenty is significantly differentiated from Akaroa, Puysegur Point, and Wellington $\left(\Phi_{\mathrm{ST}}=0.0449,0.0404,0.03513\right.$ respectively $)$.

The AMOVA showed that a significant proportion of genetic differentiation was attributable to the regional separation of the New Zealand mainland from the Chatham Islands. In total, $24.01 \%\left(\Phi_{\mathrm{CT}}=0.24006, P=0.087\right)$ of the variation was accounted for by the regional comparisons, and the remainder by site $\left(76.3 \%, \Phi_{\mathrm{ST}}=0.23704, P\right.$ $<0.0001)$. Test for three different regions in the dataset (NI, SI, Chatham Is.) show that $11.27 \%$ of the variation $\left(\Phi_{\mathrm{CT}}=0.1127, P=0.00391\right)$ could be explained, and this was the hypothesis by which most regional structure could be defined. The exclusion of the Chatham Islands from an AMOVA between North and South Island regions was unable to further explain any mainland differentiation, with all of the variation resulting from variation between sites, and none between regions. There was no evidence of a genetic disjunction at the $42^{\circ}$ latitude line, with less than $1 \%$ of variation attributable to regional separation. Differentiation between mainland islands and the Chatham Islands was also tested, with the South Island showing higher levels of differentiation than the North Island, when compared to the Chatham Islands. Over $25 \%$ of variation can be explained by comparing the South Island to the Chatham Islands $\left(\Phi_{\mathrm{CT}}=0.25383, P=0.0782\right)$, and although this was not significant at the $5 \%$ level it indicates a higher level of similarity than the comparison between North Island sites and the Chatham Islands $\left(\Phi_{\mathrm{CT}}=0.18061, P=0.27273\right)$. The overall $\Phi_{\mathrm{ST}}$ within New Zealand mainland sites is not significant $\left(\Phi_{\mathrm{ST}}=-0.00369, P=0.60997\right)$, with all molecular variance explained by site, and none by sites within regions. 


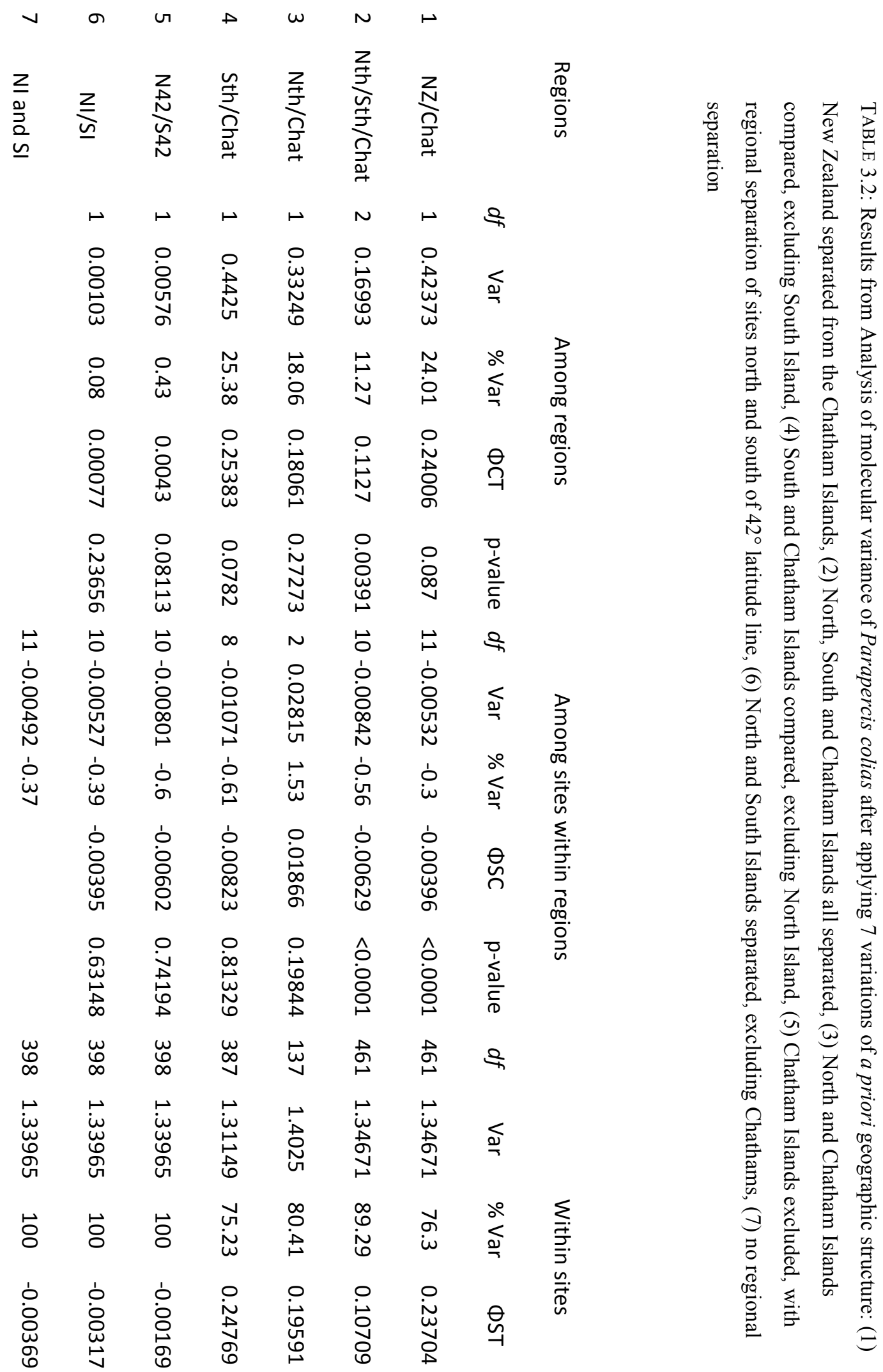

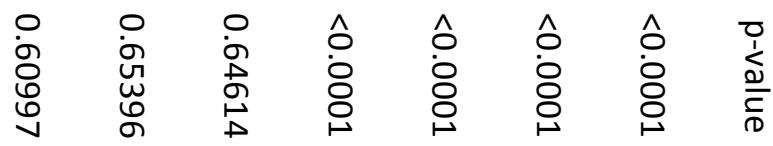




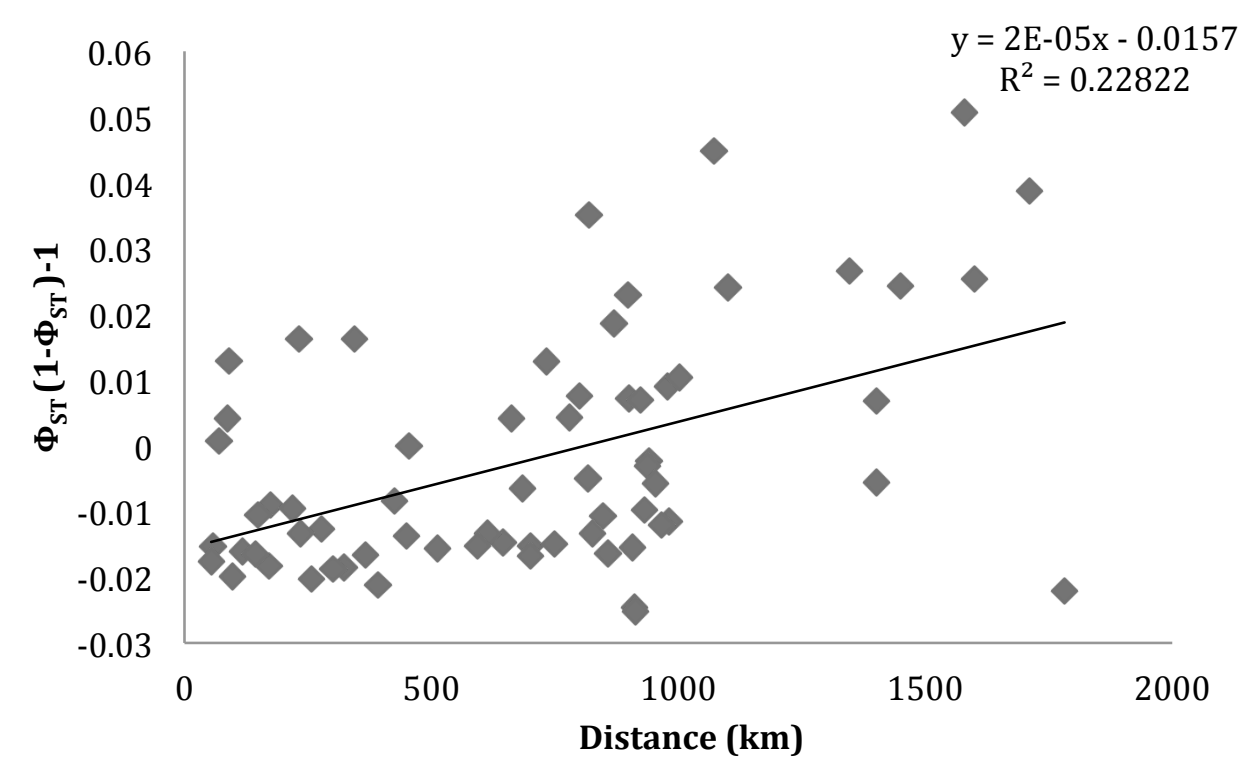

FIGURE 3.3: Pairwise $\mathrm{F}_{\mathrm{ST}}$ vs. geographic distance between all sites except Chatham Islands, as fitted by Mantel's Test with 10,000 permutations $\left(n=66, R^{2}=0.22822, p<0.001 y=2 E-05 x-0.0157\right)$

There was evidence of isolation by distance between sampling sites around mainland New Zealand, with a slight though significantly positive correlation between geographic distance and $\Phi_{\mathrm{ST}}\left(\mathrm{R}^{2}=0.1018, P=0.02\right)$. The analysis was also conducted without the Chatham Islands samples and the positive correlation was stronger (fig. 3.3. $\left.\mathrm{R}^{2}=0.26572, P=0.08\right)$.

There was a significant latitudinal gradient in the distribution of haplotypic diversity $\left(\mathrm{R}^{2}=0.11953, P=0.016\right)$, nucleotide diversity $\left(\mathrm{R}^{2}=0.39, P=0.001\right)$, and the average number of pairwise differences $\left(\mathrm{R}^{2}=0.41358, P=0.001\right)$, which were all negatively correlated with increasing latitude (fig 3.4). 

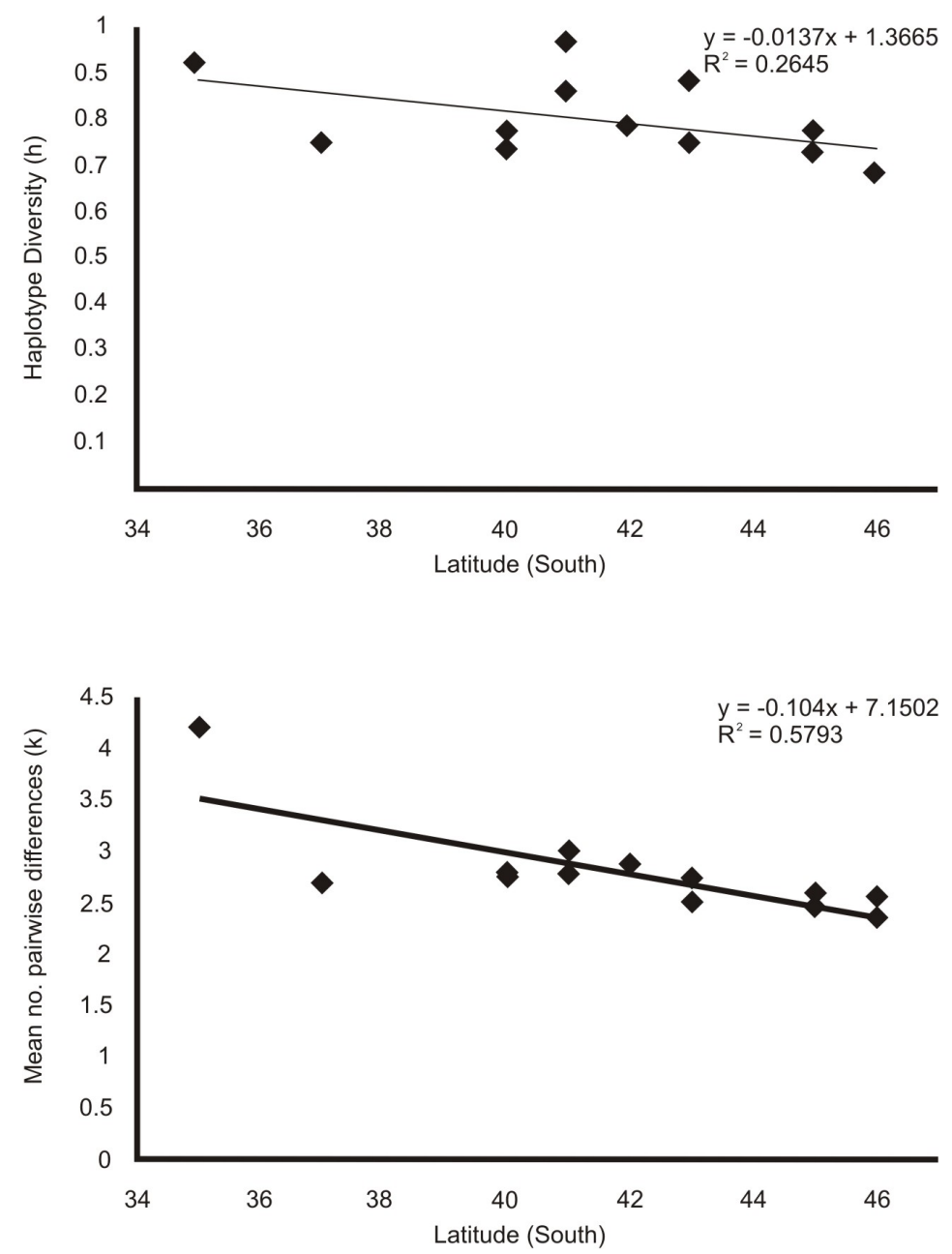

FIGURE 3.4: (a) Haplotype diversity (h) vs. latitude for all included sites ( $\mathrm{n}=13, \mathrm{R}^{2}=0.26446, \mathrm{P}=0.072$ $y=-0.0137 x+1.3665)$. (b) Mean number of pairwise differences per site (k) vs. latitude for all included sites $\left(n=13, R^{2}=0.57933, p=0.002, y=-0.104 x+7.1502\right)$

The mismatch distributions were fitted against expected frequencies of pairwise differences for each regional site (fig 3.5) (mainland New Zealand and Chatham Islands). The distribution of the mainland sequence differences was characterised by an erratic, bimodal curve, indicative of a population that has historically been of a constant size. The pairwise differences in the dataset do not range further than nine mutational differences between sequences. The distribution from the Chatham Islands dataset displayed a slightly less erratic trend, running closer to the expected pattern of pairwise differences than the mainland lineage. Neither regional group differed significantly from a unimodal pairwise distribution, though the Chatham Island sequences $(P=0.55)$ were more similar to the distribution than the mainland sequences $(P=0.15)$. Small peaks in the Chatham Island distribution, when compared to the 
mainland curve, suggest that the Chatham Island population may have undergone an expansion event more recently.

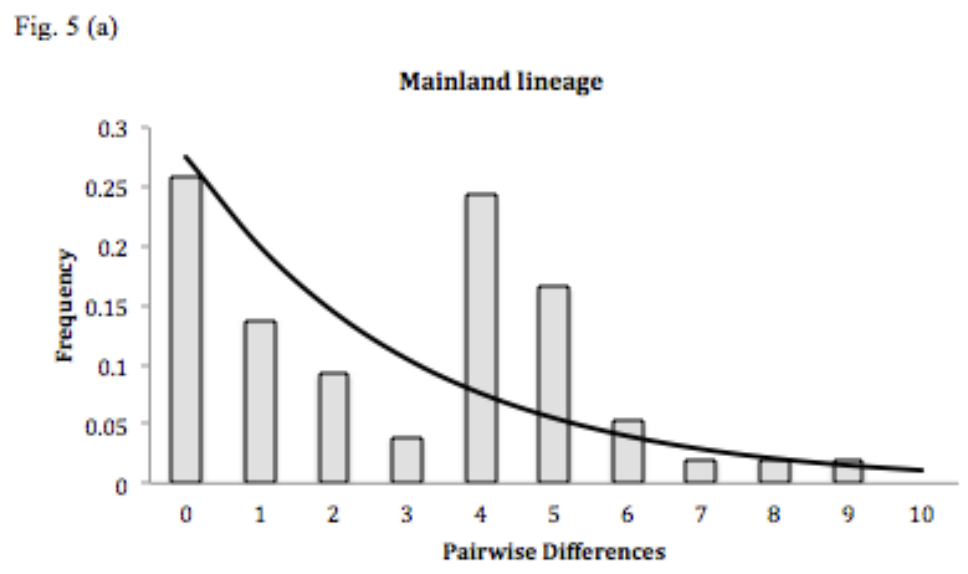

Fig. 5 (b)

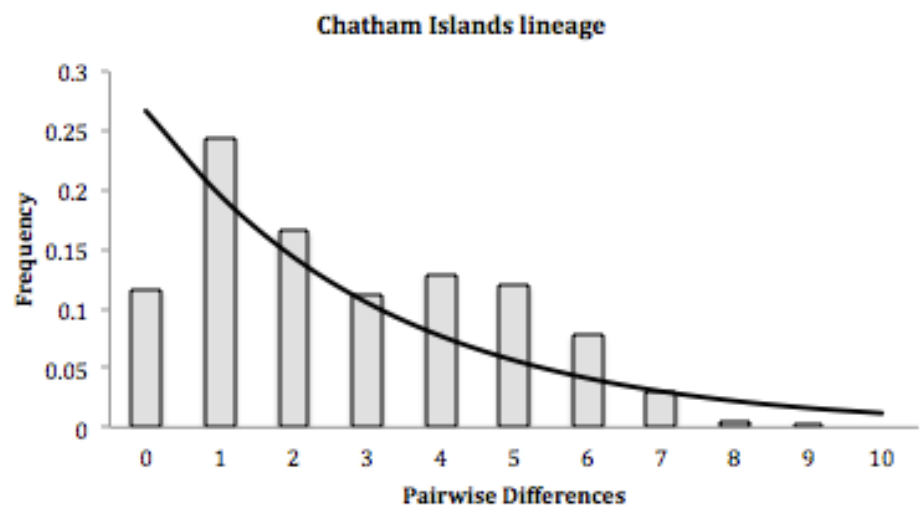

FIGURE 3.5: Mismatch distribution of the frequency of pairwise differences in sequences from mainland New Zealand (a), and the Chatham Islands (b)

This suggestion was supported by the estimates of both Fu's $F_{S}$ and time since population expansion, which estimated the Chatham Islands expansion to have occurred between ca. 94 kya and 37 kya, compared to mainland, which was estimated to be as early as $128 \mathrm{kya}$ (table 3.3 ). The plots on figure 3.6 shows that the population sizes appeared to have doubled and then stabilised approximately 50 kya. 
TABLE 3.3: Estimation of sudden population expansion using Fu's $F_{S}$, sum of squared deviation (SSD) for the mismatched distributions, Harpendings raggedness index, tau, an the estimated number of years before present that an expansion occurred

\begin{tabular}{|c|c|c|c|c|c|}
\hline & Fu's $F$ s $(P)$ & SSD (Mismatch $P$ ) & Raggedness $(P)$ & tau & Years $(2-5 \% / \mathrm{my})$ \\
\hline Chatham Is. & $-26.146(<0.001)$ & $0.0131(0.55)$ & $0.0312(0.750)$ & 3.762 & $94,050-37,620$ \\
\hline North Is. & $-6.816(0.0130)$ & $0.0380(0.1)$ & $0.0800(0.200)$ & 5.121 & $128,020-51,210$ \\
\hline South Is. & $-26.315(<0.001)$ & $0.0416(0.2)$ & $0.0831(0.300)$ & 5.029 & $125,720-50,290$ \\
\hline Mainland & $-26.069(<0.001)$ & $0.0404(0.15)$ & $0.0807(0.150)$ & 5.051 & $126,275-50,510$ \\
\hline All pops & $-25.856(<0.001)$ & $0.0359(0.3)$ & $0.0696(0.15)$ & 4.967 & $124,170-49,670$ \\
\hline
\end{tabular}
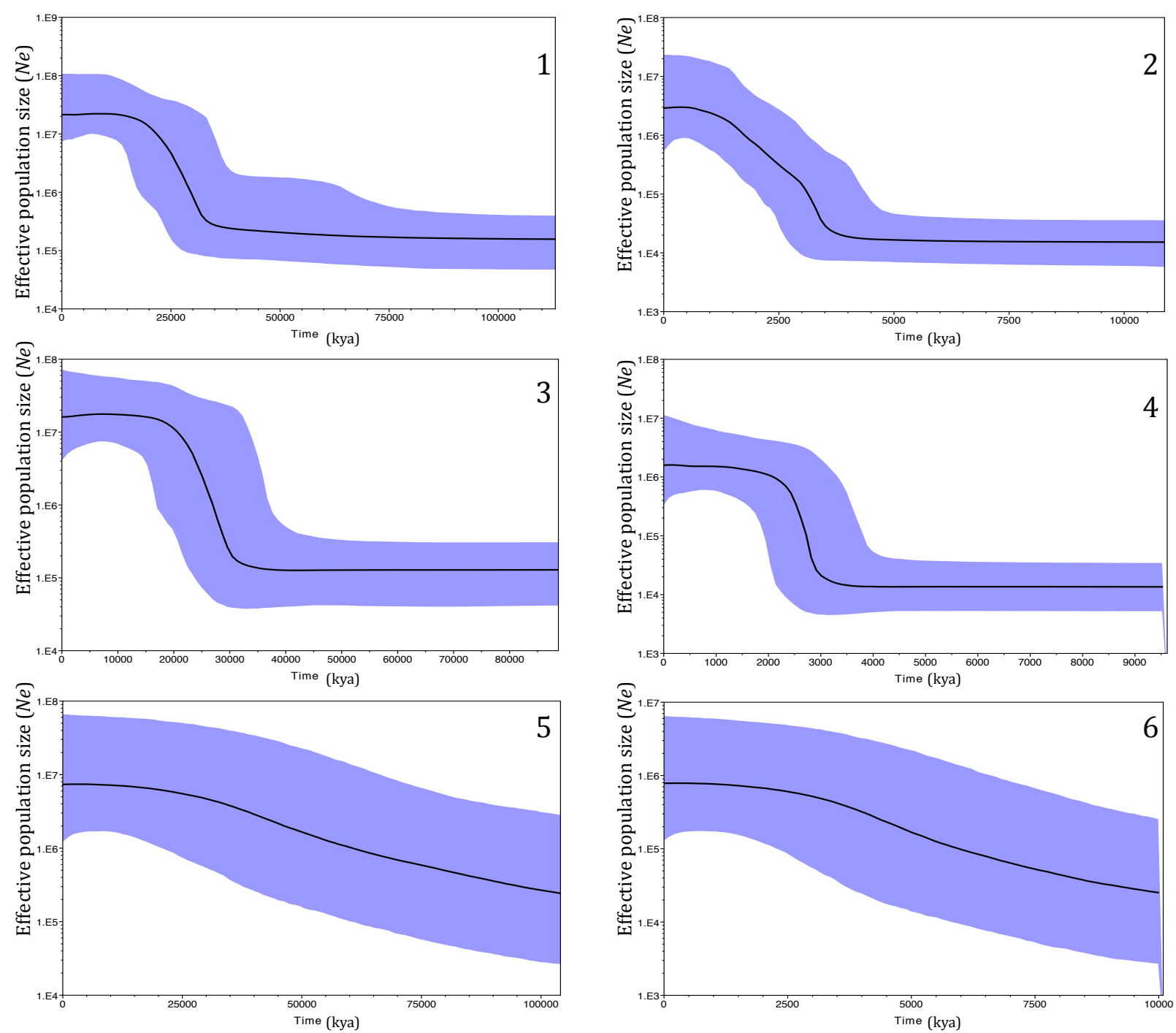

FIGURE 3.6: Bayesian Skyline plots permuted 30 million times at an evolutionary rate of $2.0 \times 10^{-8} \mathrm{~s} / \mathrm{s} / \mathrm{yr}$ for all samples (1), mainland (3), and Chatham Islands (5), as well as an evolutionary rate $2.0 \times 10^{-7} \mathrm{~s} / \mathrm{s} / \mathrm{yr}$ for all samples (2), mainland (4), and Chatham Islands (6) regions. 


\subsection{DISCUSSION}

The genetic structure of $P$. colias populations around New Zealand showed significant differentiation between the mainland and Chatham Islands populations. Significantly higher levels of genetic diversity in the Chatham Island population, coupled with considerable evidence for a recent population expansion suggest that the two populations have been separate for thousands of years. In mainland populations, a pattern of isolation by distance was found, which suggests the possibility of finer scale genetic structure being revealed with the use of more sensitive genetic markers (e.g. microsatellites).

\subsubsection{Population structure}

While previous studies have suggested $P$. colias populations are likely to be differentiated around New Zealand (Carbines \& McKenzie, 2004), no genetic studies have been conducted prior to this. The mtDNA data revealed at least two types of genetic structure exist within P. colias stocks. There is evidence in this data to reject a single stock model for this species, with evidence of independent populations in each of the Chatham Islands and mainland New Zealand $\left(\Phi_{\mathrm{ST}}=0.237, P<0.001\right)$. Secondly, mainland sites exhibit isolation by distance $\left(\mathrm{R}^{2}=0.228, P<0.001\right)$, with increasing geographic distance between sampling sites leading to decreased genetic similarity (fig. 3) (Wright, 1943).

While haplotype $\mathrm{H} 1$ dominates all mainland populations, it is nearly absent at the Chatham Islands. The genetic distinctiveness of the Chatham Islands is also supported by the composition of haplotypes. The pacific herring (Clupea pallasii) shows similar patterns across its distribution in Asia and North America, with most sampling areas dominated by one particular haplotype, though occasional regions differing significantly, with the haplotype barely represented (Liu et al., 2011). Underrepresentation of haplotype H1, and a particularly high frequency of private haplotypes may indicate that a rare stochastic population event such as a reproductive sweepstake has occurred from time to time in the past (Hedgecock, 1994). Hedgecock (1994), states that during a reproductive sweepstake a small number of individuals 
take a disproportionally large number of reproductive opportunities, and this may be applicable given the territorial nature of $P$. colias, in particular adult males.

The dominant water flow around New Zealand is from west to east, with the Cook Straight current a prevalent water body flowing between the North and South Islands and out towards the Chatham Islands ( Heath, 1985; Carter et al., 1998;). A combination of a short PLD and low rates of adult dispersal in P. colias (Robertson, 1973; Carbines, 2004) are a likely explanation for the genetic break between the mainland and Chatham Islands. Pelagic eggs would be unable to disperse as far as the Chatham Islands during their short time in the plankton. Further, given the predominantly benthic nature of $P$. colias juveniles and adults, it seems unlikely that they would disperse over large, deep areas of water. One species of endemic triplefin (Grahamina capito), and several limpet species (Cellana sp.) also show differentiation between mainland and Chatham Island populations, despite having a significantly longer PLD than P. colias (Goldstien et al., 2009; Hickey et al. 2009). Using hydrographic models and incorporating PLD, Chiswell (2009) estimated a 3050day PLD was required to cover the $850 \mathrm{~km}$ stretch of water. Therefore, it is of little surprise that $P$. colias shows a genetic separation between the two regions. Conversely, orange roughy (Hoplostethus atlanticus), a deep-water species, displays genetic homogeneity between mainland and Chatham Rise sampling sites, even though it has a PLD of similar length to P. colias (Zeldis et al., 1994; Smith et al.,1996). Smith et al. (1995) attribute the genetic similarity between such distant locations to the migratory nature of $H$. atlanticus, with adults thought to travel up to $500 \mathrm{~km}$ to spawn (Annala, 1995). Based on these results, it is clear that at least one of either PLD or migratory non-larval phases are necessary to genetically homogenise many species between the Chatham Islands and mainland New Zealand.

Although the distance between the mainland and Chatham Islands is too great to maintain genetic connectivity, there was no evidence of significant differentiation either side of Cook and Foveaux Straits. While the shallow Foveaux Straight supports populations of $P$. colias across its entirety, and depths do not exceed 50m (Cranfield et al., 2001), homogeneity across Cook Strait is likely maintained through pelagic larval dispersal. This is probably because of the deep body of water between the islands, as several tagging studies show no evidence for adult movement across the 
Cook Strait (Cole et al., 2000; Carbines, 2003; Beentjes \& Carbines, 2005). Ross et al. (2009) notes that level of differentiation in organisms with a PLD of 10 days or less is far more variable than those with longer PLD's. PLD has long been considered a useful proxy for estimating average dispersal distance (Shanks, 2009), though it may in fact be more appropriate as an estimate of the upper bound of dispersal distance (Selkoe \& Toonen, 2011). This is especially relevant for species' with a short PLD, such as $P$. colias, because dispersal distance is probably not an even series event, but a 'spiky, stochastic curve' for which the average long-term distance travelled is a combination of PLD and the frequency of events that aid transport, such as storm events and periodically strong currents (Siegel et al., 2003; Siegel et al., 2008). This may indicate that, while the trend of isolation by distance is recognised between mainland sites, a molecular marker with higher resolution may be able to detect some more fine scale patterns of genetic heterogeneity.

Despite more than half of genetic population studies on New Zealand marine species finding a genetic break at or near Cook Strait (Ross et al., 2009), only one of these was on a Teleost species (Bernal-Ramirez et al., 2003), and sampling effort for the fish was not focussed on the central area of the country. Hickey et al. (2009) found gene flow across Cook Strait to be prevalent in at least six species (Family Tripterygiidae), and higher levels of population structure in other parts of the country. Maintenance of connectivity across the Cook Strait in P. colias and triplefins demonstrates that even teleosts with a short PLD are capable of dispersing across the narrow body of water, and the genetic break in the region may be more specific to marine invertebrate and plant species, many of which exhibited no, or very limited PLD (<1-3d) (Ross et al. 2009).

\subsubsection{Historical demography}

Measures of genetic variation can provide information on the genetic history of $P$. colias population in New Zealand. The high level of genetic variation $(h)$, combined with extremely low levels of nucleotide diversity $(\pi)$ at all sites is a pattern indicative of a recent population expansion. Many phylogeographic studies have found that population bottlenecks and founder events caused by ice age perturbations lead to a reduction in levels of genetic diversity, which is often followed by a population expansion and an increase in diversity (Grant \& Bowen, 1998). The star-shaped 
haplotype network for $P$. colias is typically a result of reduced genetic drift, which is the result of recent population expansion. Aboim et al., (2005) suggests that such patterns of high diversity, star-like haplotype networks, and a mismatch distribution like that found in the Chatham Island population, are features of a recent population expansion. The mismatch distribution plot of the Chatham Island lineage is typical of a population that has recently experienced an expansion event; it has a predominantly unimodal curve, though the multimodal distribution of mainland pairwise sequence differences is a feature of a constant population size (fig. 3.6a) (Slatkin \& Hudson, 1991; Rogers \& Harpending, 1992). There is, however, a possibility that instead of being in demographic equilibrium, the mainland population has undergone a very recent bottleneck. A bottleneck can cause a similar multimodal distribution of pairwise sequence differences, as it is likely to affect the proportion of individuals with each number of pairwise differences evenly, doing so prior to the effects of stabilisation taking hold on the rebuilding population (Weber et al., 2004; Hoffman et al., 2011). Determining which of these demographic explanations best fits the mainland lineage can be resolved by the Bayesian skyline plots (BSP). The mainland BSP shows that having undergone a recent, rapid expansion event (ca 30kya; fig. 3.6) the population now sits at relative demographic equilibrium (fig. 3.6a). Growth of the mainland population was far more rapid and recent than the Chatham Island lineage. The expansion event began between 75-50 kya (fig. 3.6b), which is similar to the tau estimates of 126-50kya (table 3.3).

Estimations of $N_{e f}$ and time from BSP are particularly sensitive to changes in the molecular rate considered in the model. While it is possible to provide potential explanations for each of the figures, it is imperative that the trend is the more highly regarded feature of the analyses. Furthermore, estimations of $N_{e f}$ for a protogynous hermaphrodite such as $P$. colias are made following some significant assumptions, in particular, the understanding that all individuals begin life as females, maturing and contributing their copy of mtDNA to the population before undergoing sexual inversion to become males. This will not be the case for all individuals in the population because not all individuals begin as females, or undergo sexual inversion (Carbines, 2004). 
Grant and Waples (2000) suggest four groups that marine fish species will fit into, based on sequence divergence $(\pi)$ and haplotype diversity $(h)$. Group one is categorised by low $h, \pi$ and has likely undergone recent bottleneck events, representing a young population. Conversely, category four species have high $h$ and $\pi$ measures, and represent very old, highly established populations that were unlikely affected by glaciation. P. colias lays within group two, with high values of $h$ and a low $\pi$. Further characters of such populations are a star-shaped phylogeny, rapid expansion events and comparatively ancient bottleneck episodes.

Lower levels of molecular diversity in higher latitude sites is consistent with other studies (Hickerson \& Ross, 2001; Hickerson \& Cunningham, 2005; Mach et al., 2011), and Hickey et al. (2009) attributes a similar result to bottleneck and recolonisation events stemming from glaciation events in the past. This may help to explain the rapid growth suggested for the mainland lineage assuming the higher mutation rate of $20.0 \% / \mathrm{my}$, with glacial events limiting growth for a significantly longer period of time in mainland populations. A glacial maximum approximately $17 \mathrm{kya}$ meant significantly lower sea levels, at which point the three main islands in New Zealand (North, South, Stewart) were all connected, and some time later the Cook Strait was created with rising sea levels (Stevens et al., 1995). Unaffected by this period of substantial geologic activity, growth in the Chatham Island population remained steady, while mainland population growth was halted until after this period.

\subsubsection{Implications for fisheries management}

Stock management authorities prefer identifiable fisheries stock boundaries, or for boundaries to meet current management areas (Broderick et al., 2011). This is rarely the case. Our study reveals a limited, though significant level of population structure within the $P$. colias fishery and is evidence that the fishery should continue to be managed in separate stock areas. Failure to detect differentiation between mainland sites using mtDNA markers does not mean that there is no genetic structure, especially given the trend of isolation by distance. The application of nuclear DNA markers such as microsatellites and single nucleotide polymorphisms, which are able to provide deeper levels of resolution, could uncover a more detailed picture of population structure in $P$. colias. 
Several factors must be well understood when considering the management implications of $P$. colias' reproductive strategy. Potential for mature female fish to pass on their mitochondrial DNA before becoming males is high, and will cause a different estimate of effective population size compared with other fish species, as females may pass on their lineage before becoming males. This makes comparison of the level of genetic diversity between gonochoristic and hermaphroditic species dangerous, as the number of breeding individuals in a hermaphroditic species is going to be lower than suggested by estimates of $\mathrm{N}_{\mathrm{e}}$, when drawing the comparison from a gonochoristic species. Secondly, larger fish are most commonly males in P. colias as a result of their protogynous hermaphroditism, and because larger fish are generally targeted in wild fisheries, a reduction in the number of males is likely to occur. A loss of males may not influence the levels of genetic variation in mtDNA, as it is maternally inherited, but bi-parentally inherited nuclear markers might be more revealing, as is common in other species with similar modes of reproduction (Bhandari et al., 2004; Alonzo \& Mangel, 2005;).

Current management of $P$. colias as independent stocks is supported by results from this research, with evidence to suggest a change to treatment of populations as one panmictic stock likely to result in localised depletion as well as demographic and genetic complications. Caution is advised when setting legal size limits, as the potential for removing large proportions of male fish from populations is high, and may cause detrimental genetic and demographic changes to the population. 


\section{CHAPTER FOUR}

\section{GENERAL DISCUSSION}

\subsection{General}

Carbines (2003) was the first to note that the level of commercial catch was extremely high given so little was known about blue cod, and he suggested that in order to maintain the integrity of the fishery, it was important that a much better understanding of the species was gained. As mentioned throughout this thesis, understanding of the genetic stock structure of a species can be extremely useful for accurately applying stock assessment models and developing sustainable management strategies. The primary aim of this research was to conduct the first genetic stock identification study of the blue cod.

A better understanding of the behaviour and biology of pre-settlement blue cod is likely to significantly enhance the understanding of population differentiation, as it is known that adult fish typically do not move more than $1 \mathrm{~km}$ (Carbines, 2003). A PLD of approximately 10 days is a best estimate available for blue cod, with experiments conducted in controlled environments (Robertson, 1973), and the potential for a significantly different length of time spent by eggs and larvae in the plankton in natural situations is high. While the relationship between PLD and level of genetic connectivity remains debated, Shanks (2009) provides strong evidence for a positive correlation between the two variables. Selkoe and Toonen (2011) provide further support this view, though highlight the importance of the intensity and frequency of physical oceanographic events such as storms and currents. Considering the volatile nature of New Zealand's marine environment, physical variables such as episodic storm events may be of particular significance (Shima et al. 2010). Timing of 
spawning for blue cod is variable around the country, though in Foveaux Strait it is known to occur between November and January (Carbines, 2003). Lying between the South Island and Stewart Island, Foveaux Strait is a particularly volatile body of water, with storms from the Southern Ocean common throughout the year. However, during the summer months (November-February) is when wave height is lowest and storm frequency in the Southern Ocean is at a minimum (Pickrill \& Mitchell, 1979). This may seem counterintuitive, as it is typically expected for a species to maximise dispersal potential, which would mean this time may be the least beneficial to spawning blue cod. However, because storm events are so violent in this shallow body of water, and currents extremely strong during these periods (Cranfield et al., 2001), it is possible that eggs are swept to unsuitable settlement habitats. As a result, spawning during times when storm events are least common may prove beneficial to larval survival and settlement success. Furthermore, timing of spawning in other parts of the country is typically nearer times of the year when storm events are more common, during winter and spring months (May-October) (Rapson, 1956; Robertson, 1973; Mutch, 1983). Because storm events are less common in these parts of the country, spawning during winter months may maximise the potential for spawning during or near an episodic storm event, thus maximising dispersal potential.

\subsection{Management Suggestions}

Based on evidence for a possible decline of blue cod stocks in the Marlborough Sounds (Blackwell, 1998), several management strategies have been implemented since 2008. Amongst them, a total fishing ban in the Inner Marlborough Sounds, closed areas, catch and size limit reductions and hook size restrictions have been used to help ensure the fishery rebounds to a healthy population size. Another strategy that has been utilised recently is a maximum and minimum legal size restriction (called a slot fishery), which permits fishers to only take fish between $30 \mathrm{~cm}$ and $35 \mathrm{~cm}$. This was initially implemented to retain larger fish, whose fecundity is exponentially greater than smaller fish, as well as to allow fish smaller than $30 \mathrm{~cm}$ the chance to reproduce prior to reaching minimum legal size. A slot fishery may help to avoid exploitation driven evolution, such as directional selection, because both the largest and smallest fish remain in the population. Another goal of this program was to maintain an even sex ratio within the population, helping to ensure maximum potential for stock growth as a result. A slot fishery may prove beneficial for the 
sustainability of commercial fisheries also, with commercial fishers reporting declines in the catch per unit of effort (CPUE) in BCO 5 (see fig 1.3), which has lead to a reduction in the TACC for the region. There is evidence to suggest that these management approaches can be highly beneficial for the sustainability of fish stocks, and may prove useful for some over-exploited blue cod populations (Froese, 2004).

Hermaphroditism in blue cod is also an aspect of the biology that must be considered, with estimates of genetic diversity using mtDNA data not directly comparable to diversity in a gonochoristic species, because of the genetic contribution of mature female fish prior to sexual inversion. As a result, measurements of genetic diversity of hermaphroditic species such as blue cod from mtDNA data must be approached with caution, as the proportion of fish that change sex and timing relative to maturity is not well understood. This makes the use of mtDNA as a comparative measure of genetic diversity potentially complicating in hermaphroditic species. The use of a biparentally inherited nuclear marker may be more appropriate for assessing and comparing genetic diversity with other species, especially when drawing comparisons across numerous fisheries. When genetic diversity has been assayed for a number of species in an area (e.g. inshore New Zealand), it may be possible that these levels can be used to compare readings through time, with results useful for monitoring the effects of fishing pressure on each of the species.

In protogynous hermaphrodites the large adult blue cod are most often males. Because larger fish are generally targeted as a result of fishing methods and regulations, a loss of genetic and demographic balance (e.g. sex ratio) in harvested stocks is a risk. Alterations to the sex ratio have been shown to negatively impact stock health by reducing genetic diversity (Alonzo \& Mangel, 2005). It is possible, however, that while removal of many large males from an area may affect levels of genetic variation (Huntsman \& Schaaf, 1994; Alonzo \& Mangel, 2005), the sex ratio and fecundity of blue cod populations may not be greatly affected. Carbines (2003) argues that this is the case because of the quick sexual succession by females following the loss of a dominant male in the area, combined with a significant proportion (exact figure unknown) of small, mature primary males within the population. Carbines (2003) concludes that the effect of the minimum legal size on the blue cod population may not have as greater effects as one may expect due to the plastic nature of the 
reproductive physiology, with sex ratio alterations caused by overfishing negated relatively easily.

Separation of stock units in the New Zealand QMS into QMAs is a precautionary approach, and one that assumes a level of population subdivision within each species. Results from this study support the use of this system for blue cod, with eight separate areas currently assigned for commercial harvesting (see fig 1.3). While limited genetic differentiation was detected between mainland sampling sites, a pattern of isolation by distance indicates that a more complex population structure may be revealed with the use of higher resolution genetic markers (e.g. microsatellites). Differentiation between mainland and Chatham Island populations is another result that indicates a deeper genetic structure may exist among the mainland sites. Separation of the Chatham Island fishery into its own management area (BCO 4) is supported by genetic data presented in this thesis. While it would be unwise to enlarge any blue cod QMAs at this stage, further research may suggest modifications to the existing boundaries. This may mean more areas and reducing the size of current QMAs, or simply moving the boundaries based on the genetic stock structure.

Data from biological surveys and tagging studies led Carbines (2003) to suggest that management authorities recognise different growth and movement rates of blue cod in different areas of the Marlborough Sounds, and encourages treating the area as four different fisheries areas. Carbines (2003) believed that in general, the current management regime in use for blue cod is an inappropriate match to biological productivity, and that division of blue cod populations into smaller, local management areas would be far more beneficial for the sustainability of the species. The study identifies that the size of these management areas would need to be at least $2 \mathrm{~km}^{2}$, allowing inclusion of a number of resident populations, particularly in the Foveaux Straight region (BCO 5). While the genetic results from this study do not support such changes, there is evidence from many recent studies that blue cod populations may be vulnerable to current levels of exploitation. Furthermore, these suggestions are based mainly on tagging experiments on adult fish, with pelagic dispersal of eggs likely to genetically homogenise populations in such close proximity to one another. 
Development of a set of universal primers for the amplification of variable mtDNA regions in several of New Zealand's inshore fish species creates the potential for many exploratory genetic studies to follow from this thesis research. The primers developed in Chapter two target the control region, a highly variable portion of the mitochondrial genome in many vertebrate species (Brown et al.1986; Saccone et al. 1987). All species are commercially important, and several represent significant recreational fisheries. Using these primers, studies into the genetic stock structure of each of these species can be conducted. As reported for blue cod in Chapter three, it may be necessary for the primers to be redesigned to more specifically target the particular DNA sequence of a species' control region. Further, because of the presumptive heteroplasmy in some species, and long length of the control region, utilising the entire region may be difficult without sequencing from both directions. This can become expensive and result in poor sequence definition, so it is recommended that the hyper-variable region 1 (HRVI) (Nagata et al., 1998) is targeted. Because this area is short (5' end of CR to approx. 500bp of CR) and does not include the centrally conserved domain (CCD), which the mononucleotide tract is found within, sequencing is generally reliable and does not require the use of two primers during sequencing because of the shorter length. While information on genetic trends in marine organisms in New Zealand is growing, there is a significant gap in the literature for commercial fisheries species. It is hoped that the development of these primers will allow expansion of the dataset, which will provide invaluable evidence for future management decisions to be made. 


\section{REFERENCES}

Aboim, M. A, Menezes, G. M., Schlitt, T., \& Rogers, A. D. (2005). Genetic structure and history of populations of the deep-sea fish Helicolenus dactylopterus (Delaroche, 1809) inferred from mtDNA sequence analysis. Molecular ecology, 14(5), 1343-54.

Allendorf, F. W., England, P. R., Luikart, G., Ritchie, P. A, \& Ryman, N. (2008). Genetic effects of harvest on wild animal populations. Trends in Ecology \& Evolution, 23(6), 327-37.

Alonzo, S. H., \& Mangel, M. (2005). Sex-change rules, stock dynamics, and the performance of spawning-per-recruit measures in protogynous stocks. Fisheries Bulletin, 229-245.

Anderson, O. F., Bagley, N.W., Hurst, R.J., Francis, M. P., Clark, M. R., \& McMillan, P. J. (1998). Atlas of New Zealand fish and squid distributions from research bottom trawls. NIWA Technical Report 42.

Annala, J. H. (1995). Report from the fishery assessment plenary, May 1995: Stock assessment and yield estimates. NIWA Report. Greta Point Library, Wellington, New Zealand.

Apte, S., \& Gardner, J. P. (2002). Population genetic subdivision in the New Zealand greenshell mussel (Perna canaliculus) inferred from single-strand conformation polymorphism analysis of mitochondrial DNA. Molecular Ecology, 11(9), 1617-28.

Arnason, E., \& Rand, D. M. (1992). Heteroplasmy of Short Tandem Repeats in Mitochondrial DNA of Atlantic Cod, Gadus morhua. Genetics, 132, 211-220.

Árnason, Ú., \& Gullberg, A. (1993). Comparison between the complete mtDNA sequences of the blue and the fin whale, two species that can hybridize in nature. Journal of Molecular Evolution, 37(4), 312-322.

Árnason, Ú., Gullberg, A., Johnsson, E., \& Ledje, C. (1993). The nucleotide sequence of the mitochondrial DNA molecule of the grey seal, Halichoerus grypus, and a comparison with mitochondrial sequences of other true seals. Journal of Molecular Evolution, 37(4), 323-330.

Bagley, N W, Ballara, S. L., Horn, P L, \& Hurst, R J. (1998). A summary of commercial landings and a validated ageing method for blue warehou, Seriolella brama (Centrolophidae), in New Zealand waters, and a stock assessment of the Southern (WAR 3 ) Fishstock. NIWA Fishstock Assessment (p. 47). Greta Point Library, Wellington.

Beentjes, M. P., \& Francis, M. P. (1999). Movement of hapuku (Polyprion oxygeneios) determined from tagging studies. New Zealand Journal of Marine and Freshwater Research, 33(1), 1-12. 
Beentjes, Michael P, \& Carbines, G. D. (2005). Population structure and relative abundance of blue cod (Parapercis colias) off Banks Peninsula and in Dusky Sound, New Zealand. New Zealand Journal of Marine and Freshwater Research, 39, 77-90.

Begg, G., Kevin, D., Friedland, J., \& Pearce, B. (1999). Stock identification and its role in stock assessment and fisheries management: an overview. Fisheries Research, 43, 1-8.

Bernal-Ramirez, J. H., Adcock, G.J., Hauser, L., Carvalho, G.R., \& Smith, P.J. (2003). Temporal stability of genetic population structure in the New Zealand snapper, Pagrus auratus, and relationship to coastal currents. ICES Journal of Marine Science, (142), 567-574.

Bhandari, R. K., Komuro, H., Higa, M., \& Nakamura, M. (2004). Sex Inversion of Sexually Immature Honeycomb Grouper (Epinephelus merra) by Aromatase Inhibitor. Zoological Science, 21(3), 305-310.

Blackwell, R. G. (1998). Abundance, size and age composition, and yield-perrecruit of blue cod in the Marlborough Sounds, September 1996. NIWA. Greta Point Library, Wellington, New Zealand.

Bowen, B. W., Muss, A., Rocha, L. A., \& Grant, W. S. (2006). Shallow mtDNA coalescence in Atlantic pygmy angelfishes (genus Centropyge) indicates a recent invasion from the Indian Ocean. The Journal of Heredity, 97(1), 1-12.

Bradford, E. (1998). Harvest estimates from the 1996 recreational fishing surveys. NIWA. Greta Point Library, Wellington, New Zealand.

Broderick, D., Ovenden, J. R., Buckworth, R. C., Newman, S. J., Lester, R. J. G., \& Welch, D. J. (2011). Genetic population structure of grey mackerel Scomberomorus semifasciatus in northern Australia. Journal of fish biology, $79(3), 633-661$.

Brown, G. G., Gadaleta, G., Pepe, G., Saccone, C., \& Sbisa, E. (1986). Structural conservation and variation in the D-loop-containing region of vertebrate mitochondrial DNA. Journal of Molecular Evolution, 192(3), 503-511.

Brown, J. R., Beckenbach, A. T., \& Smith, M. J. (1992). Mitochondrial DNA Length Variation and Heteroplasmy in Populations of White Sturgeon (Acipenser transmontanus). Genetics, 132, 221-228.

Brown, W. M. (1985). The mitochondrial genome of animals (MacIntyre Press, pp. 95-130). New York: Plenum Press.

Brown, W. M., George, M., \& Wilson, A. C. (1979). Rapid evolution of animal mitochondrial DNA. Proceedings of the National Academy of Sciences of the United States of America, 76(4), 1967-71. 
Brumfield, R. T., Beerli, P., Nickerson, D. A, \& Edwards, S. V. (2003). The utility of single nucleotide polymorphisms in inferences of population history. Trends in Ecology \& Evolution, 18(5), 249-256.

Burridge, C., \& Smolenski, A. (2003). Lack of genetic divergence found with microsatellite DNA markers in the tarakihi Nemadactylus macropterus. New Zealand Journal of Marine and Freshwater Research (Vol. 37, pp. 223-230).

Carbines, G. (1999). Determination of movement of blue cod in Southland. Final Research Report for Ministry of Fisheries. Wellington, New Zealand.

Carbines, G. (2003). Age, growth, movement and repro- ductive biology of blue cod (Parapercis colias - Pinguipedidae): implications for fisheries management in the South Island of New Zealand. Phd Thesis, University of Otago. Wellington, New Zealand.

Carbines, G, \& McKenzie, J. (2004). Movement patterns and stock mixing of blue cod in Dusky Sound in 2002. Final Research Report for Ministry of Fisheries. Wellington, New Zealand.

Carbines, Glen. (2004). Age determination, validation, and growth of blue cod Parapercis colias , in Foveaux Strait, New Zealand. New Zealand Journal of Marine and Freshwater Research, 38(2), 201-214.

Carbines, G., Jiang, W., \& Beentjes, M. P. (2004). The impact of oyster dredging on the growth of blue cod, Parapercis colias, in Foveaux Strait, New Zealand. Aquatic Conservation: Marine and Freshwater Ecosystems, 14(5), 491-504.

Carter, L. G., R. D., Sutton, P., Chiswell, S., Oien, N. A., \& Stanton, B. R. (1998). Ocean circulation New Zealand. NIWA Chart, Miscellaneous Series No. 76. NIWA, Wellington, New Zealand.

Carvalho, G. R., \& Hauser, L. (1994). Molecular genetics and the stock concept in fisheries. Reviews in Fish Biology and Fisheries, 4(3), 326-350.

Caswell, H. (2001). Matrix Population Models (2nd ed.). Sunderland, Massachusetts: Sinauer Associates.

Catanese, G., Infante, C., \& Manchado, M. (2008). Complete mitochondrial DNA sequences of the frigate tuna Auxis thazard and the bullet tuna Auxis rochei. Mitochondrial DNA, 19(3), 159-166.

Chiswell, S. M. (2009). Colonisation and connectivity by intertidal limpets among New Zealand, Chatham and Sub-Antarctic Islands. II. Oceanographic connections. Marine Ecology Progress Series, 388, 121-135.

Chiswell, S. M., \& Booth, J. (1999). Rock lobster Jasus edwardsii larval retention by the Wairarapa Eddy off New Zealand. Marine Ecology Progress Series, 183, 227-240. 
Chow, S., \& Hazama, K. (1998). Universal PCR primers for S7 ribosomal protein gene introns in fish. Molecular ecology, 7(9), 1255-6.

Cole, R. G., Villouta, E., \& Davidson, R. J. (2000). Direct evidence of limited dispersal of the reef fish Parapercis colias (Pinguipedidae) within a marine reserve and adjacent fished areas. Aquatic Conservation: Marine and Freshwater Ecosystems, 10(6), 421-436.

Coleman, F. C., Koenigi, C. C., \& Collins, L. A. (1996). Reproductive styles of shallow-water groupers (Pisces : Serranidae) in the eastern Gulf of Mexico and the consequences of fishing spawning aggregations. Environmental Biology of Fishes, 47, 129-141.

Connor, R. (2001). Initial Allocation of Individual Transferable Quota in New Zeland Fisheries. In Shotton (Ed.), Case Studies on the Allocation of Transferable Quota Rights In Fisheries. Rome: FAO.

Cowen, R. K. (2000). Connectivity of Marine Populations: Open or Closed? Science, 287(5454), 857-859.

Cowen, R. K., \& Sponaugle, S. (2009). Larval Dispersal and Marine Population Connectivity. Annual Review of Marine Science, 1, 443-466.

Cranfield, H. J., Carbines, G, Michael, K., Dunn, A., Stotter, D., \& Smith, D. (2001). Promising signs of regeneration of blue cod and oyster habitat changed by dredging in Foveaux Strait, southern New Zealand. New Zealand Journal of Marine and Freshwater Research, 35(5), 897-908.

Dammannagoda, S. T., Moran, P., Hurwood, D. A, \& Mather, P. B. (2011). Genetic analysis reveals two stocks of skipjack tuna (Katsuwonus pelamis) in the northwestern Indian Ocean. Canadian Journal of Fisheries and Aquatic Sciences, 68(2), 210-223.

Drummond, A. J., \& Rambaut, A. (2007). BEAST: Bayesian evolutionary analysis by sampling trees. BMC Evolutionary Biology, 7, 214-218

Drummond, A., Ashton, B., Buxton, S., Cheung, M., Cooper, A, Heled, J., Kearse, M. (2010). Geneious 5.4.

Excoffier, L, Smouse, P. E., \& Quattro, J. M. (1992). Analysis of molecular variance inferred from metric distances among DNA haplotypes: application to human mitochondrial DNA restriction data. Genetics, 131(2), 479-91.

Excoffier, Laurent, Laval, G., \& Schneider, S. (2005). Arlequin (version 3.0): an integrated software package for population genetics data analysis. Evolutionary Bioinformatics Online, 1, 47-50. 
Frankham, R., Lees, K., Montgomery, M. E., England, P. R., Lowe, E. H., \& Briscoe, D. A. (1999). Do population size bottlenecks reduce evolutionary potential? Animal Conservation, 2(4), 255-260.

www.fs.fish.govt.nz. (2011).

Froese, R. (2004). Keep it simple: three indicators to deal with overfishing. Fish and Fisheries, 5(1), 86-91.

Goldstien, S., Gemmell, N., \& Schiel, D. (2009). Colonisation and connectivity by intertidal limpets among New Zealand, Chatham and Sub-Antarctic Islands. I. Genetic connections. Marine Ecology Progress Series, 388, 111-119.

Grant, W. A. S., \& Bowen, B.W. (1998). Shallow population histories in deep evolutionary lineages of marine fishes: insights from sardines and anchovies and lessons for conservation. Journal of Heredity, 89(5), 415-426.

Grant, W. S., \& Waples, R. S. (2000). Spatial and temporal scales of genetic variability in marine and anadromous species: implications for fisheries oceanography. In P. J. Harrison \& T. R. Parsons (Eds.), Fisheries oceanography: an integrative approach to fisheries ecology and management (pp. 63-93). Blackwell Science, Oxford.

Graves, J. E., Ferris, S. D., \& Dizon, A. E. (1984). Close genetic similarity of Atlantic and Pacific skipjack tuna (Katsuwonu spelamis) demonstrated with restriction endonuclease analysis of mitochondrial DNA. Marine Biology, 33379, 315-319.

Harpending, HC. (1994). Signature of ancient population growth in a lowresolution mitochondrial DNA mismatch distribution. Human Biology, 66, 591-600.

Hauser, L., Adcock, G. J., Smith, P. J, Ramiréz, J. H. B., \& Carvalho, G. R. (2002). Loss of microsatellite diversity and low effective population size in an overexploited population of New Zealand snapper (Pagrus auratus). Proceedings of the National Academy of Sciences of the United States of America, 99(18), 11742-7.

Heath, R. (1985). A review of the physical oceanography of the seas around New Zealand in 1982. New Zealand Journal of Marine and Freshwater Research, 19, 79-124.

Hebert, P. D. N., Penton, E. H., Burns, J. M., Janzen, D. H., \& Hallwachs, W. (2004). Ten species in one: DNA barcoding reveals cryptic species in the neotropical skipper butterfly Astraptes fulgerator. Proceedings of the National Academy of Sciences of the United States of America, 101(41), 14812-7. 
Hedgecock, D. (1994). Does variance in reproductive success limit effective population size of marine organisms? Genetic and Evolution of Aquatic Organisms (pp. 122-134). London: Chapman and Hall.

Henderson, I. M. (2009). Optimising recreational harvests of blue cod: The effects of catch-and-release mortality and size selectivity. Fisheries Research, 99(3), 184-195.

Hickerson, M. J., \& Ross, J. R. P. (2001). Post-glacial population history and genetic structure of the northern clingfish (Gobbiesox maeandricus), revealed from mtDNA analysis. Marine Biology, 138, 407-419.

Hickerson, M. J, \& Cunningham, C. W. (2005). Contrasting quaternary histories in an ecologically divergent sister pair of low-dispersing intertidal fish (Xiphister) revealed by multilocus DNA analysis. Evolution; International journal of organic evolution, 59(2), 344-60.

Hickey, A. J. R., Lavery, S. D., Hannan, D. A, Baker, C. S., \& Clements, K. D. (2009). New Zealand triplefin fishes (family Tripterygiidae): contrasting population structure and mtDNA diversity within a marine species flock. Molecular ecology, 18(4), 680-96.

Ho, S. Y. W., Phillips, M. J., Cooper, A., \& Drummond, A. J. (2005). Time dependency of molecular rate estimates and systematic overestimation of recent divergence times. Molecular Biology and Evolution, 22(7), 1561-8.

Ho, S., \& Shapiro, B. (2011). Skyline-plot methods for estimating demographic history from nucleotide sequences. Molecular Ecology Resources, 1111(10), 998-1755.

Hoffman, J. I., Grant, S. M., Forcada, J., \& Phillips, C. D. (2011). Bayesian inference of a historical bottleneck in a heavily exploited marine mammal. Molecular Ecology, 20(19), 3989-4008

Horn, P.L., Bagley, N.W., \& Sutton, C. P. (2001). Stock structure of silver warehou (SerioleIIa punctata) in New Zealand waters, based on growth and reproductive data. Ministry of fisheries Assessment (p. 30). Wellington, New Zealand.

Horn, P. L. (2003). Stock structure of bluenose (Hyperoglyphe antarctica) off the north-east coast of New Zealand based on the results of a detachable hook tagging programme. New Zealand Journal of Marine and Freshwater Research, 37(3), 623-631.

Huntsman, G. R., \& Schaaf, W. E. (1994). Simulation of the Impact of Fishing on Reproduction of a Protogynous Grouper, the Graysby. North American Journal of Fisheries Management, 14(1), 14-29. 
Ihssen, P. E., Booke, H. E., Casselman, J. M., McGlade, J. M., Payne, N. R., \& Utter, F. M. (1981). Stock Identification. Canadian Journal of Fisheries and Aquatic Sciences, 38(12), 1838-1855.

Irisson, J. O., Paris, C. B., \& Guigand, C. (2009). OCEANOGRAPHY: METHODS Detection and quantification of marine larvae orientation in the plankton. Limnology, 7, 664-672.

Ivanova, N. V., Zemlak, T. S., Hanner, R. H., \& Hebert, P. D. N. (2007). Universal primer cocktails for fish DNA barcoding. Molecular Ecology Notes, 7(4), 544548.

Jouventin, P., Cuthbert, R. J., \& Ottvall, R. (2006). Genetic isolation and divergence in sexual traits: evidence for the northern rockhopper penguin Eudyptes moseleyi being a sibling species. Molecular ecology, 15(11), 3413-23.

Kai, Y., Sato, T., Nakae, M., Nakabo, T., \& Machida, Y. (2004). Genetic divergence between and within two color morphotypes of Parapercis sexfasciata (Perciformes: Pinguipedidae) from Tosa Bay, southern Japan. Ichthyological Research, 51(4), 381-385.

Laikre, L., Palm, S., \& Ryman, N. (2005). Genetic Population Implications for Coastal of Fishes: Structure Zone Management. Ambio, 34(2), 111-119.

Lavoué, S., Sullivan, J. P., \& Hopkins, C. D. (2003). Phylogenetic utility of the first two introns of the $\mathrm{S} 7$ ribosomal protein gene in African electric fishes (Mormyroidea: Teleostei) and congruence with other molecular markers. Biological Journal of the Linnean Society, 78(2), 273-292.

Lee, W. J., Conroy, J., Howell, W. H., \& Kocher, T. D. (1995). Structure and evolution of teleost mitochondrial control regions. Journal of Molecular Evolution, 41(1), 54-66.

Leis, J. (2007). Behaviour as input for modelling dispersal of fish larvae: behaviour, biogeography, hydrodynamics, ontogeny, physiology and phylogeny meet hydrography. Marine Ecology Progress Series, 347, 185-193.

Liu, J. X., Tatarenkov, A., Beacham, T. D., Gorbachev, V., Wildes, S., \& Avise, J. C. (2011). Effects of Pleistocene climatic fluctuations on the phylogeographic and demographic histories of Pacific herring (Clupea pallasii). Molecular Ecology.

Livingston, M. E., \& Schofield, K. A. (1995). Stock discrimination of hoki (Macruronus novaezelandiae, Merlucciidae) in New Zealand waters using morphometrics. New Zealand Journal of Marine and Freshwater Research, 30(2), 197-208.

Lock, K., \& Leslie, S. (2007). New Zealand's Quota Management System: a history of the first 20 Years. Public Policy Research (p. 75). 
Mace, J. T., \& Johnston, A D. (1983). New Zealand Journal of Marine and Freshwater Research Tagging experiments on blue cod (Parapercis colias) in the Marlborough Sounds, New Zealand. New Zealand Journal of Marine and Freshwater Research, 17, 207-211.

Mach, M. E., Sbrocco, E. J., Hice, L. A, Duffy, T. A. Conover, D. O., \& Barber, P. H. (2011). Regional differentiation and post-glacial expansion of the Atlantic silverside, Menidia menidia, an annual fish with high dispersal potential. Marine Biology, 158(3), 515-530.

Mackay, A. (2011). Blue cod quota need more drastic cut. The Southland Times.

Magoulas, A., Tsimenides, N., \& Zouros, E. (1996). Mitochondrial DNA phylogeny and the reconstruction of the population history of a species: the case of the European anchovy (Engraulis encrasicolus). Molecular Biology and Evolution, 13(1), 178-90.

May, J. L., \& Blaber, S. J. M. (1989). Benthic and pelagic fish biomass of the upper continental slope off eastern Tasmania. Marine Biology, 101, 11-25.

McComish, B. J., Hills, S. F. K., Biggs, P. J., \& Penny, D. (2010). Index-free de novo assembly and deconvolution of mixed mitochondrial genomes. Genome Biology and Evolution, 2, 410-24.

Miller, P. A, Fitch, A. J., Gardner, M., Hutson, K. S., \& Mair, G. (2011). Genetic population structure of Yellowtail Kingfish (Seriola lalandi) in temperate Australasian waters inferred from microsatellite markers and mitochondrial DNA. Accepted manuscript, Aquaculture.

Mills, L. S., \& Allendorf, F. W. (1996). The One-Migrant-per-Generation Rule in Conservation and Management. Conservation Biology, 10(6), 1509-1518.

Miya, M., Takeshima, H., Endo, H., Ishiguro, N. B., Inoue, J. G., Mukai, T., Satoh, T. P., et al. (2003). Major patterns of higher teleostean phylogenies: a new perspective based on 100 complete mitochondrial DNA sequences. Molecular Phylogenetics and Evolution, 26(1), 121-38.

Molloy, P. P., Goodwin, N. B., Cote, I. M., Gage, M. J., \& Reynolds, J. D. (2007). Predicting the effects of exploitation on male-first sex changing fish. Animal Conservation, 10, 30-38.

Moritz, C., Dowling, T. E., \& Brown, W.M. (1987). Evolution of animal mitochondrial DNA: relevance for population biology and systematics. Annual Review of Ecology and Systematics, 18, 269-292.

Moss, G. A., \& Tong, L. J. (1992). Effect of stage of larval development on the settlement of the abalone, Haliotis iris. New Zealand Journal of Marine and Freshwater Research, 26(1), 69-73. 
Mutch, P. G. (1983). Factors influencing the density and distribution of the blue cod (Parapercis colias)(Pisces: Mugiloididae). University of Auckland.

Nagata, J., Masuda, R., Kaji, K., Kaneko, M., \& Yoshida, M. C. (1998). Genetic variation and population structure of the Japanese sika deer (Cervus nippon) in Hokkaido Island based on mitochondrial D-loop sequences. Molecular Ecology, 7, 871-877.

Nakamura, M., Kobayashi, Y., Miura, S., Alam, M. A., \& Bhandari, R. K. (2005). Sex change in coral reef fish. Fish Physiology and Biochemistry, 31(2-3), 117-22.

Park, K. (1994). Developments in molecular genetic techniques in fisheries. Fisheries Science, 299, 272-299.

Pickrill, R. A., \& Mitchell, J. S. (1979). Ocean wave characteristics around New Zealand. New Zealand Journal of Marine and Freshwater Research, 13(4), 3749.

Poore, G. C. B. (1972). Ecology of New Zealand abalones, Haliotis species (Mollusca: Gastropoda). New Zealand Journal of Marine and Freshwater Research, 6, 11-22.

Pourkazemi, M., Skibinski, D. O. F., \& Beardmore, J. (1999). Application of mtDNA d-loop region for the study of Russian sturgeon population structure from Iranian coastline of the Caspian Sea. Journal of Applied Ichthyology, 15(4-5), 23-28.

Quinn, T., \& Deriso, R. (1999). Quantitative Fish Dynamics. Oxford University Press, USA.

Rapson, A. M. (1956). Biology of the Blue Cod (Parapercis colias Forster) of New Zealand. PhD Thesis, Victoria University of Wellington.

Riccioni, G., Landi, M., Ferrara, G., Milano, I., Cariani, A., Zane, L., Sella, M. (2010). Spatio-temporal population structuring and genetic diversity retention in depleted Atlantic bluefin tuna of the Mediterranean Sea. Proceedings of the National Academy of Sciences of the United States of America, 107(5), 2102-7.

Robertson, D. A. (1973). Planktonic Eggs and Larvae of some New Zealand Marine Teleosts. PhD Thesis, University of Otago.

Roeder, A. D., Ritchie, P. A., \& Lambert, D. M. (2002). New DNA markers for penguins. Conservation Genetics, 3, 341-344.

Rogers, A. R., \& Harpending, H. (1992). Population growth makes waves in the distribution of pairwise genetic differences. Molecular Biology and Evolution, $9(3), 552-69$. 
Rohl, A. (2000). Network: phylogenetic network analysis. v. 3.1.1.1 Fluxus Technology, Ltd.

Ross, P. M., Hogg, I. D., Pilditch, C. a, \& Lundquist, C. J. (2009). Phylogeography of New Zealand's coastal benthos. New Zealand Journal of Marine and Freshwater Research, 43(5), 1009-1027.

Rozas, J., Sanchez-DelBarrio, J. C., Messeguer, X., \& Rozas, R. (2003). DnaSP, DNA polymorphism analyses by the coalescent and other methods. Bioinformatics, 19(18), 2496-2497.

Saccone, C., Attimonelli, M., \& Sbish, E. (1987). Structural Elements Highly Preserved During the Evolution of the D-Loop Containing Region in Vertebrate Mitochondrial DNA. Journal of Molecular Evolution, 205-211.

Sanger, F., Nicklen, S., \& Coulson, A. R. (1977). DNA sequencing with chainterminating inhibitors. Proceedings of the National Academy of Sciences of the United States of America, 74, 5463-5467.

Schelly, R., Salzburger, W., Koblmüller, S., Duftner, N., \& Sturmbauer, C. (2006). Phylogenetic relationships of the lamprologine cichlid genus Lepidiolamprologus (Teleostei: Perciformes) based on mitochondrial and nuclear sequences, suggesting introgressive hybridization. Molecular Phylogenetics and Evolution, 38(2), 426-38.

Selkoe, K., \& Toonen, R. (2011). Marine connectivity: a new look at pelagic larval duration and genetic metrics of dispersal. Marine Ecology Progress Series, 436, 291-305.

Shanks, A. L. (2009). Pelagic larval duration and dispersal distance revisited. The Biological Bulletin, 216(3), 373-85.

Shima, J. S., Noonburg, E. G., \& Phillips, N. E. (2010). Life history and matrix heterogeneity interact to shape metapopulation connectivity in spatially structured environments. Ecology, 91(4), 1215-24.

Siegel, D. A., Kinlan, B. P., Gaylord, B., \& Gaines, S. D. (2003). Lagrangian descriptions of marine larval dispersion. Marine Ecology Progress Series, 260, 83-96.

Siegel, D. A, Mitarai, S., Costello, C. J., Gaines, S. D., Kendall, B. E., Warner, R. R., \& Winters, K. B. (2008). The stochastic nature of larval connectivity among nearshore marine populations. Proceedings of the National Academy of Sciences of the United States of America, 105(26), 8974-9.

Slatkin, M., \& Hudson, R. (1991). Pairwise Comparisons of Mitochondrial DNA Sequences in Stable and Exponentially Growing Population. Genetics, 129(2), 555-562. 
Smith, P. (1997). Genetic diversity in orange roughy from the east of New Zealand. Fisheries Research, 31(3), 197-213.

Smith, P. J., \& Johnston, A. D. (1985). Glucosephosphate isomerase and $\alpha$ glycerophosphate dehydrogenase electromorph frequencies in groper Polyprion oxygeneiosis from central New Zealand. New Zealand Journal of Marine and Freshwater Research, 19(2), 173-177.

Smith, P. J., McVeagh, S. M., \& Ede, A. (1996). Genetically isolated stocks of orange roughy (Hoplostethus atlanticus), but not of hoki (Macruronus novaezelandiae), in the Tasman Sea and Southwest Pacific Ocean around New Zealand. Marine Biology, 125(4), 783-793.

www.stats.govt.nz. (2011). Statistics New Zealand.

Stevens, G., McGlone, M., \& McCulloch, B. (1995). Prehistoric New Zealand. Auckland: Reed Publishing.

Vawter, L., \& Brown, W M. (1986). Nuclear and mitochondrial DNA comparisons reveal extreme rate variation in the molecular clock. Science, 234(4773), 194-6.

Victor, B., \& Wellington, G. (2000). Endemism and the pelagic larval duration of reef fishes in the eastern Pacific Ocean. Marine Ecology Progress Series, 205, 241-248.

Ward, R.D., \& Elliot, N. G. (2001). Genetic population structure of species in the South East Fishery of Australia. Marine and Freshwater Research, 52, 563573.

Ward, Robert D, Zemlak, T. S., Innes, B. H., Last, P. R., \& Hebert, Paul D N. (2005). DNA barcoding Australia's fish species. Philosophical transactions of the Royal Society of London. Series B, Biological sciences, 360(1462), 1847-57.

Warren, E., Grindley, R., Carbines, G., \& Teirney, L. (1997). Characterisation of the Southland Blue Cod Fishery (1991-1996) (p. 38).

Weber, D. S., Stewart, B. S., \& Lehman, N. (2004). Genetic Consequences of a Severe Population Bottleneck in the Guadalupe Fur Seal (Arctocephalus townsendi). Journal of Heredity, 95(2), 144-153.

Will, M. (2009). Genetic variation in New Zealand abalone, Haliotis iris. PhD Thesis, University of Canterbury, New Zealand.

Wright, S. (1943). Isolation by Distance. Genetics, 28(2), 114-38.

Yang, L., Lu, M., Ye, X., Zhu, H., Gao, F., Mo, Y., \& Huang, Z. (2009). Complete mitochondrial genome DNA of the Nile tilapia Oreochromis niloticus and phylogenetic analysis. Unpublished work. 
Zeldis, J. R., Grimes, P. J., \& Ingerson, J. K. V. (1994). Ascent rates, vertical distribution, and a thermal history model of development of orange roughy, Hoplostethus adanticus, eggs in the water column. Fisheries Bulletin, 93, 373-385. 